Pablo Alejandro de Abreu Urbizagastegui

Modelagem de células de Renshaw e sua utilização em simulações do sistema neuromuscular 
Pablo Alejandro de Abreu Urbizagastegui

\section{Modelagem de células de Renshaw e sua utilização em simulações do sistema neuromuscular}

Dissertação apresentada à Escola Politécnica da Universidade de São Paulo para a obtenção do título de Mestre em Ciências.

Área de Concentração:

Engenharia Biomédica

Orientador:

André Fabio Kohn

São Paulo 
Autorizo a reprodução e divulgação total ou parcial deste trabalho, por qualquer meio convencional ou eletrônico, para fins de estudo e pesquisa, desde que citada a fonte.

\section{Catalogação-na-publicação}

\section{Urbizagastegui, Pablo Alejandro de Abreu}

Modelagem de células de Renshaw e sua utilização em simulações do sistema neuromuscular / P. A. A. Urbizagastegui -- São Paulo, 2019.

$98 \mathrm{p}$.

Dissertação (Mestrado) - Escola Politécnica da Universidade de São Paulo. Departamento de Engenharia de Telecomunicações e Controle.

1.Neurônios motores 2.Neurofisiologia 3.Simulação 4.Célula de Renshaw I.Universidade de São Paulo. Escola Politécnica. Departamento de Engenharia de Telecomunicações e Controle II.t. 
Urbizagastegui, Pablo Alejandro de Abreu. Modelagem de células de Renshaw e sua utilização em simulações do sistema neuromuscular. 2019. 98 f. Dissertação (Mestrado) - Escola Politécnica, Universidade de São Paulo, São Paulo, 2019.

Aprovado em:

\section{Banca Examinadora}

Prof. Dr.

Instituição:

Julgamento:

Prof. Dr.

Instituição:

Julgamento:

Prof. Dr.

Instituição:

Julgamento: 


\section{AGRADECIMENTOS}

Ao Prof. Dr. André, pela excelente orientação e pelos ensinamentos inestimáveis, tanto na vida pessoal quanto profissional. Ao Prof. Dr. Renato, pelo apoio, incentivo e ideias durante todo o mestrado.

À minha mãe, meu pai, meu irmão e minhas avós pelo apoio incondicional e por sempre me inspirar.

Aos colegas do LEB Felipe, Fernando, Roberto e Ana pelo apoio e amizade.

Aos meus amigos Matheus Ferreira, Lucas Severo e Daniel Cunha que, apesar da distância, nunca deixam de estar presentes. Aos meus amigos Felipe Marangoni e Rodrigo Siqueira, pelos conselhos e por ter tornado minha estadia em São Paulo muito mais agradável. Um agradecimento especial à Joice Vieira, pelo apoio, carinho e pela paciência.

À Superintendência de Tecnologia da Informação da Universidade de São Paulo, pelo auxílio com os recursos de HPC, e à Ana Maria, por me ajudar com a formatação final desse trabalho.

O presente trabalho foi realizado com apoio do CNPq, Conselho Nacional de Desenvolvimento Científico e Tecnológico - Brasil (132587/2018-1). 


\section{RESUMO}

Urbizagastegui, Pablo Alejandro de Abreu. Modelagem de células de Renshaw e sua utilização em simulações do sistema neuromuscular. 2019. 98 f. Dissertação (Mestrado) - Escola Politécnica, Universidade de São Paulo, São Paulo, 2019.

O objetivo principal desse trabalho foi realizar um estudo computacional sobre as influências da célula de Renshaw nos motoneurônios em diferentes situações, mas também envolveu parametrizações e recomendações de técnicas para melhorar o desempenho do sistema de simulação utilizado. O ajuste de parâmetros e as simulações foram guiados por dados experimentais de gatos disponíveis na literatura. Os resultados obtidos, além de mostrar que - modelo utilizado foi capaz de reproduzir de forma satisfatória várias observações experimentais, sugerem que as células de Renshaw podem afetar a força muscular gerada e a taxa de disparos e o recrutamento de motoneurônios. Dentre as simulações e análises realizadas, destacam-se os fatos de que, quando as células de Renshaw estavam presentes, foram observados aumentos na ocorrência de inversões na ordem de recrutamento, na velocidade de desenvolvimento da força muscular e na capacidade de diminuir oscilações em $10 \mathrm{~Hz}$ por meio de cancelamento de fases. O modelo foi disponibilizado como uma ferramenta open source, facilitando a reproduzibilidade e extensão dos resultados abordados.

Palavras-chave: Célula de Renshaw. Neurônios motores. Neurofisiologia. Simulação. 


\section{ABSTRACT}

Urbizagastegui, Pablo Alejandro de Abreu. Modelling of Renshaw cells and its utilization in simulations of the neuromuscular system. 2019. $98 \mathrm{f}$. Dissertação (Mestrado) - Escola Politécnica, Universidade de São Paulo, São Paulo, 2019.

The present work carries out a computational study on the influences of Renshaw cell on motoneurons in different situations, but also involves parametrization and recommendations of techniques to improve the performance of the simulation system utilized. The adjustments of parameters and simulations were guided by cat experimental data available in the literature. The results obtained not only showed that the model used could properly reproduce several experimental observations, but also suggested that Renshaw cells can affect muscle force and motoneuronal rate and recruitment. Among the simulations and analyses performed, one finding was that when the Renshaw cells were included there was a greater tendency to occur inversions in the recruitment of motoneurons, greater speed of muscle force development and decrease of oscillations at $10 \mathrm{~Hz}$ caused by phase cancellation. The model code was distributed as an open source tool, facilitating the reproducibility and extension of the results described.

Keywords: Renshaw cell. Motoneurons. Neurophysiology. Simulation. 


\section{LISTA DE FIGURAS}

Figura 1.1 - Visão da sessão transversal da medula espinhal . . . . . . . . . . . . . . 18

Figura 1.2- Circuitaria espinhal na qual as células de Renshaw estão inseridas . . . 21

Figura 1.3 - Conexões observadas entre células de Renshaw e motoneurônios . . . . 25

Figura 3.1 - Potencial excitatório pós-sináptico na célula de Rewshaw . . . . . . . . 39

Figura 3.2 - Características de disparos da célula de Renshaw . . . . . . . . . . . . . 40

Figura 3.3 - Potencial inibitório pós-sináptico agindo nos motoneurônios . . . . . . . 41

Figura 3.4 - Distribuição topográfica de potenciais inibitórios pós-sinápticos recorrentes . . . . . . . . . . . . . . . . . . . . . . 42

Figura 3.5 - Características dinâmicas da célula de Renshaw . . . . . . . . . . . . . . 43

Figura 3.6 - Resultados experimentais sobre características de potenciais inibitórios pós-sinápticos recorrentes . . . . . . . . . . . . . . . . . . . . . . . 44

Figura 3.7 - Resultados experimentais sobre relações estáticas de entrada e saída . . 45

Figura 3.8 - Células de Renshaw e sua resposta à um estímulo antidrômico . . . . . 46

Figura 3.9 - Tensão isométrica do músculo sóleo (ordenada) em função da frequência de estímulo do nervo (abcissa). . . . . . . . . . . . . . . . . . 47

Figura 3.10-Efeitos da ausência e presença da célula de Renshaw em análises espectrais 50

Figura 4.1 - Resultados de aceleração e eficiência em função do número de processos 54

Figura 4.2 - Potencial excitatório pós-sináptico em uma célula de Renshaw . . . . . 56

Figura 4.3 - Evolução temporal da variável de transição $q(t) \ldots$. . . . . . . . . . 57

Figura 4.4- Característica de disparos da célula de Renshaw . . . . . . . . . . . . 58

Figura 4.5 - Disparos espontâneos de uma célula de Renshaw . . . . . . . . . . . . 58

Figura 4.6 - Comparação dos potenciais de membrana para uma corrente injetada de $12 \mathrm{nA} \ldots \ldots \ldots \ldots \ldots$ 
Figura 4.7 - Potencial inibitório pós-sináptico de uma célula de Renshaw

Figura 4.8- Distribuição topográfica de potenciais inibitórios pós-sinápticos recorrentes ........................... 61

Figura 4.9 - Características dinâmicas de uma célula de Renshaw modelada . . . . . 62

Figura 4.10-Validação de resultados com Hamm et al. (1987b) . . . . . . . . . . . 64

Figura 4.11-Distribuição de amplitudes de potenciais inibitórios pós-sinápticos recorrentes . . . . . . . . . . . . . . . . . 6 65

Figura 4.12-Relações de entrada e saída da célula de Renshaw modelada . . . . . . 66

Figura 4.13-Taxa de disparos intantâneos de uma célula de Renshaw após um estímulo antidrômico . . . . . . . . . . . . . . . . . . . . . . . 67

Figura 4.14-Instantes de disparo dos somas de todos os motoneurônios simulados com uma corrente injetada . . . . . . . . . . . . . . . . . . . . 68

Figura 4.15-Visão de um intervalo reduzido dos disparos dos motoneurônios sob efeito da inibição recorrente . . . . . . . . . . . . . . . . . . . . . . . 69

Figura 4.16-Inversão na ordem de recrutamento de motoneurônios . . . . . . . . . 70

Figura 4.17-Primeiros instantes de disparos dos motoneurônios . . . . . . . . . . . 71

Figura 4.18-Taxa de disparo de motoneurônios em função da taxa de disparo de fibras descendentes . . . . . . . . . . . . . . . . . . . . . . . 72

Figura 4.19-Efeitos da presença da célula de Renshaw no força gerada pelo modelo e nos disparos de motoneurônios . . . . . . . . . . . . . . . . . . . . 74

Figura 4.20-Efeitos da célula de Renshaw na densidade espectral de potência dos disparos de motoneurônios com compensação obtida por meio de fibras

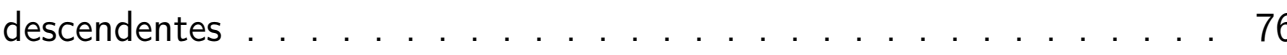

Figura 4.21-Análise espectral sem compensação quando o feedback das células de Renshaw é adicionado . . . . . . . . . . . . . . . . . . . . 77

Figura 4.22-Exemplo de como um cancelamento de fases causado pelas células de Renshaw pode ser observado . . . . . . . . . . . . . . . . 78

Figura 4.23-Fases da coerência entre entradas excitatórias e inibitórias em $10 \mathrm{~Hz}$ de 10 simulações . . . . . . . . . . . . . . . . . . . . . 79 
Figura 4.24-Efeitos das células de Renshaw em contrações isométricas rápidas . . . 80

Figura 4.25-Medidas de coeficientes de sincronia e variação . . . . . . . . . . . . . . . 81

Figura 4.26-Linhas verticais para cada instante de disparo são sobrepostas para indicar uma tendência dos motoneurônios a dispararem juntos . . . . . 82

Figura 4.27 -Transformada de Fourier da força muscular . . . . . . . . . . . . . . . 83

Figura 4.28-Trens de disparos cumulativos filtrados e normalizados dos motoneurônios 84

Figura 4.29-Trens de disparos cumulativos filtrado e normalizado das células de Renshaw ........................ . . 85

Figura 4.30-Instantes de disparo dos somas do motoneurônios simulados com a entrada utilizada nessa seção . . . . . . . . . . . . . . . . . 86 


\section{LISTA DE TABELAS}

Tabela 3.1-Dados experimentais de unidades motoras utilizados na parametrização dos MNs. . . . . . . . . . . . . . . . . . . . . . . . . 38

Tabela 3.2 -Valores médios das entradas utilizadas nas simulações em cada uma das situações estudadas. . . . . . . . . . . . . . . . . . . . . . . . . . . . . . . . 49

Tabela 4.1-Tempo de execução das simulações com diferentes matrizes de condutâncias e quantidades de MNs. . . . . . . . . . . . . . . . . . 55

Tabela 4.2-Valores a serem atribuídos aos parâmetros das células de Renshaw no arquivo de configuração do ReMoto. . . . . . . . . . . . . . . . . 63

Tabela 4.3-Relações entre picos da transformada de Fourier da força . . . . . . . . . 82 


\section{LISTA DE SIGLAS}

ACh Acetilcolina

AHP Hiperpolarização pós-potencial de ação (do inglês Afterhyperpolarization)

CR Célula de Renshaw

CST Trem de disparos cumulativo (do inglês Cumulative Spike Train)

CVM Contração voluntária máxima

EMG Eletromiografia

Fxl Frequência de disparo versus corrente injetada

FF Unidade motora de contração rápida e fadiga rápida (do inglês fast fatiguing)

FR Unidade motora de contração rápida e resistente à fadiga (do inglês fast fatigue resistant)

IN Interneurônio

MN Motoneurônio

PEPS Potencial excitatório pós-sináptico

PIPS Potencial inibitório pós-sináptico

S Unidade motora de contração lenta (do inglês slow)

SNC Sistema nervoso central 


\section{LISTA DE SÍMBOLOS}

\begin{tabular}{|c|c|}
\hline$\tau$ & Constante de tempo \\
\hline$R_{m}$ & Resistência específica de membrana \\
\hline$C_{m}$ & Capacitância específica de membrana \\
\hline$S$ & Speedup \\
\hline$t_{s}$ & Tempo de execução serial \\
\hline$t_{p}$ & Tempo de execução paralelo \\
\hline$E$ & Eficiência \\
\hline$N_{\text {proc }}$ & Número de processadores \\
\hline$G_{a}$ & Implementação antiga da matriz de condutância \\
\hline$G_{n}$ & Implementação nova da matriz de condutância \\
\hline$F$ & Frequência de disparo \\
\hline$I$ & Corrente injetada \\
\hline$V_{l}$ & Tensão de limiar da membrana \\
\hline$I_{r}$ & Corrente de reobase \\
\hline$a$ & Área superficial total do compartimento \\
\hline$l$ & Comprimento do compartimento \\
\hline$d$ & Diâmetro do compartimento \\
\hline $\bar{g}_{\max _{F F}}$ & Condutância máxima de um motoneurônio FF \\
\hline$g_{d y n}$ & Condutância quando há depressão pós-sináptica \\
\hline $\bar{g}_{\max }$ & Condutância máxima \\
\hline var & Taxa de depressão pós-sináptica \\
\hline$\tau_{d}$ & Constante de tempo da depressão pós-sináptica \\
\hline$t_{d}$ & Instante do último potencial de ação \\
\hline$f_{C R}$ & Taxa média de disparos de um célula de Renshaw em regime estacionário \\
\hline$c$ & Constante de saturação \\
\hline$f_{A D}$ & Frequência do estímulo antidrômico \\
\hline$k$ & Constante de semissaturação \\
\hline$i$ & Corrente injetada em função do tempo \\
\hline$F D$ & Frequência de disparos das fibras descendentes \\
\hline$C_{p}$ & Valor relativo à uma porcentagem da contração voluntária máxima \\
\hline
\end{tabular}


Número de motoneurônios recrutados

Média do potencial de membrana do soma de motoneurônios

Potencial de membrana do soma de um motoneurônio

$\sigma^{2}$

Variância

$\chi^{2}$

Coeficiente de sincronia

$Q_{1}$

Quantificador 1

$B_{i}$

Picos do módulo da resposta em frequência nas harmônicas do sinal

$Q_{2}$

Quantificador 2

$Q_{3}$

Quantificador 3

$B_{j}$

Picos diferentes de $B_{i}$ no espectro do sinal

$R_{i}$

Resistência de entrada

$\alpha_{Q}$

Variável de transição de estados relacionada com a abertura dos canais de potássio lento

$\beta_{Q} \quad$ Variável de transição de estados relacionada com o fechamento dos canais de potássio lento

Variável de ativação dos canais de potássio lento 


\section{SUMÁRIO}

1 INTRODUÇÃO 17

1.1 O sistema motor . . . . . . . . . . . . . . . 17

1.2 A circuitaria da medula espinhal e a força muscular . . . . . . . . . . . 17

1.3 O controle motor . . . . . . . . . . . . . . . . . . . . . 19

1.4 As células de Renshaw . . . . . . . . . . . . . . . . . . . . . . . . 20

1.4.1 Origens das entradas das células de Renshaw . . . . . . . . . . 21

1.4.2 Alvos das células de Renshaw . . . . . . . . . . . . . . . . . . . 23

1.4.3 Considerações sobre o circuito de inibição recorrente . . . . . . 24

1.4.4 Hipóteses sobre a função de células de Renshaw . . . . . . . . 25

1.5 Modelagens computacionais descritas na literatura . . . . . . . . 26

1.5.1 Maltenfort, Heckman e Rymer . . . . . . . . . . . . . . . 26

1.5.2 Uchiyama, Johansson e Windhorst . . . . . . . . . . . . . . . . . 27

1.5.3 Cisi e Kohn . . . . . . . . . . . . . . . . . . . . . . . . . . . . 29

1.5.4 Williams e Baker . . . . . . . . . . . . . . . . . . . 30

1.6 Detalhes sobre os modelos de motoneurônios e Células de Renshaw . 31

1.7 Breve histórico do ReMoto . . . . . . . . . . . . . . . . . . . . . 32

1.7 .1 Versões . . . . . . . . . . . . . . . . . . . . 32

1.7.2 Considerações sobre as parametrizações . . . . . . . . . . . . 32

2 OBJETIVOS $\quad 34$

2.1 Melhora de desempenho . . . . . . . . . . . . . . . . . . 34

2.2 Avaliação e validação do circuito de inibição recorrente . . . . . . . . 34 
3.1 Desempenho computacional . . . . . . . . . . . . . . 35

3.1 .1 Cluster Águia . . . . . . . . . . . . . . . . . . . . . . 35

3.1.2 Matrizes de condutâncias . . . . . . . . . . . . . . . . . . . 36

3.2 Estudo das parametrizações . . . . . . . . . . . . . . . . . . . 37

3.2.1 Parametrização do modelo de motoneurônios . . . . . . . . . . . 37

3.2.2 Parametrização do modelo de célula de Renshaw . . . . . . . . 38

3.2.3 Validação do modelo . . . . . . . . . . . . . . . . . . . . . . . . 44

3.3 Efeitos da parametrização em simulações . . . . . . . . . . . . . . . 46

3.3.1 Disparos de motoneurônios . . . . . . . . . . . . . . . . . . . . . 46

3.3.2 Diminuições dos níveis de força . . . . . . . . . . . . . . . . . . . 47

3.3.3 Análise espectral da força gerada pelo modelo . . . . . . . . . . 48

3.3.4 Estudos de contrações isométricas . . . . . . . . . . . . . . . . . . 50

3.3.5 Distorções na saída do núcleo motor e controle da força . . . . 51

4 RESULTADOS E DISCUSSÕES

4.1 Desempenho computacional . . . . . . . . . . . . . . . 54

4.2 Parametrizações . . . . . . . . . . . . . . . . . . . . . . 55

4.2.1 Potencial excitatório pós-sinápico nas células de Renshaw . . . 55

4.2.2 Características dos disparos das células de Renshaw . . . . . . 56

4.2.3 Potencial inibitório pós-sináptico em motoneurônios causados pela célula de Renshaw . . . . . . . . . . . . . . . . . . . . . . . 60

4.2.4 Distribuição e amplitudes da inibição recorrente . . . . . . . . . 60

4.2.5 Característica dinâmica e depressão pós-sináptica da célula de Renshaw ..................... . . 61

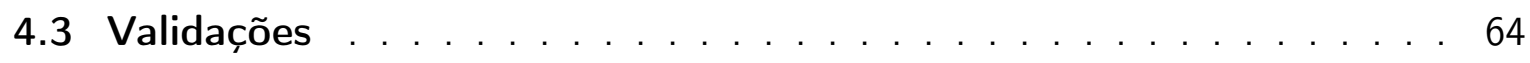


4.3.1 Características de potenciais inibitórios pós-sinápticos recorrentes . . . . . . . . . . . . . . . . . . . 64

4.3.2 Relação estática das entradas e saídas das células de Renshaw 65

4.3.3 Respostas das células de Renshaw sujeitas a um estímulo antidrômico . . . . . . . . . . . . . . . . . . . . 66

4.4 Efeitos da inibição recorrente em simulações . . . . . . . . . . . . . . . 68

4.4.1 Características de recrutamento de motoneurônios . . . . . . . 68

4.4.2 Taxa de disparos de motoneurônios . . . . . . . . . . . . . . . . 71

4.4.3 Diminuições dos níveis de força . . . . . . . . . . . . . . . . . . 73

4.4.4 Análise no domínio da frequência . . . . . . . . . . . . . . . . . 75

4.4.5 Análises de contrações isométricas . . . . . . . . . . . . . . . . 79

4.4.6 Distorções e controle da força . . . . . . . . . . . . . . . . . . . 82

5 CONCLUSÕES $\quad 87$

Referências Bibliográficas $\quad 89$ 


\section{INTRODUÇÃO}

\subsection{O sistema motor}

O Sistema Nervoso Central (SNC) é composto pelo encéfalo e pela medula espinhal. O segundo é subdividido em cervical, torácico, lombar e sacral, sendo cada um desses divididos em vários segmentos. A medula espinhal recebe e processa informação de músculos, articulações, pele, encéfalo e, dentre outras funções, auxilia no controle de movimentos. Nesse contexto, o termo aferente é usado para identificar sinais chegando à medula espinhal, enquanto sinais levados aos músculos são chamados de eferentes (KANDEL et al., 2013).

O tipo de músculo estudado aqui é o músculo esquelético, que é responsável por atividades como locomoção, respiração e fala (BEAR; CONNORS; PARADISO, 2016). Considerando os movimentos possibilitados pela existência de articulações entre dois ou mais ossos, é possível classificar os que diminuem o ângulo entre um segmento e seu segmento proximal como flexão, enquanto movimentos que aumentam esse ângulo são chamados de extensão (SIMPSON; WEINER; PRESS, 1989). Dessa forma, músculos podem ser classificados como flexores e extensores. Se eles têm a mesma função em uma dada tarefa motora, são chamados de sinergistas um do outro. Como cada grau de liberdade de uma articulação é controlada por pelo menos dois músculos fornecendo ações opostas, é útil também defini-los como agonistas (aqueles que proporcionam aceleração em determinada direção) ou antagonistas (aqueles que geram aceleração na direção oposta) (ENOKA, 2008).

Em cada músculo esquelético existem, em geral, centenas de fibras musculares. Elas são importantes não somente para a geração de força, mas também para propriocepção, já que o fuso muscular, que consiste em várias fibras esqueléticas especializadas contidas em uma cápsula fibrosa, fornece informação sobre o comprimento do músculo (BEAR; CONNORS; PARADISO, 2016).

\subsection{A circuitaria da medula espinhal e a força muscular}

Um corte transversal da medula espinhal é mostrado na Figura 1.1. O núcleo central é a matéria cinzenta, que contém o corpo de células nervosas. A substância branca em volta dessa 
região abriga axônios ascendentes e descendentes. A substância cinza ainda é subdividida em corno ventral e corno dorsal.

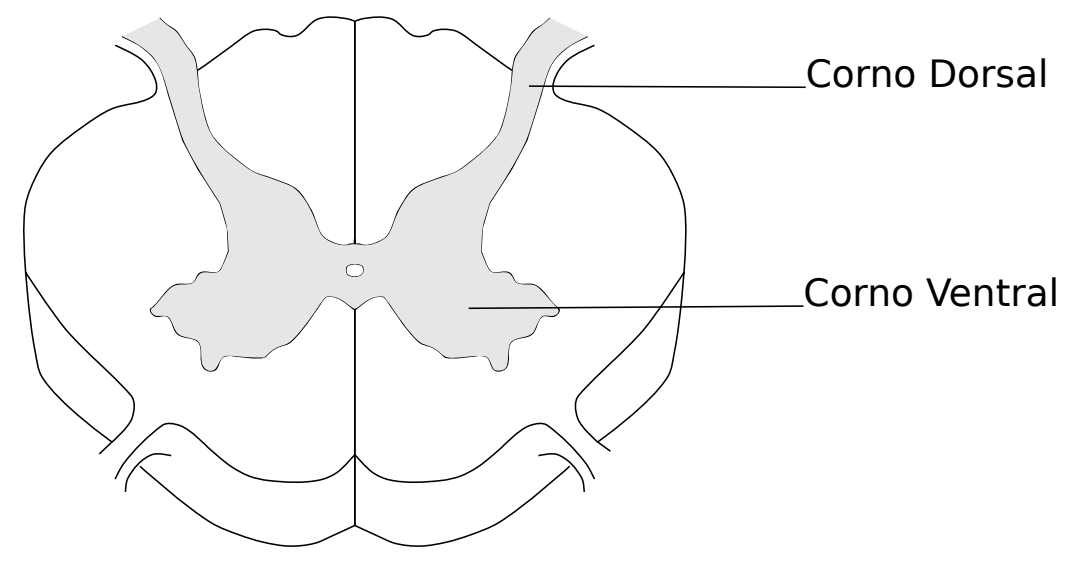

Figura 1.1 - Visão da sessão transversal da medula espinhal. A parte delimitada central representa a matéria cinzenta, enquanto a parte que a circunda representa a substância branca.

O corno ventral contém tipos especializados de neurônios: o motoneurônio (MN), que possui axônios motores inervando músculos específicos, e o interneurônio (IN), que está envolvido em vários circuitos neuronais, seja no nível do segmento ou conectando com estruturas de níveis superiores.

A raiz dorsal consiste em fibras nervosas aferentes que carregam informações dos músculos, tendões, articulações e pele para a medula espinhal, enquanto a raiz ventral, por sua vez, consiste em axônios inervando músculos e fusos musculares. Existem duas categorias de MN: alfa e gama. O primeiro inicia diretamente as contrações de fibras musculares. O conjunto de MNs alfa que inervam um único músculo é chamado de núcleo motor ou pool de MN. Núcleos motores formam colunas que percorrem o comprimento da medula espinhal (KANDEL et al., 2013; BEAR; CONNORS; PARADISO, 2016).

O conjunto de um MN, seu axônio e todas as fibras musculares que este inerva é chamado de unidade motora (LIDDELL et al., 1925; SHERRINGTON; M; S, 1925). Apesar de existirem diferentes tipos de fibras musculares em um dado músculo, uma unidade motora inerva fibras de apenas um tipo. Essas fibras são classificadas como: fibras lentas (do inglês slow, S), que podem sustentar uma contração por um longo tempo sem fadigar; fibras resistentes à fadiga que geram forças moderadas e contrações rápidas com relativa resistência à fadiga (do inglês fast, fatigue resistant, FR); e fibras rapidamente fadigáveis (do inglês fast, fatiguing, FF), que geram as contrações mais fortes e rápidas, porém são as mais sensíveis à fadiga (BEAR; CONNORS; PARADISO, 2016). Essas classificações, entretanto, não funcionam muito bem em seres humanos, pois sabe-se que as primeira unidades motoras ativadas durante uma contração voluntária são fracas e resistentes à fadiga, mas não necessariamente são lentas 
(ENOKA, 2008).

A partir dessas distinções, uma unidade motora que inerva fibras do tipo $S$ é chamada de unidade motora lenta. Analogamente, uma unidade motora rápida contém fibras do tipo FR ou FF. Essa classificação é importante por que as propriedades dos MNs também mudam de acordo com o tipo de fibras que estes inervam. Um exemplo é o fato de que MNs de unidades FF são os maiores, os FR são intermediários e os $S$ são os menores (BEAR; CONNORS; PARADISO, 2016). Vale ressaltar que o tamanho de um MN é uma característica morfológica importante pois, de acordo com o princípio do tamanho, a ordem de ativação de unidades motoras ocorre das menores para as maiores (ENOKA, 2008).

Os padrões de conectividade também são características importantes. O axônio de um MN surge do seu corpo celular e, na maioria dos MNs lumbosacrais, dá origem a uma ou até cinco ramificações chamadas ramos colaterais antes de deixar a medula espinhal (CULLHEIM; KELLERTH, 1978).

As terminações dos axônios motores inervando um músculo se separam em diversos ramos para formar a junção neuromuscular, aonde é liberado o neurotransmissor acetilcolina (ACh). Cada terminal pré-sináptico é posicionado sobre uma região especializado da membrana muscular contendo uma alta densidade de receptores de ACh nicotínicos. Como resultado, ACh liberada dos terminais dos axônios motores interagem com esses receptores para produzir um potencial excitatório pós-sináptico (PEPS) que, por sua vez, irá ultrapassar o limiar e gerar um potencial de ação (KANDEL et al., 2013). Tal atividade elétrica, conhecida como potencial de ação de unidades motoras, se propaga pelas fibras musculares e dá origem à suas atividades contráteis.

A medição da somatória dos potenciais de ação de unidades motoras gerados em um músculo é conhecida como eletromiografia e o sinal em si é denominado eletromiograma (EMG). O sinal de EMG pode ser utilizado para diferentes fins, inclusive para estimar a força muscular. Em seres humanos, uma das formas utilizadas para de fato medir a força muscular é por meio do estudo da contração voluntária máxima (CVM) de um indivíduo. Nessa tarefa, a força máxima exercida durante uma contração em que não há alteração no comprimento do músculo como um todo (designada como contração isométrica) é mensurada (ENOKA, 2008).

\subsection{O controle motor}

Em conjunto com o princípio do tamanho, que se baseia na observação de uma forte correlação entre o tamanho de um MN com sua ordem de ativação dentro do núcleo motor 
(HENNEMAN; SOMJEN; CARPENTER, 1965), o conceito de common drive introduzido por De Luca e Erim (1994) ajuda a entender como o SNC controla unidades motoras em certos tipos de contrações musculares: ao invés de ativar cada unidade motora separadamente, uma entrada comum é distribuída por um núcleo motor com MNs que são ativados de acordo com uma gradação ordenada de seus tamanhos.

Considerando esses conceitos, Farina e Negro (2015) postularam que, para frequências menores que a taxa média de disparo dos MNs, o núcleo motor age como um filtro linear capaz de eliminar ruídos independentes (entradas que afetam cada MN, mas que são independentes entre si) e transmitir para o músculo um sinal parecido com a entrada comum. Nesse contexto, eventuais distorções entre o comando descendente e a força gerada diminuem com o aumento de MNs ativos na contração.

O controle dessa força muscular não só depende do recrutamento de unidades motoras, mas também de suas taxas de disparos. Existem, entretanto, diferentes enfoques sobre esse assunto que ainda carecem de investigação (PIOTRKIEWICZ; TÜRKER, 2017).

Esse é o caso de um padrão conhecido como onion skin, em que unidades motoras recrutadas com limiares mais baixos mantém uma taxa de disparo maior do que as com limiares maiores. Isso causa um aninhamento de curvas de taxa de disparo, criando o aspecto de uma casca de cebola (DE LUCA; ERIM, 1994). Existem também situações em que se observa uma inversão desse fenômeno (curvas se cruzando), configurando a onion skin invertida (HU; RYMER; SURESH, 2014; OYA; RIEK; CRESSWELL, 2009).

\subsection{As células de Renshaw}

A célula de Renshaw (CR) é um IN localizado na corno ventral da medula espinhal, medial às colunas de MNs. Suas ramificações axonais se espalham por distâncias maiores que $12 \mathrm{~mm}$ rostralmente ou caudalmente (JANKOWSKA; LINDSTRÖM, 1971; JANKOWSKA; SMITH, 1973) e fazem sinapses com uma variedade de neurônios.

A existência da CR foi descrita pela primeira vez em 1941 por Birdsey Renshaw em um experimento em animais com suas raízes dorsais seccionadas cirurgicamente. Esse autor demonstrou que uma estimulação antidrômica de axônios motores causavam um inibição de MNs alfa inervando os mesmos músculos (ou homônimos) e os músculos sinergistas (RENSHAW, 1941). Mais tarde, foi descoberto que essa inibição é mediada por ramos colaterais de axônios motores fornecendo entradas sinápticas excitatórias para CRs, que por sua vez inibem diversos MNs que inervam o respectivo músculo (ECCLES; FATT; KOKETSU, 1954). 
A Figura 1.2 apresenta um diagrama com as principais conexões envolvendo as CRs. Para facilitar a compreensão, a inibição, por meio das CRs, dos INs la mediando inibição recíproca no sentido do músculo extensor para o flexor foi omitida. Os detalhes de cada uma dessas conexões serão apresentados na seção 1.4.1.

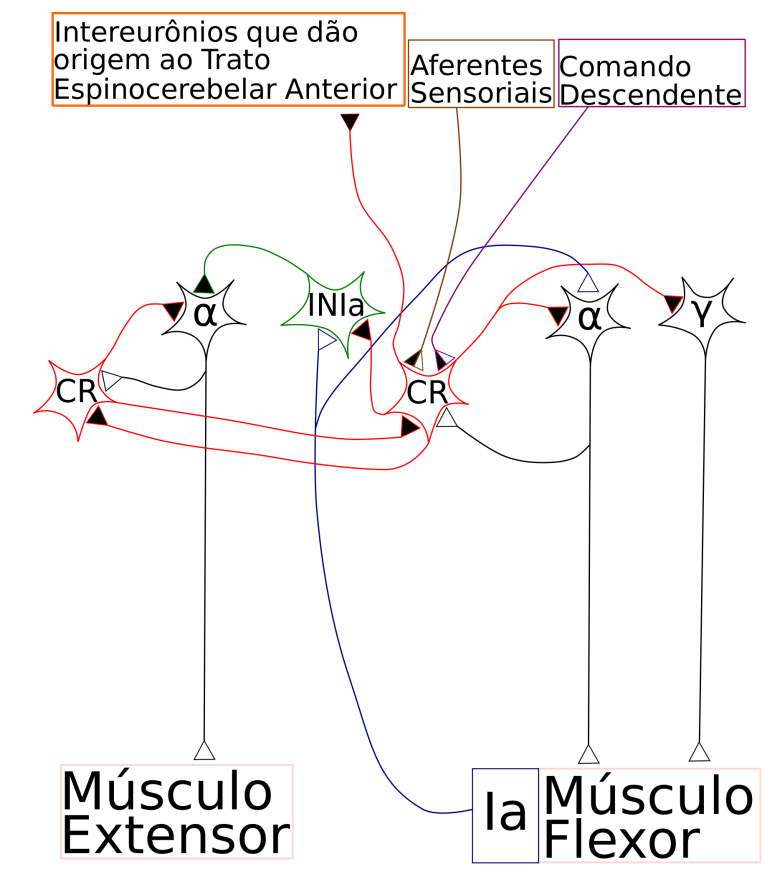

Figura 1.2 - Circuitaria espinhal na qual as células de Renshaw estão inseridas. Os triângulos representam sinapses, que podem ser excitatórias (brancas) ou inibitórias (pretas). Os símbolos $\alpha$ e $\gamma$ se referem ao tipo de motoneurônio.

Pode-se perceber a presença de um circuito disináptico que começa e termina no mesmo neurônio: um MN excita uma CR, que por sua vez inibe os MNs homônimos. Essa situação, em que um núcleo motor inibe a si mesmo por meio de INs inibitórios, é conhecida como uma inibição recorrente. Outros elementos envolvidos nesse esquema também recebem esse termo, como, por exemplo, ramos colaterais recorrentes e potencial inibitório pós-sináptico (PIPS) recorrente.

\subsubsection{Origens das entradas das células de Renshaw}

\subsubsection{Motoneurônios alfa}

A ativação de CRs é causada por estimulações de vários nervos e aumenta gradativamente com o acréscimo da intensidade de estimulação de nervos individuais, sugerindo que uma única CR é excitada por ramos colaterais de vários MNs (ECCLES; FATT; KOKETSU, 1954; ECCLES et al., 1961b). Esses colaterais recorrentes se espalham por uma distância de não mais do que $1 \mathrm{~mm}$ dos seus corpos celulares de origem e possuem a maioria de seus terminais axonais 
(ou botões sinápticos) convergindo para a área onde as CRs estão localizadas (CULLHEIM; KELLERTH, 1978). Essa característica mostra que excitações podem ser obtidas somente de núcleos motores localizados na vizinhança de determinada CR e, portanto, depende da proximidade entre os neurônios. Além disso, como alguns núcleos motores podem ocupar comprimentos de $10 \mathrm{~mm}$, apenas uma parte de um núcleo motor pode ativar uma determinada CR (ROMANES, 1951; BURKE et al., 1977).

Além de depender de distâncias, convergência para CRs também são baseadas em fatores funcionais. Essa ideia é sustentada por evidências mostrando que CRs são excitadas principalmente por MNs de músculos homônimos e sinergistas, e não por aqueles estritamente antagonistas (PIERROT-DESEILLIGNY; BURKE, 2012; RYALL, 1972; ECCLES et al., 1961b). Essa característica pode ser devido a um fator de proximidade, uma vez que MNs sinergistas tendem a se localizar em regiões similares do corno ventral (KERNELL, 2006).

Existem também estudos que mostram uma variação dos pesos sinápticos dessa entrada de acordo com o tipo de MN. Foi observado que, em média, MNs FF possuem mais colaterais recorrentes e botões sinápticos do que os MNs FR, que por sua vez possuem mais do que os MNs S. Dessa forma, a proporção de entradas excitatórias para CRs de MNs FF, FR e S seria 4:2:1 (CULLHEIM; KELLERTH, 1978). Isso, entretanto, é observado em média e não significa que CRs individuais recebam uma entrada homogênea dos tipos de MNs (HULTBORN et al., 1988).

\subsubsection{Vias aferentes}

Outra via de ativação descrita na literatura é a excitação e/ou inibição polissináptica ocasionada pela estimulação de aferentes cutâneos, raízes dorsais, fibras aferentes ipsilaterais dos grupos II e III e aferentes contralaterais de alto limiar (BALDISSERA; HULTBORN; ILLERT, 2011).

\subsubsection{Vias descendentes}

Respostas inibitórias ou excitatórias também podem ser observadas nas CRs quando estímulos elétricos são aplicados em alguns centros supra espinhais, como o córtex cerebral (MACLEAN; LEFFMAN, 1967), o núcleo vestibular (POMPEIANO; WAND; SRIVASTAVA, 1985), o tálamo (MACLEAN; LEFFMAN, 1967), entre outros. Esses efeitos podem se expressar direta ou indiretamente por meio dos MNs alfa. 


\subsubsection{Alvos das células de Renshaw}

\subsubsection{Motoneurônios alfa}

As ramificações axonais de uma CR são de alta densidade em regiões proximais ao soma e decrescem à medida que a distância da ramificação ao soma aumenta (JANKOWSKA; SMITH, 1973; VAN KEULEN, 1979). Dessa forma, é de se esperar que o efeito de uma inibição recorrente seja mais forte em MNs alfa adjacentes. Outra particularidade de distribuição espacial nesse tipo de conexão vem das diferenças de extensões axonais entre MNs e CRs: conexões de CRs para MNs podem cobrir vários milímetros e por isso são menos localizadas do que as conexões de MNs para CRs (WINDHORST, 1990).

Fatores funcionais também podem determinar a distribuição de colaterais de CRs. Uma inibição recorrente é evocada em grupos de núcleos motores após um estímulo de MNs de um dado músculo. Esse PIPS recorrente é mais forte em MNs homônimos, mas também muitos outros MNs podem ser fortemente inibidos. Essa inibição recorrente heterônima pode ser observada em MNs de músculos sinergistas de uma mesma ou outra articulação (ECCLES; FATT; KOKETSU, 1954; ECCLES et al., 1961b), apesar de estarem localizados em segmentos diferentes (HULTBORN; JANKOWSKA; LINDSTRÖM, 1971b).

Também nesse tipo de conexão existe uma dependência do tipo do MN. O PIPS recorrente é maior em MNs do tipo $S$ do que no tipo FR, que por sua vez é maior do que no tipo FF (FRIEDMAN et al., 1981). Entretanto, existem evidências de que esses efeitos desaparecem quando os MNs alfa estão próximos ao limiar (HULTBORN; KATZ; MACKEL, 1988). Além disso, medições da corrente efetiva mostram um valor médio constante que é entregue igualmente aos MNs, independente de seus tipos. Dessa forma, essa variação de amplitudes dos PIPS em um núcleo motor pode ser causada pelas variações nas propriedades dos MNs (LINDSAY; BINDER, 1991).

\subsubsection{Motoneurônios gama}

Os MNs gama do tipo estático e dinâmico recebem inibição recorrente das CRs (ELLAWAY; MURPHY, 1981; APPELBERG et al., 1983).

Vale ressaltar que MNs gama apenas ocasionalmente dão origem a ramos colaterais recorrentes e não parecem ser de grande influência na ativação das CRs (WESTBURY, 1982; GRANIT; PASCOE; STEG, 1957; KATO; FUKUSHIMA, 1974), sugerindo, assim, que MNs gama recebem inibição recorrente via $\mathrm{CR}$ predominantemente por meio de $\mathrm{MNs}$ alfa (EL- 
LAWAY; MURPHY, 1981; APPELBERG et al., 1983).

\subsubsection{Interneurônios la}

Uma CR também pode inibir um IN la realizando inibição recíproca entre músculos antagonistas (HULTBORN; JANKOWSKA; LINDSTRÖM, 1971a). Dessa forma, CRs excitadas por MNs de um núcleo motor agonista inibem INlas, que por sua vez inibem MNs antagonistas e recebem entradas excitatórias homônimas ou sinergistas de aferentes la.

\subsubsection{Outras células de Renshaw}

Existem estudos que mostram CRs se inibindo mutuamente. Essa inibição é mais forte entre CRs associadas com núcleos motores antagonistas, mas é possível que também exista entre CRs associadas ao mesmo núcleo motor e a sinergistas (RYALL, 1981). Tal inibição, juntamente com a apresentada anteriormente sobre INs la, pode explicar a facilitação recorrente de MNs observada em alguns casos (RENSHAW, 1941; WINDHORST, 1990).

\subsubsection{Neurônios do trato espinocerebelar anterior}

As mesmas CRs que projetam seus colaterais para MNs alfa e INs la também podem os projetar para alguns neurônios de origem do trato espino cerebelar anterior (LINDSTRÖM; SCHOMBURG, 1973), que são responsáveis por transmitir sinais da medula espinhal para o cerebelo (KANDEL et al., 2013). A significância quantitativa dessas conexões parece ser pequena e sua relevância fisiológica não está clara (WINDHORST, 1996).

\subsubsection{Considerações sobre o circuito de inibição recorrente}

O diagrama mostrado na Figura 1.2, na verdade, é uma simplificação. Primeiramente, deve-se considerar que os elementos representados nesse circuito são populações que interagem entre si, sendo que estas podem não ser exatamente homogêneas. Um exemplo disso é o fato de, além das interações mútuas entre CRs e MNs, existirem casos de MNs ativando CRs, mas que não recebem inibição das mesmas, e de CRs ativando MNs sem serem ativadas por estes (VAN KEULEN, 1981). Isso é ilustrado na Figura 1.3.

Outro fator não explicitado no diagrama é o fato de existirem evidências mostrando que as sinapses das CRs sobre os MNs são localizadas sobre os dendritos, com 64 até $705 \mu \mathrm{m}$ 


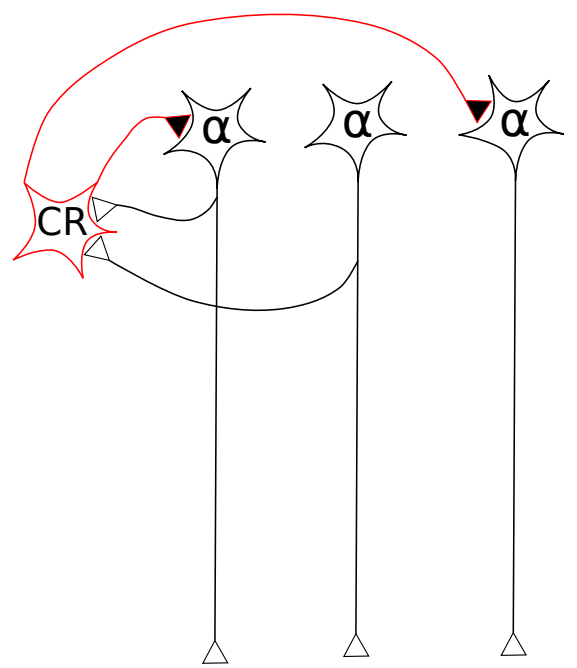

Figura 1.3 - Conexões observadas entre células de Renshaw e motoneurônios.

de distância do soma (FYFFE, 1991). Outros trabalhos de estimação e simulação também mostraram resultados compatíveis (MALTENFORT et al., 2004).

A distribuição espacial de inibição recorrente também é um aspecto importante. Estudos mostram que, até para músculos diferentes, esta é mais forte entre MNs que estejam separados por distâncias menores do que 14 mm (MCCURDY; HAMM, 1994). Além disso, outros trabalhos sugerem que um MN pode fazer sinapse com mais de uma $C R$, e vice versa (HAMM et al., 1987b; MALTENFORT et al., 2004).

\subsubsection{Hipóteses sobre a função de células de Renshaw}

Apesar de existirem inúmeros estudos sobre as CRs, a função desse IN ainda não está bem estabelecida. Isso deve-se, em parte, à complexidade da circuitaria da medula espinhal como um todo e ao fato de que a inibição recorrente poderia ter múltiplas funções, principalmente quando se trata de núcleos motores em diferentes tarefas (WINDHORST, 1996).

A seguir são apresentadas algumas das principais teorias sobre a função da inibição recorrente de MNs:

a) as CRs são responsáveis por inverter o recrutamento ordenado dos MNs (FRIEDMAN et al., 1981). Essa possibilidade, entretanto, se tornou questionável por causa de inúmeros estudos experimetais a favor do recrutamento ordenado de unidades motoras (WINDHORST, 1996);

b) as CRs funcionam como um regulador de ganho de uma relação linear entre as entradas e saídas de um MN (HULTBORN; PIERROT-DESEILLIGNY; WIGSTRÖM, 1979). 
Apesar de sua boa aceitação, essa teoria apresenta algumas limitações pois foi desenvolvida com suposições que ainda precisam ser testadas experimentalmente e considerando apenas as características estáticas das CRs (WINDHORST, 1996);

c) as CRs são responsáveis por descorrelacionar os disparos de MNs (MALTENFORT; HECKMAN; RYMER, 1998). Existem estudos, entretanto, que relatam resultados conflitantes (MCCURDY; HAMM, 1994; UCHIYAMA; WINDHORST, 2007).

\subsection{Modelagens computacionais descritas na literatura}

Como mostrado nas seções anteriores, uma grande quantidade de trabalhos experimentais foram realizados com o intuito de elucidar as funções da CR. O circuito de inibição recorrente, entretanto, é consideravelmente complexo e tais estudos são desafiadores, de forma que até hoje ainda não há uma resposta definitiva para essa questão.

Nesse aspecto, modelagens computacionais podem ser de grande utilidade, pois podem ser usadas para testar teorias, fornecer representações adequadas da neurobiologia, inferir comportamentos muitas difíceis de serem observados na experimentação, entre outros (STERRATT et al., 2011).

Nesse caso, já que o estudo de CRs por meio de simulações pode trazer informações valiosas sobre esse IN, uma breve revisão sobre alguns trabalhos de simulação envolvendo CRs será apresentada.

\subsubsection{Maltenfort, Heckman e Rymer}

Maltenfort, Heckman e Rymer (1998) fizeram um modelo com 256 MNs que foram posicionados em uma matriz de 4 colunas por 64 linhas (direções mediolaterais por rostrocaudais). De forma semelhante, as CRs foram posicionadas em uma única coluna com 64 elementos.

Além de uma constante de tempo de membrana de aproximadamente $8 \mathrm{~ms}$, o pico e a constante de tempo de decaimento das condutâncias de potássio sobre as CRs foram determinadas empiricamente para reproduzir os resultados experimentais descritos por Hultborn e Pierrot-Deseilligny (1979b), como duração da hiperpolarização e curvas de relação entre corrente injetada e taxa de disparos. A resistência de entrada utilizada foi estimada como $4 \mathrm{M} \Omega$, de acordo com comparações entre o tamanho desse neurônio com o de MNs do tipo S. Um limiar de disparo negativo foi responsável por reproduzir a atividade espontânea das CRs. 
As condutâncias sinápticas dos MNs sobre as CRs foram ajustadas de acordo com as proporções de axônios colaterais providos por cada tipo de MN. Sendo assim, esses valores estão distribuídos entre 7 e 35 nS. Foi utilizada uma constante de tempo de 15 ms para o decaimento dessa condutância excitatória, de forma que o PEPS gerado na CR decaísse a 10\% de seu pico após 55 ms e, portanto, fosse semelhante aos PEPS descritos por Walmsley e Tracey (1981).

O valor de condutância máxima adotado para o PIPS das CRs sobre os MNs foi de $36 \mathrm{nS}$, com $-7.5 \mathrm{mV}$ de potencial de reversão e constante de tempo de decaimento de $5 \mathrm{~ms}$. O PIPS médio obtido foi semelhante ao que foi observado por Van Keulen (1981).

Uma estimativa do número de sinapses de CRs em MNs, baseada em trabalhos com dados fisiológicos (ECCLES et al., 1961a; CLEVELAND; KUSCHMIERZ; ROSS, 1981; LINDSAY; BINDER, 1991), resultou em CRs com alcance de \pm 15 linhas na matriz do modelo, de forma que cada MN recebesse entrada inibitória de 31 CRs. Esse valor, considerando o núcleo motor do músculo gastrocnêmio medial do gato, equivale a uma distribuição espacial de aproximadamente $\pm 1.6 \mathrm{~mm}$ e foi usado no cálculo de uma função dependente da distância entre o neurônio disparando e seu alvo, que foi multiplicada pelos valores de condutância das CRs para incorporar um decaimento da eficácia sináptica ao longo da direção rostrocaudal ao modelo. Essa função resultou em uma gaussiana e sua utilização, junto com as propriedades do MNs, geraram PIPS de CRs com mesmos valores de máximos, mínimos e médias $(55,1.6$ e $12.5 \mu \mathrm{V}$ ) descritos por Van Keulen (1981).

Um procedimento semelhante foi realizado para o número de sinapses de MNs nas CRs, mas dessa vez baseado nos trabalhos de Hamm et al. (1987a) e Van Keulen (1981). Essa estimativa resultou em um alcance de \pm 2 linhas, de forma que cada MN fizesse sinapse com cinco CRs.

O principal resultado desses autores foi que a inibição recorrente pode agir como um mecanismo de realimentação negativa que descorrelaciona a atividade dos MNs envolvidos.

\subsubsection{Uchiyama, Johansson e Windhorst}

Em Uchiyama, Johansson e Windhorst (2003a), os autores criaram um modelo com 300 MNs alfa (150 do tipo FF, 75 do tipo FR e 75 do tipo S) e 300 CRs, que foram modeladas apenas como trens de pulsos que reproduzem algumas de suas características fisiológicas.

Para modelar a organização topográfica da inibição recorrente nesse trabalho, os autores utilizaram dados de número e distribuição espacial de botões sinápticos distribuídos pelos MNs 
(CULLHEIM; KELLERTH, 1978) e distribuição espacial de botões sinápticos de CRs (VAN KEULEN, 1979; LAGERBÄCK; KELLERTH, 1985). Foram supostos $78.5 \pm 7.5,43.0 \pm 4.2$ e $35.5 \pm 3$ botões sinápticos (média \pm erro) fornecidos por unidades motoras do tipo FF, FR e $S$, respectivamente. Suas distribuições, que são usadas como peso das entradas excitatórias dos MNs nas CRs, seguiram uma gaussiana centrada na posição do MN e com desvio padrão de $1 / 6 \mathrm{~mm}$. A força sináptica de uma CR para um MN depende da distância destes e segue uma gaussiana com desvio padrão de $3.5 / 3 \mathrm{~mm}$.

O grau de excitação fornecido às CR por determinado tipo de MN também foi estimado de acordo com o número de botões sinápticos fornecidos, como mostrado anteriormente. O PIPS recorrente em cada tipo de MN foi descrito por uma soma de duas exponenciais, uma com constante de tempo de decaimento de 2 ms e outra com constante de tempo de membrana média de 5.9 (tipo FF), 8 (tipo FR) e 10.4 (tipo S) ms. As amplitudes adotadas foram de 7.0 \pm 1.4 (tipo FF), $14.0 \pm 3.0$ (tipo FR) e $26.0 \pm 3.9$ (tipo S) $\mu \mathrm{V}$ (média \pm erro), estimadas por meio de médias e normalizações de resultados experimentais (FRIEDMAN et al., 1981; HULTBORN; KATZ; MACKEL, 1988; VAN KEULEN, 1981).

O método dos mínimos quadrados foi utilizado para aproximar as taxas de disparos das CRs descritas por Eccles et al. (1961b) por uma função. Nesta, foram incorporadas uma taxa de disparos espontâneos de 7 pps (WALMSLEY; TRACEY, 1981) e uma constante de tempo proporcional ao nível de ativação da CR, com valor máximo e mínimo de 15 e 0.7 ms, respectivamente.

Para de fato computar os disparos das CRs, primeiramente, o número de botões sinápticos de um dado MN é distribuído entre todas as CRs dentro de seu alcance de acordo com uma gaussiana normalizada. Esse procedimento é repetido para todos os MNs para que se determine o número total de botões sinápticos em cada CR. Dentre esse número total, apenas os que estão ativos e alguns recentemente ativados contribuem para o nível de ativação de uma CR que foi citado no parágrafo anterior. Muitos dos parâmetros usados nesses cálculos foram determinados empiricamente para satisfazer características fisiológicas, como por exemplo a saturação da taxa de disparo de CRs em 250 pps.

Esse modelo foi utilizado por Uchiyama, Johansson e Windhorst (2003b) para investigar o papel da inibição recorrente nos disparos de MNs e CRs e na força muscular em diferentes situações, sejam elas hipotéticas ou fisiológicas. Os autores mostraram que a mudança da distribuição espacial da inibição recorrente de não homogênea para homogênea não alterou significativamente as relações estáticas de entrada e saída. Mudanças nas condutâncias em cada tipo de MN, por outro lado, mostram alterações significativas. Além disso, as simulações 
mostraram que o modelo de CR usado é capaz regular o ganho de uma ação motora.

\subsubsection{Cisi e Kohn}

Cisi e Kohn (2008) desenvolveram um simulador em que se pudesse observar o comportamento da circuitaria da medula espinhal em diferentes situações, sendo capaz de reproduzir experimentos fisiológicos. Esse sistema recebeu o nome de ReMoto, que é uma abreviação de rede motoneuronal e remete à forma como o acesso ao sistema era realizado (via Internet). A partir desse trabalho, várias outras extensões e estudos foram realizados (ELIAS; WATANABE; KOHN, 2014; WATANABE; KOHN, 2015, 2017).

Muitos dos parâmetros das CRs foram ajustados empiricamente para reproduzir o que é mostrado na literatura. Isso resultou em $2 \mathrm{mV}$ de amplitude e $30 \mathrm{~ms}$ de duração da hiperpolarização pós-potencial de ação (do inglês afterhyperpolarization, AHP), taxa de disparo de até 1000 pps por meio de um período refratário absoluto de 1 ms (HULTBORN; PIERROTDESEILLIGNY, 1979b).

As conexões sinápticas no simulador seguiram o modelo cinético de transmissão e ligação de neurotransmissores proposto por Destexhe, Mainen e Sejnowski (1994a). Esse método retrata de maneira fidedigna as dinâmicas de transmissão e recepção sinápticas e pode ser otimizado para acelerar simulações, que podem conter uma grande quantidade de sinapses (DESTEXHE; MAINEN; SEJNOWSKI, 1994b; LYTTON, 1996).

Os PEPS gerados nas CRs pelos MNs foram parametrizados para apresentar tempo para atingir o pico de $3 \mathrm{~ms}$ e constante de decaimento entre 10 e $15 \mathrm{~ms}$. Utilizando estudos sobre essas sinapses (HULTBORN et al., 1988) e saturação da taxa de disparos das CRs (CLEVELAND; KUSCHMIERZ; ROSS, 1981), a condutância sináptica máxima de MNs em CRs foi ajustada iterativamente até se obter resultados satisfatórios. Dessa forma, o valor final adotado foi 150 nS (tipo S), 170 nS (tipo FR) e 300 nS (tipo FF). Além disso, para reproduzir uma depressão pós-ativação entre os colaterais dos MNs e as CRs descrita por (HULTBORN; PIERROT-DESEILLIGNY, 1979b), essas condutâncias foram multiplicadas por funções dependentes da concentração de neurotransmissores e suas dinâmicas.

Para determinar as condutâncias máximas da sinapse de um MN para uma $C R$, os valores de PIPS recorrentes homônimos e heterônimos de Hultborn, Katz e Mackel (1988) foram usados como base. Após várias simulações e ajustes, foram obtidos os valores de 220 nS (tipo S), 150 nS (tipo FR) e 120 nS (tipo FF). Entretanto, com o intuito de reduzir o tempo de execução neste simulador, os autores adotaram uma densidade de CRs na coluna neuronal 
reduzida pela metade, mas com o dobro dos valores de condutâncias obtidos.

O decaimento da força sináptica da conexão dos MNs nas CRs (CULLHEIM; KELLERTH, 1978) foi modelado multiplicando uma função dependente da distância entre esses neurônios pela condutância máxima da sinapse em questão. Dessa forma, para uma distância de $1 \mathrm{~mm}$, a influência sináptica foi adotada como sendo $1 \%$ do valor máximo. 0 mesmo foi feito para sinapses de CRs para MNs, mas fazendo com que, a $1.4 \mathrm{~mm}$, a influência valesse $10 \%$ do valor máximo.

Para reproduzir a taxa de disparos espontâneos, foram gerados ruídos nas CRs por meio de uma condutância sináptica de $15 \mathrm{nS}$ associada a ativação por trens pré-sinápticos Poisson. Isso gerou potenciais de ação distribuídos conforme uma gaussiana truncada, com taxa média de 7 pps, conforme dados de Walmsley e Tracey (1981), e desvio padrão de 0.3.

Por fim, vale ressaltar que o ReMoto foi disponibilizado com um software open source que pode ser utilizado por quem estiver interessado. O simulador foi originalmente desenvolvido para ser uma aplicação web, acessada remotamente pelo endereço http://remoto.leb. usp.br. Atualmente, existem ainda versões em Python e Fortran do simulador, que podem ser baixadas pelo GitHub em https://github.com/rnwatanabe/projectPR e https:// github.com/rnwatanabe/projectFR, respectivamente.

\subsubsection{Williams e Baker}

O modelo de Williams e Baker (2009) consiste em 377 MNs que recebem entradas do córtex motor. A inibição recorrente foi adicionada por meio de 64 CRs com modelo semelhante ao de Maltenfort, Heckman e Rymer (1998), de forma que a AHP apresentou duração de 36 $\mathrm{ms}$ e pico de $2.3 \mathrm{mV}$.

As entradas sinápticas dos MNs nas CRs produziram PEPS com $7.6 \mathrm{~ms}$ de tempo de subida, $50 \mathrm{~ms}$ de duração e pico de $0.6 \mathrm{mV}$, semelhante ao que foi reportado por Walmsley e Tracey (1981). As CRs receberam, ainda, um ruído gaussiano branco capaz de gerar uma taxa de disparo espontâneo de $11 \mathrm{~Hz}$.

A distribuição de inibição recorrente adotada é uniforme e independente do tipo do MN no modelo. O número de CRs fazendo sinapse com cada MN variou de 10 até 20 , enquanto o número de MNs para cada CR, por sua vez, variou de 20 até 50 . Esses valores foram baseados em dados de conectividade retirados de experimentos em ratos (ALVAREZ et al., 1999) e gatos (VAN KEULEN, 1981; HAMM et al., 1987b). O atraso de condução, tanto dos MNs para CRs, quanto na direção contrária, foi de $1 \mathrm{~ms}$. 
As sinapses das CRs foram posicionadas no compartimento dendrítico dos $\mathrm{MNs}$, de acordo com Fyffe (1991). Os PIPS unitários gerados nos MNs no potencial de repouso tiveram amplitude de $46.2 \mu \mathrm{V}$, tempo de subida de $5.5 \mathrm{~ms}$ e tempo de meia-vida de $18.5 \mathrm{~ms}$. Esses valores estão próximos de resultados experimentais (HAMM et al., 1987b).

Com esse modelo, os autores parametrizaram as propriedades dos MNs e de suas entradas excitatórias para fazer com que todos os MNs recrutados disparassem com uma taxa de aproximadamente $10 \mathrm{~Hz}$, gerando forças de 5\% do MVC. As análises dos resultados gerados sugeriram que a presença da inibição recorrente ajuda a reduzir oscilações de $10 \mathrm{~Hz}$ que são transmitidas por tratos corticoespinhais para a medula espinhal e dela para os músculos.

\subsection{Detalhes sobre os modelos de motoneurônios e Células de Renshaw}

No ReMoto, que é o software utilizado para realizar as simulações nesse trabalho, a posição de MNs e CRs é determinada de forma a representar a distribuição rostro-caudal desses neurônios na medula espinhal. O modelo de MN é composto por um compartimento representando a árvore dendrítica e outro para o soma. As CRs, por sua vez, possuem apenas um compartimento para o soma. Esses modelos são do tipo integrate and fire e contém condutâncias sinápticas, de fuga e, no caso do soma, de canais de sódio e de potássio ( $\mathrm{CISI}$, 2007).

A constante de tempo de membrana dos modelos aqui utilizados é definida como $\tau=$ $R_{m} C_{m}$, sendo $R_{m}$ e $C_{m}$ a resistência e capacitância específicas, respectivamente. Essa grandeza expressa, de forma geral, quão rápido é o carregamento ou descarregamento da membrana (STERRATT et al., 2011). Quando o potencial de membrana do modelo utilizado ultrapassa - limiar de disparo, a condutância de sódio do neurônio aumenta rapidamente e logo decai. Por outro lado, as condutâncias de potássio rápida e lenta causam uma repolarização, sendo que esta última tem mais influência sob a AHP.

Como o modelo de condutância utilizado é baseado em pulsos (DESTEXHE; MAINEN; SEJNOWSKI, 1994a), as variáveis de ativação de cada condutância podem ser expressas como exponenciais com taxas de crescimento ou decaimento dependendo de variáveis de transição. 


\subsection{Breve histórico do ReMoto}

\subsubsection{Versões}

O ReMoto foi originalmente escrito em Java para facilitar seu o desenvolvimento como aplicação web, mas seu código se tornou demasiadamente complexo, dificultando sua manutenção e a adição de novas funcionalidades. Com o intuito de lidar com essas limitações, o simulador foi reescrito em Python (R. N. Watanabe, informação pessoal).

Uma das grandes vantagens da linguagem de programação Python é a facilidade de modularização do código sendo desenvolvido. Esse aspecto, quando usado apropriadamente, pode ser de grande utilidade para a neurociência computacional, pois esta frequentemente envolve processamento de grande volume de dados e simulações de sistemas complexos (MULLER et al., 2015). Além disso, a simplicidade da linguagem e a grande disponibilidade de bibliotecas faz com que a escrita de códigos em Python seja relativamente rápida.

Entretanto, à medida que mais detalhes são adicionados às simulações, o tempo de execução se torna maior. Python, nesse sentido, não só possui limitações por causa de suas características de gerenciamento de memória e tipagem dinâmica, mas também por ser uma linguagem interpretada (GORELICK; OZSVALD, 2014). Como simulações no ReMoto em geral envolvem uma grande quantidade de neurônios e sinapses, o baixo desempenho computacional da versão em Python se tornou uma grande desvantagem. Para solucionar esse problema, uma versão em Fortran do ReMoto foi desenvolvida por R. N. Watanabe (informação pessoal).

Naturalmente, simulações com a versão do ReMoto em Fortran têm um tempo de execução significativamente menor do que em Python, fazendo com que a transição para a versão em Fortran seja a escolha mais coerente. Dentro do contexto da computação científica e análise numérica, Fortran é uma linguagem de programação conhecida por seu alto desempenho. Essa linguagem foi criada em 1957, mas veio se atualizando ao longo dos anos, de forma que sua versão mais recente possui suporte a programação concorrente, operações vetorizadas e orientação a objetos.

\subsubsection{Considerações sobre as parametrizações}

A parametrização original das CRs no trabalho de Cisi e Kohn (2008) ocasionou resultados inesperados em alguns casos, como inversão na ordem de recrutamento de MNs ou supressão na atividades das CRs. Como isso pode ser resultado de uma elevada influência inibitória desses 
INs, um trabalho subsequente envolvendo inibição recorrente foi realizado com conectividades entre CRs e MNs reduzidas, diminuindo, assim, essa força da inibição (WATANABE; KOHN, 2015).

Tais comportamentos inesperados ou alterações nos parâmetros motivam uma nova avaliação da parametrização como um todo, já que uma eventual modificação para corrigir algum problema poderia fazer com que outras características do circuito de inibição fossem alteradas, como PIPS e PEPS gerados nos neurônios envolvidos. Infelizmente, há pouquíssimos dados experimentais sobre as CRs em seres humanos. Como a literatura sobre as CRs em gatos é extensa e o objetivo principal do trabalho apresentado aqui é o estudo da inibição recorrente, considerou-se preferível adequar a parametrização dos MNs no ReMoto (originalmente feita para reproduzir experimentos fisiológicos em seres humanos) para gatos. 


\section{OBJETIVOS}

\subsection{Melhora de desempenho}

O tempo de execução de uma simulação se torna um fator limitante quando se deseja estudar sistemas mais complexos. Sendo assim, um dos objetivos desse trabalho foi avaliar estratégias para melhorar o desempenho computacional do simulador. Vale ressaltar que esse não foi o foco principal, pois esse tipo de desenvolvimento pode ser bastante complexo e demorado por si só.

\subsection{Avaliação e validação do circuito de inibição recorrente}

Outro objetivo deste trabalho foi reparametrizar e validar o modelo das CRs em níveis de neurônios e de redes de neurônios, analisando se os resultados são consistentes com dados fisiológicos de gatos.

\subsection{Estudo exploratório do circuito de inibição recorrente}

Como último objetivo, desejou-se realizar um estudo exploratório para entender como o modelo parametrizado se comporta em diferentes situações, algumas das quais se basearam em trabalhos experimentais e computacionais. 


\section{METODOLOGIA}

Em todas as simulações descritas a seguir, foi utilizado o método de integração numérica de Runge-Kutta de quarta ordem e com passo de integração de 0.05 ms. Os dados obtidos podem ser acessados por meio do link: https://dx. doi .org/10.17605/OSF. IO/QNMBH. Os códigos desenvolvidos para realizar as simulações e processar os resultados, por sua vez, podem ser encontrados no GitHub: https://github.com/pabloabur/projectFR/tree/masters.

\subsection{Desempenho computacional}

Duas abordagens distintas foram consideradas nessa parte: A utilização de um cluster e a implementação de uma única matriz com as condutâncias de um determinado neurônio. As medições do tempo de execução, realizadas por meio da biblioteca time, levaram em conta apenas os trechos do código que se repetem várias vezes e que, consequentemente, contém os maiores "gargalos" na simulação.

Vale notar que, na época da escrita dessa seção e dos resultados obtidos, a versão do ReMoto em Fortran ainda não estava disponível. Dessa forma, apenas aqui e na seção 4.1, a versão utilizada do ReMoto foi a em Python.

\subsubsection{Cluster Águia}

O cluster Águia é composto por 64 servidores físicos com 20 cores e 512 GB de RAM. Seu processador é um Intel(R) Xeon(R) CPU E7-2870 com 2.4 GHz. A versão do Python disponível para utilização nesse sistema é a 2.7.13, da distribuição Anaconda2 4.4.0.

O uso de ferramentas para passagem de mensagens em um sistema distribuído foi analisado em uma simulação simples, com uma corrente de 10 nA injetada no soma de MNs e força muscular sendo computada. Para esse fim, o pacote MPI4Py, que possibilita o uso de todos os recursos do cluster, foi utilizado para criar 2, 4, 8 e 16 processos em um único servidor.

Para possibilitar que o problema abordado pudesse ser dividido em unidades menores de computação, foram identificadas as seguintes tasks primitivas: o cálculo da força gerada e das equações diferenciais das unidades motoras. As unidades motoras são independentes entre si 
e não precisam receber mensagens durante a simulação, mas o cálculo da força depende dos disparos dos MNs. Sendo assim, as tasks das unidades motoras enviam, ao final de cada passo da simulação, seus disparos para a task de cálculo da força.

As tasks das unidades motoras foram divididas igualmente entre os processos criados, enquanto a task de cálculo da força ocupou sozinha um único processo. Os parâmetros que foram usados para analisar a qualidade do programa paralelo foram o Speedup (ou aceleração, em português) $S$, calculado pela equação

$$
S=\frac{t_{s}}{t_{p}}
$$

em que $t_{s}$ e $t_{p}$ são o tempo de execução serial e paralelo, respectivamente, e a eficiência $E$, calculada por

$$
E=\frac{t_{s}}{N_{\text {proc }} t_{p}}
$$

sendo $N_{\text {proc }}$ o número de processadores utilizados (GRAMA et al., 2003).

Os valores de $t_{s}$ e $t_{p}$ são obtidos a partir da média de 10 simulações com 400 unidades motoras e duração de 0.5 segundos.

\subsubsection{Matrizes de condutâncias}

Originalmente, o cálculo dos potenciais de membrana de um neurônio no ReMoto era realizado com uma matriz contendo as condutâncias dos compartimentos em questão. A estratégia proposta aqui se baseia no uso de uma única matriz com os valores das condutâncias de um grupo de neurônios (por exemplo, MNs de um núcleo motor), de forma que as computações pudessem ser vetorizadas. Isso foi realizado para todos os MNs, INs e algumas outras variáveis envolvidas no cálculo do potencial de membrana. A implementação antiga das matrizes foi identificada como $G_{a}$ e a nova proposta, como $G_{n}$.

Nessa parte, foi utilizado um sistema operacional Linux 64 bits com oito processadores Intel Core i7-2600 a $3.40 \mathrm{GHz}$ e 7.8 GB de RAM. A versão do Python utilizada foi a 2.7.14, da distribuição Anaconda2 5.0.1-1. De forma geral, as simulações consistiram de comandos descendentes ativando MNs. O tempo de execução foi obtido a partir da média de 5 resultados para diferentes quantidades de MNs (variação no tamanho da matriz de condutância). 


\subsection{Estudo das parametrizações}

Os dados utilizados aqui vêm de experimentos realizados em membros inferiores de gatos por que estudos experimentais ou computacionais sobre o circuito de inibição recorrente em seres humanos são escassos e indiretos. Todas as simulações foram realizadas com o ReMoto versão Fortran em um computador com sistema operacional Linux 64 bits com oito processadores Intel Core i7-2600 a 3.40 GHz e 7.8 GB de RAM. Os dados foram processados e analisados com Python versão 3.7.3.

\subsubsection{Parametrização do modelo de motoneurônios}

O modelo adotado foi o de um núcleo motor do músculo gastrocnêmio medial do gato. Em simulações envolvendo populações desses neurônios, foi considerado um comprimento de $6 \mathrm{~mm}$ do núcleo motor (BURKE et al., 1977) com 75 MNs do tipo S, 75 do tipo FR e 150 do tipo FF, como em Uchiyama, Johansson e Windhorst (2003a).

Para representar as fibras descendentes responsáveis pela ativação do núcleo motor, foram utilizados 400 elementos pré- sinápticos disparando potenciais de ação de acordo com um processo pontual Gama e com 30\% de conectividade com o compartimento dendrítico dos MNs. A ordem desses processos estocásticos em função do nível de força estudado foi adotada como no trabalho de Watanabe et al. (2013).

Os valores de pico dos twitches e força tetânica das unidades motoras utilizados foram os publicados por Mrówczyński, Celichowski e Krutki (2006), considerando que os limites dos intervalos fornecidos estivessem relacionados linearmente com o tamanho dos MNs. A partir disso, as relações twitch-tétano foram calculadas para cada MN como o valor da força tetânica divido pela amplitude de pico do twitch.

Também considerando uma distribuição de parâmetros que acompanham linearmente o tamanho do MN, o tempo que o twitch leva para alcançar o pico e a velocidade de condução axonal foram interpolados a partir dos valores máximos e mínimos fornecidos em Burke et al. (1971) e Zengel et al. (1985), respectivamente.

No ReMoto, a saturação da força das unidades motoras se dá por meio de uma sigmoide. Dessa forma, também foi necessário encontrar uma constante de saturação que fizesse com que essa função, para cada MN, tivesse como saídas o recíproco da relação twitch-tétano e 1 quando as entradas fossem iguais a 1 e a força tetânica, respetivamente.

Existem outros parâmetros do modelo de MN no ReMoto, mas esses não foram alterados 
ou por que a parametrização adequada já foi feita (CISI, 2007) ou por que não influem nas simulações realizadas. Os dados experimentais utilizados e suas referências são apresentados na Tabela 3.1.

Tabela 3.1 - Dados experimentais de unidades motoras utilizados na parametrização dos MNs. Os valores, fornecidos na forma de intervalos, foram distribuídos linearmente pelo núcleo motor de acordo com os tamanhos dos MNs. Referências: (a) Mrówczyński, Celichowski e Krutki (2006), (b) Burke et al. (1971) e (c) Zengel et al. (1985).

\begin{tabular}{lcccc}
\hline \multirow{2}{*}{ Propriedades } & \multicolumn{3}{c}{ Unidades motoras } & \multirow{2}{*}{ Referência } \\
& 12 até 380 & 2 até 74 & 2 até 53 & $(\mathrm{a})$ \\
\hline Twitches $(\mathrm{mN})$ & 30 até 1032 & 37 até 570 & 17 até 396 & (a) \\
Forças tetânicas $(\mathrm{mN})$ & 20 até 47 & 30 até 55 & 58 até 110 & (b) \\
Tempos de contrações $(\mathrm{ms})$ & $99 \pm 1$ & $100 \pm 1$ & $86 \pm 1$ & (c) \\
Velocidade de condução axonal $(\mathrm{m} / \mathrm{s})$ & &
\end{tabular}

\subsubsection{Parametrização do modelo de célula de Renshaw}

As parametrizações foram efetuadas na ordem em que são apresentadas e iterativamente, com base nos conhecimentos sobre a CR ou o circuito de inibição recorrente descritos na literatura. Como a estimativa é de que existam em média 100 CRs para cada $1 \mathrm{~mm}$ de extensão da medula espinhal do gato (CARR et al., 1998), simulações do núcleo motor inteiro foram realizadas com 600 CRs. Os demais parâmetros, quando não mencionados na metodologia, foram mantidos de acordo com o que foi descrito em Cisi (2007).

\subsubsection{Potenciais excitatórios pós-sinápticos}

Mantendo-se o padrão de $C_{m}=1 \mu \mathrm{Fcm}^{-2}$, a resistência específica foi ajustada para reproduzir os seguintes resultados descritos na literatura:

a) Walmsley e Tracey (1981): Medições da atividade intracelular em CRs após uma estimulação de raízes ventrais forneceram alguns dados sobre os PEPSs resultantes, como mostrado na Figura 3.1;

b) Williams e Baker (2009): Nesse trabalho de simulações, os autores adotam $7.6 \mathrm{~ms}$ de tempo de subida e 50 ms de duração dos PEPSs descritos por Walmsley e Tracey (1981).

Para simular o experimento descrito, uma corrente suficiente para causar um único potencial de ação foi injetada no soma de um MN do tipo $S$ que fazia sinapse com uma CR. Para garantir uma atividade passiva da membrana, a condutância sináptica ativada pelo disparo do MN foi diminuída. 


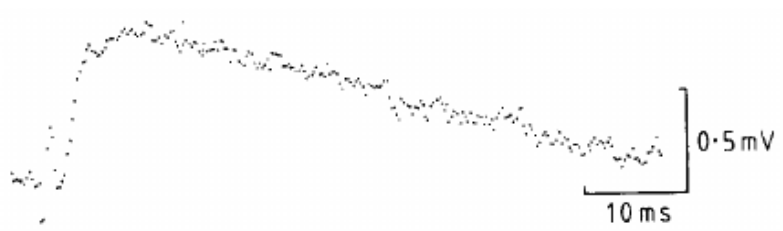

Figura 3.1 - Potencial excitatório pós-sináptico na célula de Rewshaw. Fonte: Adaptado de Walmsley e Tracey (1981).

\subsubsection{Características de disparos}

Os parâmetros de limiar, comprimento, diâmetro e densidade e variáveis de transição das condutâncias iônicas do modelo da CR podem ser alterados para reproduzir diferentes características de disparos. As alterações feitas foram baseadas nas seguintes referências:

a) Walmsley e Tracey (1981): Foi mostrado que CRs disparam espontaneamente a uma taxa de 7 pps;

b) Hultborn e Pierrot-Deseilligny (1979b): Relações de frequência de disparo versus corrente injetada $(F \times I)$ foram obtidas para diferentes correntes, como visto na Figura 3.2(a). Nessas curvas, informações sobre a forma como a CR se adapta a uma dada corrente e a intensidade de corrente necessária para que os disparos comecem a acontecer também podem ser extraídas. Além dessas contribuições, os autores mostraram que, após um breve pulso de corrente injetada, a AHP apresentou uma amplitude de -2 $\mathrm{mV}$ e duração por volta de $30 \mathrm{~ms}$, como visto na Figura 3.2(b);

c) Fyffe (1990): Estudos morfológicos mostraram CRs com diâmetro médio de $27 \mu \mathrm{m}$;

d) Bui (2003): Estimativas da área superficial média do soma e do dendrito foram 1753.8 $\mu \mathrm{m}^{2}$ e $16756 \mu \mathrm{m}^{2}$, respectivamente.

Primeiramente, é necessário definir quando a CR irá disparar um potencial de ação. Sabese que esses neurônios possuem baixo limiar (UCHIYAMA; JOHANSSON; WINDHORST, 2003a), mas não existem estudos quantitativos especificamente sobre esse parâmetro. O valor do limiar foi calculado como

$$
V_{l}=\frac{I_{r} R_{m}}{a}
$$

com $V_{l}$ sendo a tensão de limiar, $I_{r}$ a corrente de reobase e $a$ a área superficial total (CISI, 2007). Para calcular o comprimento $l$ de um único compartimento, por sua vez, foi usada a expressão 


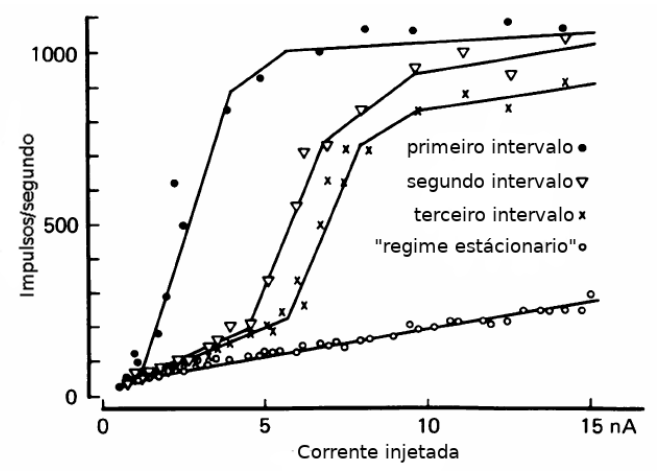

(a)

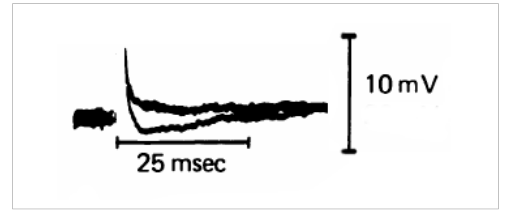

(b)

Figura 3.2 - Características de disparos da célula de Renshaw. Fonte: Adaptado de Hultborn e PierrotDeseilligny (1979b). (a) Relação entre corrente injetada e taxa de disparo de uma célula de Renshaw. A taxa de disparo instantânea entre o primeiro e segundo potencial de ação é entendido como o primeiro intervalo, e assim por diante. O regime estacionário foi considerado como sendo após 80 ms. (b) Detalhes de amplitude e duração da pós-hiperpolarização.

$$
a=\pi l d
$$

sendo $d$ o diâmetro da CR (STERRATT et al., 2011).

A partir de então, simulações foram realizadas com diferentes valores de variáveis de transição e densidade das condutâncias iônicas de uma única CR para se encontrar resultados de AHP e curva $F \times I$ apropriados. As correntes injetadas em cada caso estiveram de acordo com os dados mostrados na Figura 3.2. Por fim, para obter uma taxa de disparos espontâneos de 7 pps, foi necessário alterar o valor da condutância máxima do ruído agindo sobre a CR.

\subsubsection{Potenciais inibitórios pós-sinápticos}

As condutâncias sinápticas ativadas pelos disparos das CRs em cada tipo de MN foram ajustadas, levando em conta os seguintes dados experimentais:

a) Friedman et al. (1981): Correlações foram encontradas entre amplitude dos PIPS e o tipo do MN, mas não entre essas amplitudes e resistências de entrada dos MNs em cada tipo;

b) Fyffe (1991): Conexões sinápticas identificadas como provenientes de CRs foram todas localizadas nos dendritos de MNs do tipo alfa;

c) Uchiyama, Johansson e Windhorst (2003a): Baseado em dados fisiológicos (FRIEDMAN et al., 1981; HULTBORN; KATZ; MACKEL, 1988; VAN KEULEN, 1979), um procedi- 
mento para estimar PIPS nos MNs de um núcleo motor foi adotado, tendo os resultados mostrados na Figura 3.3.

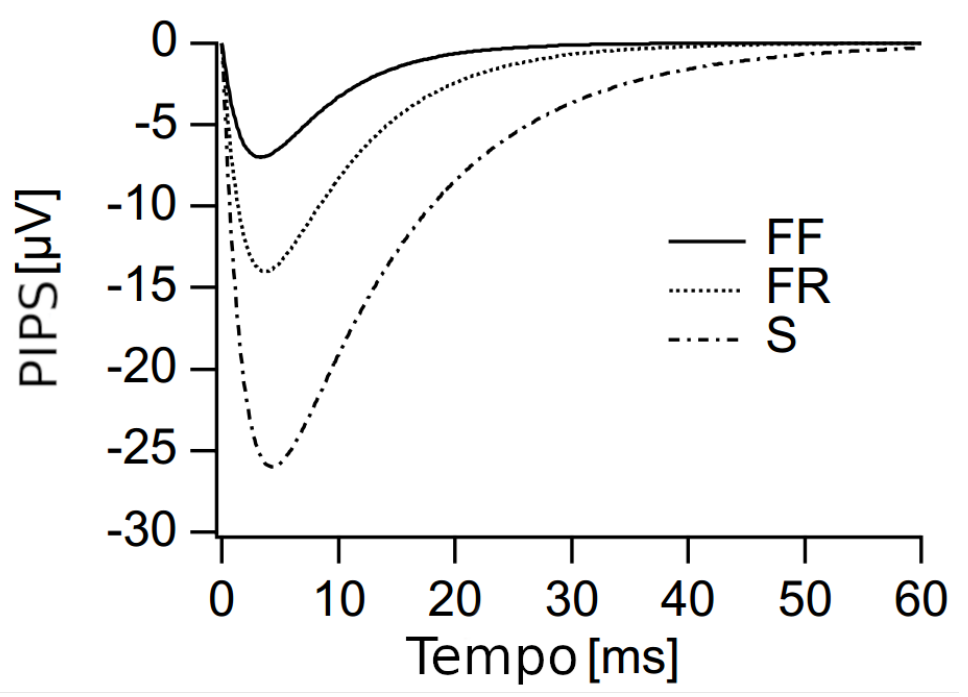

Figura 3.3 - Potencial inibitório pós-sináptico agindo nos motoneurônios. Fonte: Adaptado de Uchiyama, Johansson e Windhorst (2003a).

Sendo assim, a localização das sinapses das CRs foi definida no compartimento dendrítico do MN e simulações foram realizadas para encontrar três valores de condutâncias (um para cada tipo) que reproduzam a Figura 3.3.

\subsubsection{Distribuição de potenciais inibitórios pós-sinápticos recorrentes}

A distribuição dos PIPS recorrentes pelo núcleo motor depende de fatores topográficos e funcionais. No ReMoto, isso está relacionado com condutâncias sinápticas e suas conexões. Nas simulações realizadas, a conectividade entre MNs e CRs foi considerada como sendo de $100 \%$ e as condutâncias e suas distribuições topográficas são parametrizadas de acordo com:

a) McCurdy e Hamm (1994): A Distribuição topográfica das amplitudes significativas de PIPS recorrentes obtida de pares de MNs é inversamente correlacionada com a distância. Os autores fornecem uma visão geral, independente do núcleo motor. MNs do músculo gastrocnêmio medial separados por no máximo $1 \mathrm{~mm}$ são classificados como próximos. Fora dessa zona, são considerados distantes. A Figura 3.4 mostra o resultado dos autores. Para o músculo em questão, os valores médios de amplitudes foram de $-19,63$ $\pm 2,42 \mu \mathrm{V}$ e $-41.36 \pm 7.19 \mu \mathrm{V}$ para pares distantes e próximos, respectivamente;

b) Uchiyama, Johansson e Windhorst (2003a): O padrão de distribuição topográfica da força sináptica é o de uma gaussiana que decresce na medida em que se afasta do 
neurônio pré-sináptico. O desvio padrão da curva é de $0.167 \mathrm{~mm}$ e $1.164 \mathrm{~mm}$ para os MNs e para as CRs, respectivamente. A quantidade de botões sinápticos também é um indicativo da força sináptica das conexões. Estima-se que os axônios colaterais dos MNs que alcançam a região onde as CRs se encontram possuam $78.5 \pm 7.5,43.0 \pm 4.2 \mathrm{e}$ $35.5 \pm 3$ destes botões sinápticos se forem do tipo FF, FR e S, respectivamente.

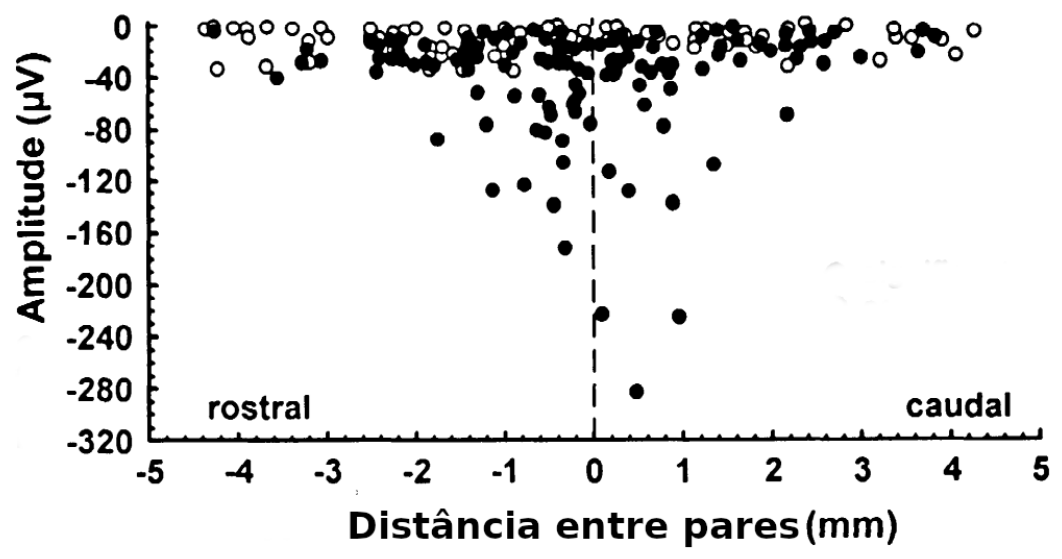

Figura 3.4 - Distribuição topográfica de potenciais inibitórios pós-sinápticos recorrentes. Valores na abcissa indicam a distância entre os pares de motoneurônios enquanto a ordenada mostra o valor da amplitude do potencial inibitório pós-sináptico recorrente gerado. Pontos pretos e brancos representam as respostas significantes e as possivelmente equívocas, respectivamente. Fonte: Adaptado de McCurdy e Hamm (1994).

Para reproduzir o experimento como em McCurdy e Hamm (1994), as simulações consistiram em correntes injetadas no soma de MNs por um curto período de tempo para que o PIPS recorrente pudesse ser observado em outros MNs. Foram levados em conta 180 pares, separados por distâncias entre $86 \mu \mathrm{m}$ e $4.7 \mathrm{~mm}$.

O número de botões sinápticos de cada tipo de MN nas CRs foi implementado (de forma indireta) como valores de condutância seguindo uma proporção de 1:0.55:0.45 (FF:FR:S). Isso permitiu que apenas a condutância máxima dos MNs do tipo FF $\bar{g}_{\max _{F F}}$ fosse parametrizada, sendo as outras ajustadas de acordo com a proporção.

\subsubsection{Dinâmica e depressão sináptica}

Para abordar as características dinâmicas e de depressão pós-sináptica, as referências utilizadas foram:

a) Hultborn e Pierrot-Deseilligny (1979b): Os autores apresentaram evidências da existência de um mecanismo de decréscimo da eficácia sináptica dos terminais de axônios colaterais agindo sobre as CRs. Essa conclusão foi baseada na diminuição de taxas de disparo para diferentes frequências de estímulo; 
b) Uchiyama, Johansson e Windhorst (2003a): Um aumento abrupto na frequência de estimulação da CR fez com que sua taxa de disparo apresentasse um overshoot, como mostrado na Figura 3.5.

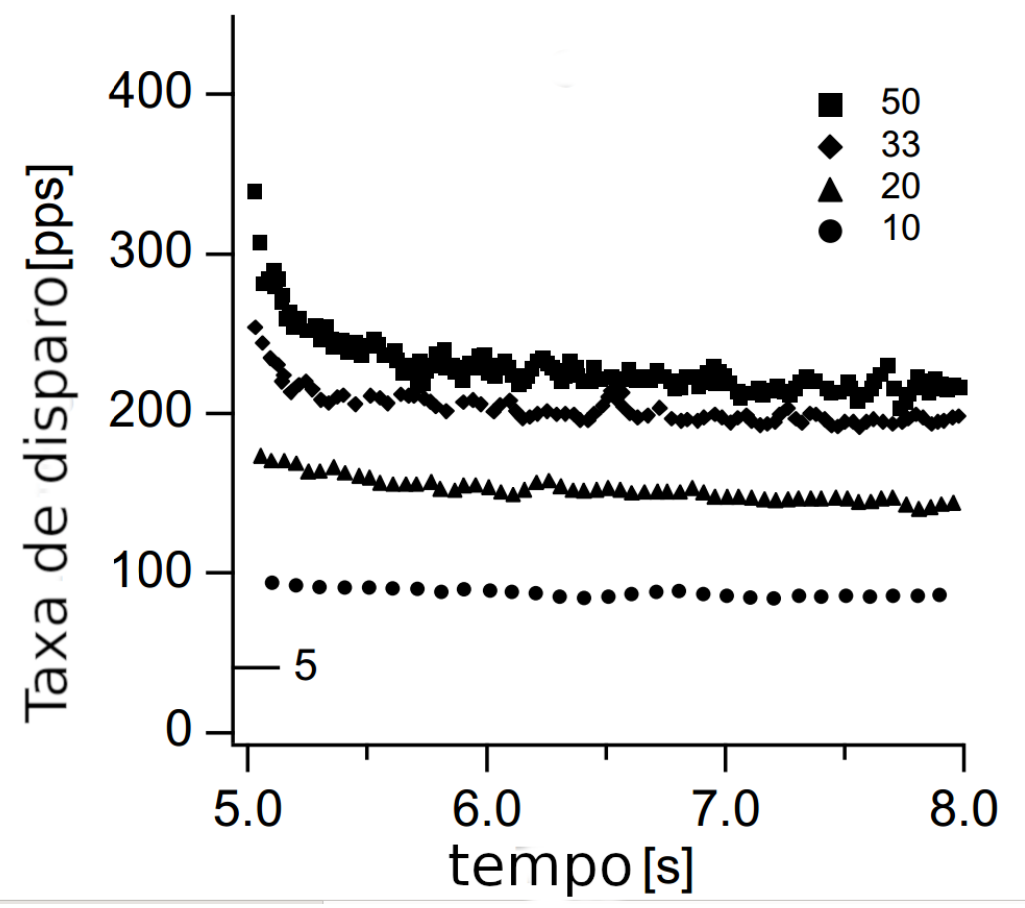

Figura 3.5 - Características dinâmicas da célula de Renshaw. A frequência do estímulo aplicado, inicialmente de $5 \mathrm{~Hz}$ (com resposta indicada pelo traço horizontal com o número 5 no eixo vertical), foi abruptamente aumentada para um dos valores indicados na legenda, em Hz. Fonte: Adaptado de Uchiyama, Johansson e Windhorst (2003a).

No ReMoto, uma depressão pós-sináptica em função do tempo é descrita por

$$
g_{d y n}(t)=\bar{g}_{\text {max }}-\left(\bar{g}_{\text {max }}-g_{d y n} v a r\right) e^{-\frac{\left(t_{d}+t\right)}{\tau_{d}}}
$$

sendo $g_{d y n}$ a condutância dinâmica alterada pela depressão após um disparo, $\bar{g}_{\max }$ a condutância máxima original, var o quanto de depressão ocorrerá $(0 \leq \operatorname{var} \leq 1), \tau_{d}$ a constante de tempo e $t_{d}$ o instante do último disparo.

As simulações para ambas características foram feitas com uma população de CRs recebendo um estímulo antidrômico com frequências variadas para que a taxa de disparos gerada fosse contabilizada. 


\subsubsection{Validação do modelo}

Nesta seção, de forma qualitativa e semiquantitativa, a robustez da parametrização adotada foi testada por meio da comparação de resultados de procedimentos experimentais com resultados obtidos da simulação desses experimentos.

\subsubsection{Características de potenciais inibitórios pós-sinápticos recorrentes}

As características de PIPS recorrentes que foram verificadas são mostradas na Figura 3.6, na forma de histogramas. As simulações realizadas foram as mesmas da parametrização na Seção 3.2.2.4.
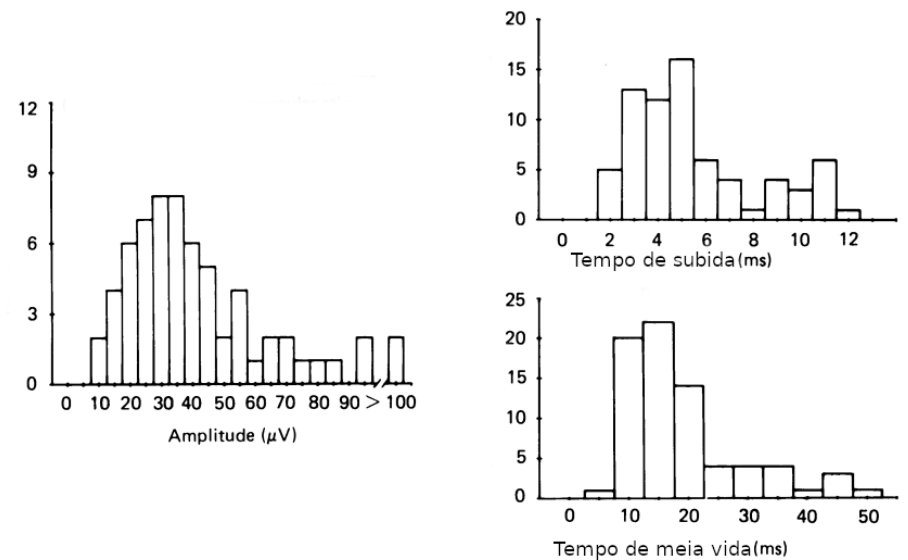

Figura 3.6 - Resultados experimentais sobre características de potenciais inibitórios pós-sinápticos recorrentes. Eixos verticais são as contagens de ocorrências. Fonte: Adaptado de Hamm et al. (1987b).

\subsubsection{Relação estática das entradas e saídas das células de Renshaw}

A relação estática de entrada e saída realizada por Cleveland, Kuschmierz e Ross (1981) é importante para a caracterização de CRs. Foi observado que os resultados obtidos poderiam ser ajustados a uma função hiperbólica, que por conveniência foi chamada de função de Langmuir pelos autores. Esta abordagem também foi empregada nesse trabalho e a função em questão foi calculada como

$$
f_{C R}=\frac{c f_{A D}}{k+f_{A D}}
$$

em que $f_{A D}$ é a frequência do estímulo, $f_{C R}$ é a taxa de disparo média da CR após sua resposta transiente, $c$ é a constante de saturação e $k$ é a constante de semissaturação. Esta análise foi reproduzida no modelo parametrizado, passado um período de adaptação do 
neurônio de 500 ms e considerando as frequências de estímulos antidrômicos como entrada e taxas de disparos das CRs como saída. Os resultados experimentais da literatura são os mostrados na Figura 3.7

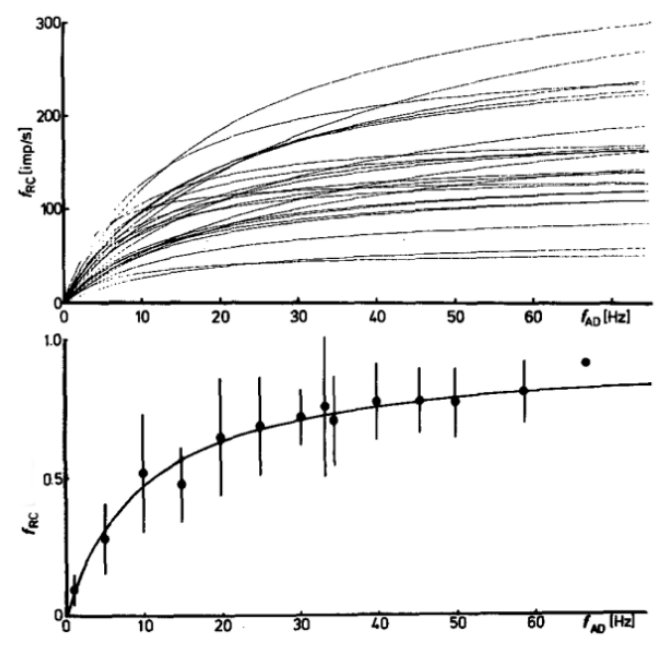

Figura 3.7 - Resultados experimentais sobre relações estáticas de entrada e saída. Uma frequência de estímulo antidrômica $f_{A D}$ em $\mathrm{Hz}$ gera uma taxa de disparos $f_{R C}$ na célula de Renshaw. No gráfico superior, 24 funções de Langmuir são ajustadas às respostas de 24 células de Renshaw. No gráfico inferior, a média normalizada desse grupo é apresentada, também com uma função de Langmuir ajustada a ela. Barras verticais representam o desvio padrão. Fonte: Adaptado de Cleveland, Kuschmierz e Ross (1981).

\subsubsection{Respostas das células de Renshaw sujeitas a um estímulo antidrômico}

As CRs, quando ativadas por todos os axônios motores convergindo nelas, exibem disparos que podem durar até algumas dezenas de milissegundos e taxas de disparos instantâneas decrescentes com o tempo e dependentes da força sináptica total (ECCLES et al., 1961b; UCHIYAMA; JOHANSSON; WINDHORST, 2003a). Essa característica é mostrada na Figura 3.8

Nas simulações realizadas, a atividade espontânea das CRs foi ativada e os estímulos antidrômicos foram aplicados com diferentes intensidades para ativar diferentes tipos de MNs. As taxas de disparos instantâneas foram calculadas como o recíproco do intervalo entre cada potencial de ação, em pps. 


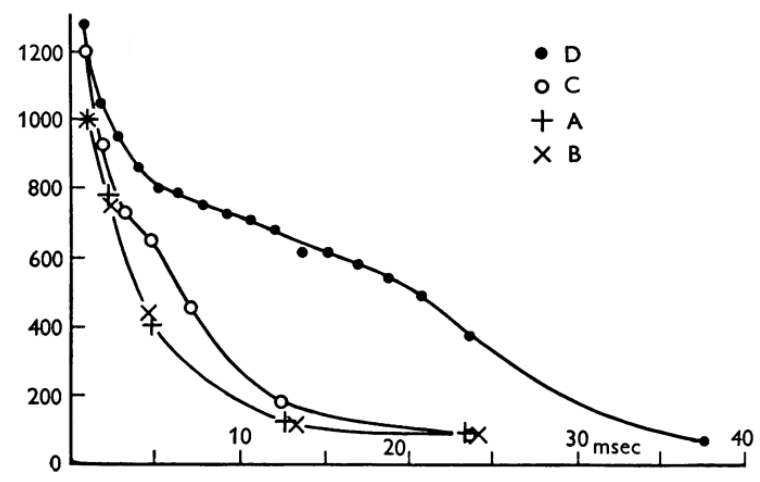

Figura 3.8 - Células de Renshaw e sua resposta à um estímulo antidrômico. O tempo é mostrado na abcissa, em ms, enquanto a taxa de disparos, na ordenada, em pps. São mostradas respostas de diferentes núcleos motores, de acordo com a legenda: A, plantar; B, sóleo; C, gastrocnêmio medial; D, gastrocnêmio lateral. Fonte: Adaptado de Eccles et al. (1961b).

\subsection{Efeitos da parametrização em simulações}

As simulações realizadas nessa seção foram configuradas para serem, na medida do possível, semelhantes às situações estudadas nos trabalhos usados como referência, possibilitando que os resultados pudessem ser apropriadamente comparados. De formal geral, optou-se por utilizar CRs disparando espontaneamente em todas as simulações.

\subsubsection{Disparos de motoneurônios}

Com o intuito de analisar o recrutamento dos MNs, uma corrente $i$ em função do tempo foi injetada no soma de todos esses neurônios. Nessa simulação, a presença ou ausência da inibição recorrente é analisada no mesmo circuito e a corrente $i(t)$ é descrita pela seguinte equação:

$$
i(t)=40 t / 1000
$$

Outra opção utilizada para estimular os MNs foi com uma entrada excitatória que aumenta com o tempo de simulação, mas, nesse caso, isso se dá por meio de fibras descendentes com frequência de disparos $F D$ dada por

$$
F D(t)=1500 t / 1000
$$

Em outra situação, para estudar a taxa de disparos dos MNs, a entrada utilizada foi dada por 


$$
F D(t)=\left\{\begin{array}{l}
\frac{C_{p}}{4000} t, \quad t \leq 4000 m s \\
C_{p}, \quad 4000<t<5000 m s \\
-\frac{C_{p}}{4000}(t-9000), \quad t \geq 5000 m s
\end{array}\right.
$$

sendo $C_{p}$ o valor necessário para alcançar a porcentagem da CVM desejada. Esta equação representa os disparos de fibras descendentes agindo sobre o núcleo motor com o intuito de realizar uma contração em rampa até 70 \% da CVM. Após 1 segundo nesse valor, eles decaíram com a mesma derivada.

Nas simulações com inibição recorrente, $C_{p}$ de 950 foi suficiente para recrutar por volta de 240 MNs (WALMSLEY; HODGSON; BURKE, 1978) no pico da Equação (3.9). Para fazer com que o nível de força muscular gerado nessa situação se mantivesse na ausência das CRs, o valor dessa variável foi diminuído para 710 .

As taxas de disparos foram calculadas por meio da convolução de uma janela de Hann de 400 ms de largura e área unitária com um trem de impulsos unitários representando os instantes de disparos dos MNs.

\subsubsection{Diminuições dos níveis de força}

O efeito do modelo de CR na força muscular foi estudado baseando-se no trabalho de Granit e Renkin (1961), que fizeram uma estimativa do quanto a inibição recorrente diminuiria a tensão gerada pelo músculo sóleo do gato. Isso é mostrado na Figura 3.9

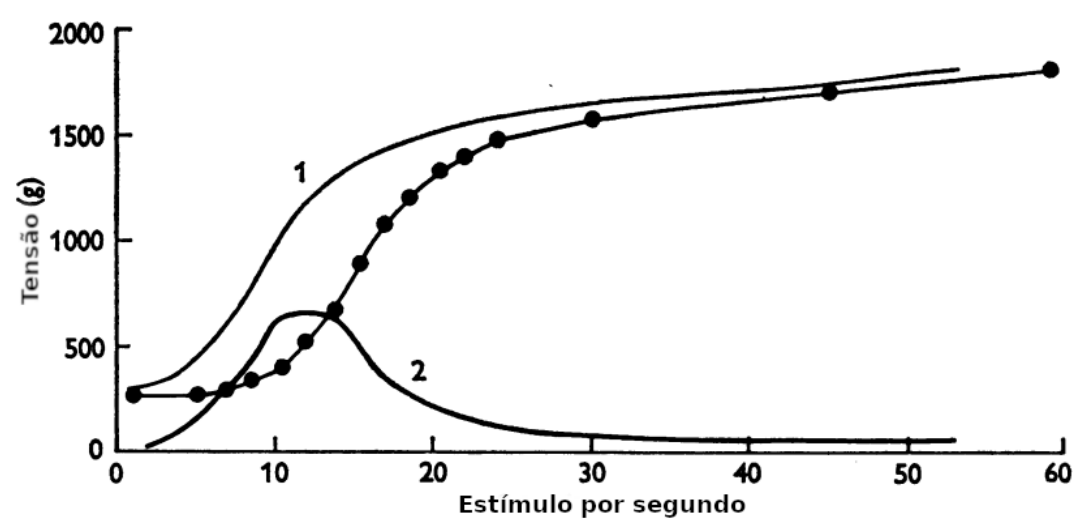

Figura 3.9 - Tensão isométrica do músculo sóleo (ordenada) em função da frequência de estímulo do nervo (abcissa). Os círculos preenchidos representam os valores de referência de tensão muscular, enquanto a curva 1 é uma estimativa dessa na ausência de inibição recorrente. A curva 2 é a diferença das outras duas. Fonte: Adaptado de Granit e Renkin (1961).

Como o músculo utilizado nesse experimento é diferente do empregado nas parametri- 
zações, algumas considerações foram necessárias. Foi pressuposto que as relações dos MNs desse núcleo motor com as CRs e as fibras descendentes (condutâncias sinápticas e conectividade) sejam as mesmas apresentadas anteriormente. Ademais, as características de unidades motoras relacionadas aos twitches, propriedades eletrotônicas e geométricas foram as mesmas adotadas para o núcleo motor gastrocnêmio medial. Sendo assim, apenas as quantidades e distribuições de tamanhos desses neurônios foram alteradas, de forma semelhante ao trabalho de Maltenfort, Heckman e Rymer (1998).

A simulação, portanto, foi realizada com 150 MNs do tipo $S$, de acordo com estimativas realizadas em trabalhos experimentais (BURKE, 2011). Respeitando a proporção de 50 $\mathrm{MN} / \mathrm{mm}$ de medula espinhal (CISI, 2007), esses neurônios foram distribuídos em $3 \mathrm{~mm}$. Sendo assim, 300 CRs foram dispostas nesse comprimento (CARR et al., 1998). O núcleo motor foi ativado por fibras descendentes durante $4 \mathrm{~s}$, com taxas suficientes para gerar os níveis de força reportados na Figura 3.9.

A média da força em cada nível de estimulação foi calculada, descartando $1 \mathrm{~s}$ inicial que poderia conter respostas transitórias. Por estar diretamente relacionada com a força gerada, a taxa de disparos média dos MNs (computada como a média das taxas individuais) e sua diminuição causada pela inibição recorrente também foi analisada.

\subsubsection{Análise espectral da força gerada pelo modelo}

Algumas condições simuladas por Williams e Baker (2009), como explicado na seção 1.5.4, foram reproduzidas aqui para verificar se o modelo implementado no ReMoto era capaz de reduzir oscilações em $10 \mathrm{~Hz}$.

Cada MN foi ativado por fibras descendentes com taxas de disparos moduladas por uma senoide com período de 100 ms e valor médio suficiente para gerar um nível de força desejado. Ruídos excitatórios nos compartimentos dendríticos dos MNs foram adicionados por meio de condutâncias sinápticas com valor de pico igual a $12 \mu \mathrm{S}$ ativadas por um processo pontual Poisson. As frequências médias dessas duas entradas excitatórias foram determinadas como mostrado a seguir.

Primeiramente, usando o caso sem inibição recorrente, a frequência média de disparo de fibras descendentes necessária para recrutar cerca de $75 \mathrm{MNs}$ foi determinada. Essa quantidade foi próxima de $25 \%$ da população de MNs ativados em níveis de força de $5 \%$ da CVM (HOFFER et al., 1987; WALMSLEY; HODGSON; BURKE, 1978). Por causa de fatores como conectividade e propriedades dos MNs, algumas unidades motoras do tipo FR foram ativadas. 
O mesmo procedimento foi realizado para níveis de 70\% da CVM, mas tendo a atividade de $80 \%$ do núcleo motor como alvo (HOFFER et al., 1987; WALMSLEY; HODGSON; BURKE, 1978).

Em seguida, para cada porcentagem da CVM adotada, foram considerados cenários com inibição recorrente em que a condutância das sinapses das CRs sobre os MNs de cada tipo fosse igual, o dobro e a metade dos respectivos valores parametrizados (apresentados na Tabela 4.2). Em cada um desses casos, frequências médias de disparos de fibras descendentes foram ajustadas para fazer com que as médias das forças geradas estivessem dentro de uma faixa de $10 \%$ em torno da respectiva força gerada na ausência de CRs.

As frequências médias determinadas anteriormente foram utilizadas como valor médio de uma senoide. Sua amplitude pico a pico, determinada na situação com condutâncias das CRs inalteradas e com 5\% da CVM, foi aquela necessária para fazer com que se fosse possível observar picos no espectro da força e na coerência córtico-muscular parecidos com os de Williams e Baker (2009).

As características das fibras descendentes são resumidas na Tabela 3.2. Em todos os cenários, a amplitude pico a pico da senoide que modulou a intensidade do processo pontual descendente foi de $4.6 \mathrm{~Hz}$. Ademais, um ruído independente com base em um processo Poisson a uma taxa pequena de $90 / \mathrm{s}$, suficiente para gerar cerca de $1 / 10$ da condutância total causada pelas fibras descendentes no compartimento dendrítico, foi associado a todos os MNs.

Tabela 3.2 - Valores médios das entradas utilizadas nas simulações em cada uma das situações estudadas.

\begin{tabular}{ccc}
\hline \multirow{2}{*}{ Situação da inibição recorrente } & \multicolumn{2}{c}{ Frequências (Hz) } \\
& 5\% CVM & 70\% CVM \\
\hline Ausente & 141 & 665 \\
Fraca & 190 & 795 \\
Normal & 230 & 930 \\
Forte & 333 & 1180 \\
\hline
\end{tabular}

Uma outra condição simulada foi uma em que o valor médio da senoide foi mantido o mesmo sem e com inibição recorrente. Nesse caso, apenas a situação com 5\% da CVM e condutâncias das CRs inalteradas foi considerada.

A densidade espectral de potência da força muscular foi estimada por meio do método de Welch (BENDAT; PIERSOL, 2011) com 5 janelas de Hann com 50\% de sobreposição. A coerência entre o sinal de EMG e o potencial de membrana do dendrito do MN de índice 1 , tomado como representativo da atividade neural descendente oriunda do encéfalo, foi estimada da mesma forma, mas com 33 janelas. O MN em questão recebia apenas as entradas 
sinápticas excitatórias (potenciais de ação de fibras descendentes e ruído), não era capaz de gerar potenciais de ação e nem de fazer conexões com CRs.

As simulações realizadas tiveram duração de $11 \mathrm{~s}$ e passo de integração de $0.05 \mathrm{~ms}$. Para evitar interferências de respostas transitórias, apenas os últimos 10 segundos dos sinais gerados pelo ReMoto foram utilizados. As simulações foram repetidas dez vezes para que se fosse obtida uma resposta média dos resultados, que foram, então, comparadas qualitativamente com os resultados de Williams e Baker (2009), mostrados na Figura 3.10.

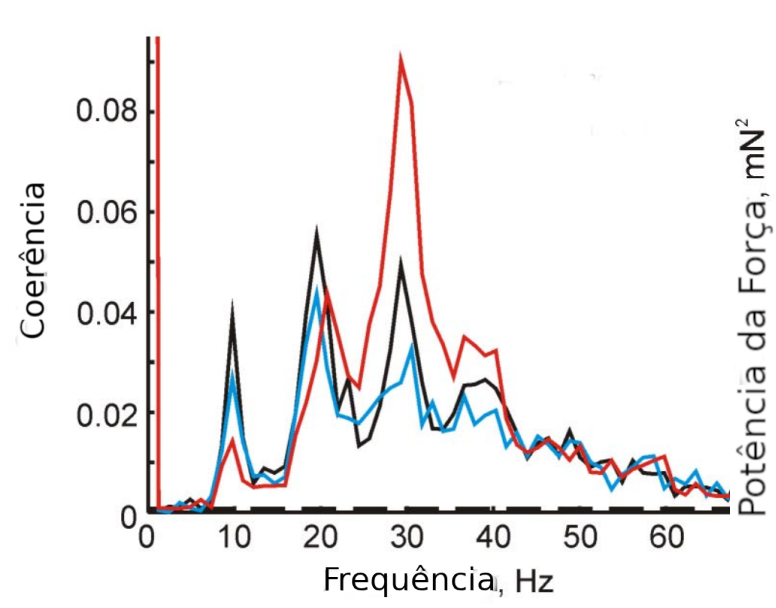

(a)

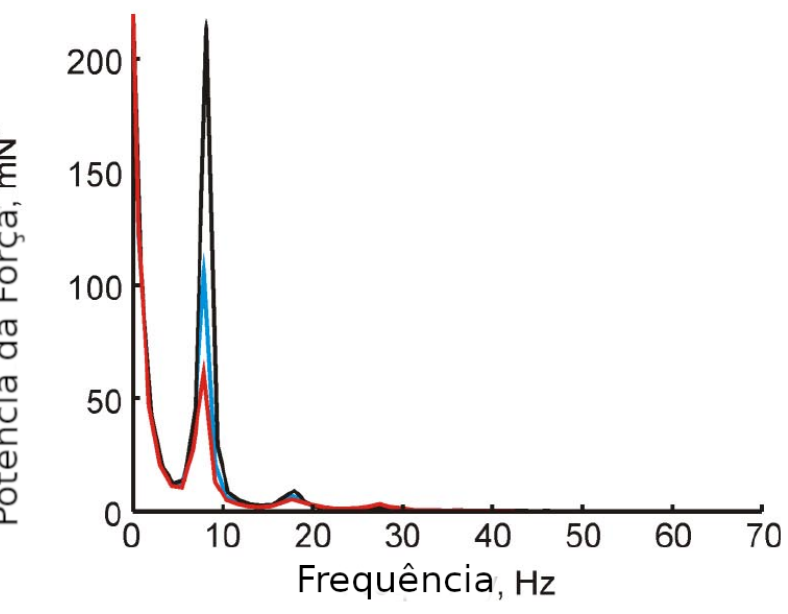

(b)

Figura 3.10 - Efeitos da ausência e presença da célula de Renshaw em análises espectrais. Linhas pretas e vermelhas são os resultados de simulações sem e com inibição recorrente, respectivamente. A linha azul representa uma situação intermediária e não será reproduzida aqui. Fonte: Adaptado de Williams e Baker (2009). (a) Coerência córtico-muscular. (b) Espectro de potência da força muscular.

\subsubsection{Estudos de contrações isométricas}

Para realizar esses estudos, as forças de inibição recorrente (ausente, fraca, normal e forte) e a forma como as entradas foram definidas para cada caso foram as mesmas descritas na seção anterior. A ativação do núcleo motor nessas simulações foi realizada por meio de fibras descendentes com taxa de disparos constante e suficiente para gerar valores de força próximos à CVM. Essa taxa foi mantida por $500 \mathrm{~ms}$. Tal configuração permitiu que a derivada da força, ou seja, sua sensibilidade ao comando descendente, pudesse ser avaliada. Em termos funcionais, isto poderia estar relacionado a um situação de fuga do animal em face de uma ameaça repentina.

Outros cenários analisados foram os da manutenção da força a 5\% e 70\% da CVM por meio de fibras descendentes com taxas de disparos de potenciais de ação constantes e suficientes 
para recrutar uma porcentagem de MNs próxima à apropriada (WALMSLEY; HODGSON; BURKE, 1978). Essas simulações foram realizadas 10 vezes para cada caso. O coeficiente de variação da força muscular gerada foi calculado pela equação (3.10) mostrada abaixo:

$$
\text { Coeficiente de variação }(\%)=\frac{\text { desvio padrão da força }}{\text { média da força }} \cdot 100
$$

Nesse caso, as simulações tiveram duração de $2 \mathrm{~s}$ e os primeiros 500 ms foram removidos para evitar a presença de componentes transitórios no sinal. Os graus de sincronia foram calculados de acordo com o trabalho de Golomb, Hansel e Mato (2001) e comparados.

O coeficiente de sincronia foi calculado da seguinte forma: Primeiramente, a média do potencial membrana do soma dos $N$ MNs que dispararam em uma simulação foi dada como

$$
\bar{V}(t)=\frac{1}{N} \sum_{i=1}^{N} V_{i}(t)
$$

sendo sua variância calculada como

$$
\sigma^{2}=\left\langle\bar{V}(t)^{2}\right\rangle_{t}-\langle\bar{V}(t)\rangle_{t}^{2}
$$

O operador $\langle\cdot\rangle_{t}$ denota uma média no tempo. Em seguida, um fator de normalização que leva em consideração cada MN pode ser calculado como

$$
\sigma_{i}^{2}=\left\langle V_{i}(t)^{2}\right\rangle_{t}-\left\langle V_{i}(t)\right\rangle_{t}^{2}
$$

Por fim, obtém-se o coeficiente

$$
\chi^{2}=\frac{\sigma^{2}}{\frac{1}{N} \sum_{i=1}^{N} \sigma_{i}^{2}}
$$

em que $0 \leq \chi^{2} \leq 1$. Sendo assim, valores mais próximos de 1 indicam uma atividade mais sincronizada do núcleo motor.

\subsubsection{Distorções na saída do núcleo motor e controle da força}

Nas simulações descritas aqui, as entradas sinápticas agindo sobre o núcleo motor foram: fibras descendentes com taxas de disparos com determinado valor médio e moduladas por 3 
senoides; ruídos independentes agindo sobre cada MN. As senoides usadas para a modulação tiveram frequências de $0.5,1.0$ e $2.5 \mathrm{~Hz}$, tendo amplitudes de $10,5.0$ e $2.5 \mathrm{~Hz}$, respectivamente. Por sua vez, os ruídos, gerados por processos Poisson, tiveram condutância sináptica máxima de $12 \mu \mathrm{S}$ e taxa de disparos de $50 / \mathrm{s}$.

As simulações envolveram situações com e sem inibição recorrente. O valor médio da taxa de disparo das fibras descendentes na ausência das CRs foi ajustado para recrutar cerca de 130 MNs. Em simulações com CRs, o valor médio foi aumentado para que fossem geradas forças com valor médio dentro de uma faixa de $10 \%$ em torno da força média gerada na situação anterior. Dessa forma, os valores utilizados foram de 300 e 438 potenciais de ação por segundo.

No total, foram realizadas 30 simulações com $10 \mathrm{~s}$ de duração cada, sendo os primeiros $2 \mathrm{~s}$ dos sinais gerados removidos para eliminar possíveis respostas transitórias nas análises subsequentes. A representação no domínio da frequência da força muscular resultante foi obtida por meio da transformada de Fourier com uma resolução espectral de $0.125 \mathrm{~Hz}$. Além disso, denominando $B_{i}$ como o pico do módulo do espectro da força em $0.5(i=1), 1.0$ $(i=2)$ e $2.5(i=3) \mathrm{Hz}$ e $B_{j}$ como o de todas as frequências (inclusive $i=1,2$ e 3 ), os seguintes quantificadores foram calculados:

$$
\begin{gathered}
Q_{1}=\frac{B_{1}}{B_{2}} \\
Q_{2}=\frac{B_{1}}{B_{3}} \\
Q_{3}=\frac{\sqrt{B_{1}^{2}+B_{2}^{2}+B_{3}^{2}}}{\sqrt{\sum B_{j}^{2}}}
\end{gathered}
$$

Essa última expressão, que teve a somatória realizada apenas até as componentes em frequência de $6 \mathrm{~Hz}$, foi usada para investigar se as CRs poderiam gerar componentes espectrais adicionais ou espúrias. Aplicando os quantificadores acima para o sinal de entrada do núcleo motor, os resultados das equações (3.15) e (3.16) seriam 2 e 4, respectivamente. Mesmo sem a ação das CRs, entretanto, não se pode garantir que os valores de $Q_{1}$ e $Q_{2}$ para o sinal de força sejam iguais aos da entrada e nem que $Q_{3}$ seja igual a 1 . Os valores desses quantificadores aplicados sobre o sinal de força, sem as CRs, é que serviram de referência para se quantificar a ação do feedback das CRs sobre o sinal da força. 
Por fim, para representar o sinal de ativação dos músculos gerado pelos MNs recrutados, foi utilizado um trem de disparos cumulativo (CST, do inglês cumulative spike train): os instantes de disparos de 5 MNs foram utilizados para formar um novo trem de disparos que espelha a contribuição total e temporal do conjunto de MNs selecionados. Esse CST foi filtrado por um filtro passa-baixas de quarta ordem, do tipo Butterworth e com frequência de corte de $10 \mathrm{~Hz}$. 


\section{RESULTADOS E DISCUSSÕES}

\subsection{Desempenho computacional}

Na Figura 4.1a são apresentados os valores de Speedup das simulações com diferentes números de processos. Como se pode perceber, foi possível alcançar uma diminuição no tempo de execução com as simulações feitas em paralelo, de forma que os valores de Speedup aumentam de forma linear, aproximadamente. Na Figura 4.1b, por sua vez, são apresentados os valores das eficiências calculadas. Esses valores são bem próximos para 2, 4 e 8 processos, mas uma queda começa a se tornar visível com 16 processos, sugerindo que, a partir desse número, a queda de eficiência se acentue.

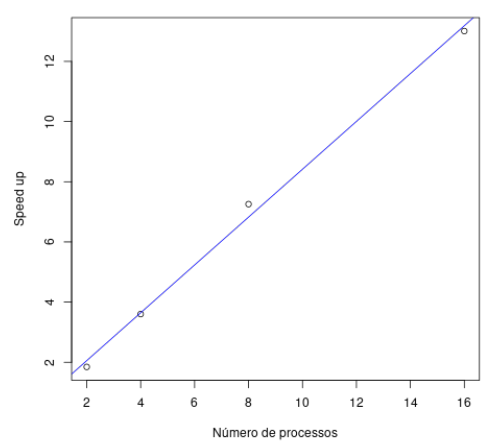

(a)

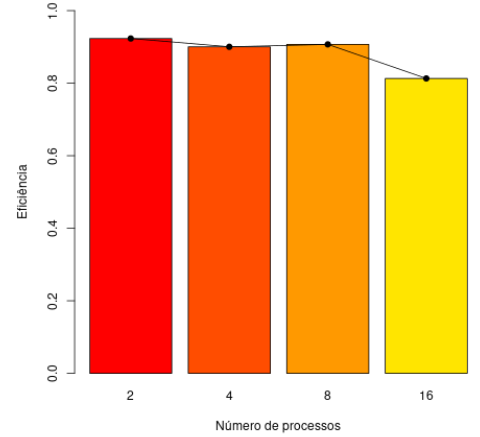

(b)

Figura 4.1 - Resultados de aceleração e eficiência em função do número de processos. (a) Os círculo vazio representam o Speedup obtido para cada número de processos utilizado. A reta em azul mostra uma regressão linear dos resultados. (b) eficiência em função do número de processos.

Outro resultado sobre desempenho computacional obtido foi o de tempo de execução com as matrizes de condutância alteradas no código em Python. Como mostrado na Tabela 4.1, não foi observada uma melhora de desempenho quando se usa a $G_{n}$ com $10 \mathrm{MNs}$. Entretanto, à medida em que se aumenta o número de elementos neuronais para 50, 100 e $400 \mathrm{MNs}$, esta implementação apresenta uma diminuição do tempo de execução de aproximadamente $23 \%$, $29 \%$ e $26 \%$ em relação à $G_{a}$. Isso sugere que as otimizações trazidas por essa estratégia só são vantajosas para simulações que envolvam $G_{n}$ relativamente grandes.

Os resultados mostrados anteriormente são positivos, mas possuem limitações. Em primeiro lugar, é preciso enfatizar que os MNs das simulações realizadas no cluster não recebem 
Tabela 4.1 - Tempo de execução das simulações com diferentes matrizes de condutâncias e quantidades de MNs.

\begin{tabular}{ccccc}
\hline & $10 \mathrm{MNs}$ & $50 \mathrm{MNs}$ & $100 \mathrm{MNs}$ & $400 \mathrm{MNs}$ \\
\hline$G_{a}$ & $5.21 \mathrm{~s}$ & $21.22 \mathrm{~s}$ & $42.34 \mathrm{~s}$ & $170.97 \mathrm{~s}$ \\
$G_{n}$ & $5.63 \mathrm{~s}$ & $16.50 \mathrm{~s}$ & $30.01 \mathrm{~s}$ & $125.31 \mathrm{~s}$ \\
\hline
\end{tabular}

nenhuma entrada sináptica de INs. A paralelização desse tipo de configuração é facilmente obtida e dificilmente apresenta resultados negativos, pois, como as unidades motoras são independentes umas das outras, os processos podem executar em paralelo sem a necessidade de se comunicar (são os chamados problemas embaraçosamente paralelos). Em um cenário mais realista, como o que está sendo estudado na Figura 1.2, MNs em um processo podem precisar receber informações geradas em outro. Por causa da alta complexidade de conexões sinápticas, seriam necessárias muitas comunicações entre processos e isso poderia causar uma diminuição significativa nos valores de Speedup.

Isso, de qualquer forma, não tira a validade desse resultado, visto que existem maneiras de paralelizar simuladores de redes neuronais complexas mantendo um bom desempenho computacional, como feito no trabalho de Morrison et al. (2005). Entretanto, se essa estratégia for adotada no ReMoto, seria aconselhável utilizar a versão em Fortran por causa de seu desempenho superior.

Vale notar que, como o Fortran possui suporte nativo à operações vetorizadas, a implementação de $G_{n}$ já foi realizada por R. N. Watanabe (informação pessoal) na versão do ReMoto em Fortran.

\subsection{Parametrizações}

\subsubsection{Potencial excitatório pós-sinápico nas células de Renshaw}

O resultado mostrado na Figura 4.2 foi obtido com $R_{m}=2500 \Omega \mathrm{cm}^{2}$. O PEPS é iniciado em 10.35 ms e atinge o pico em 16.90 ms, configurando, assim, um tempo de subida de 6.55 ms.

O valor de aproximadamente $4.5 \%$ do pico do PEPS foi atingido $55 \mathrm{~ms}$ após a ativação da sinapse. Esta abordagem para analisar a duração foi utilizada por Maltenfort, Heckman e Rymer (1998), que obtiveram $10 \%$ do pico em 55 ms.

Em relação ao PEPS, existem, ainda, aspectos sobre a convergência de axônios motores e a força de entrada sináptica dependente do tipo de MN. Essas características foram analisadas 


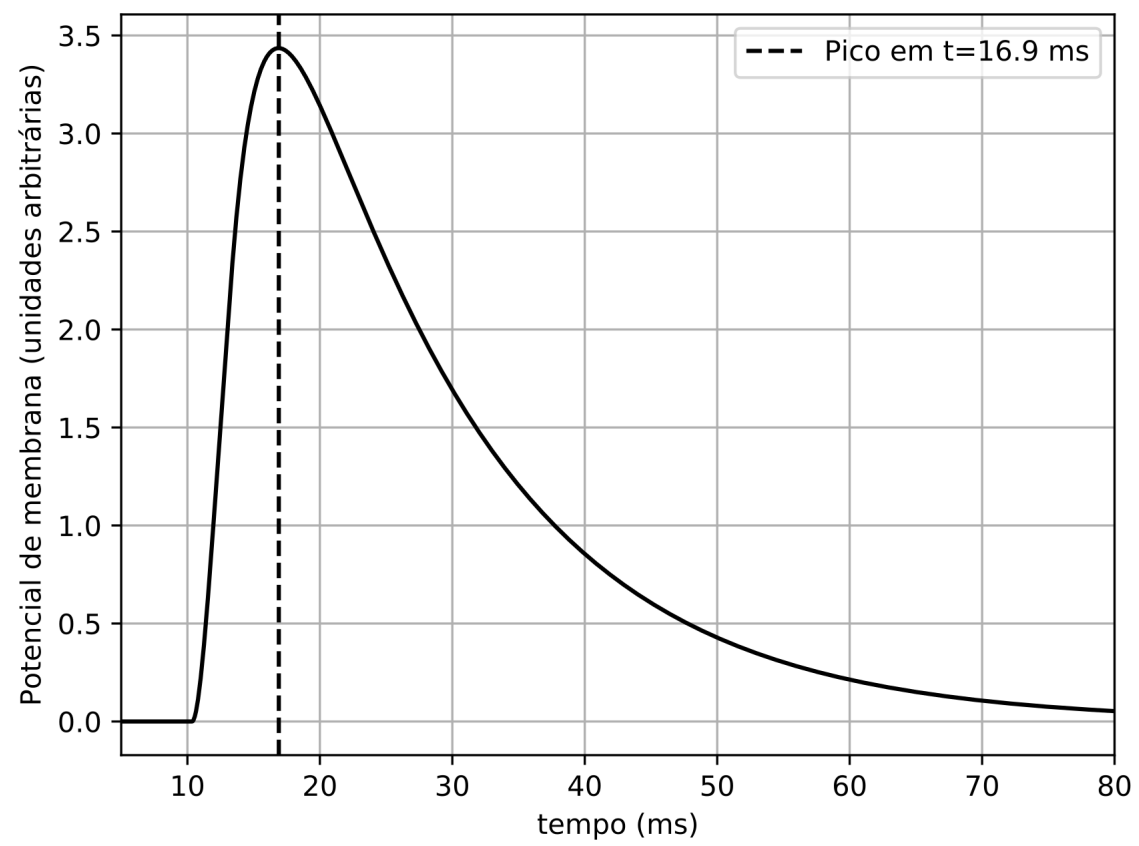

Figura 4.2 - Potencial excitatório pós-sináptico em uma célula de Renshaw.

junto com estudos sobre conectividade e foram abordadas na seção 4.2.4. A utilização de outros valores de resistência para diminuir a amplitude de PEPS, como feito por Williams e Baker (2009), alteraram significativamente as características de disparos mostrados na seção 4.2.2 e, por isso, não foram adotados.

O tempo de subida foi um pouco menor do que o de Williams e Baker (2009), mas ainda está de acordo com o que foi descrito na literatura (WALMSLEY; TRACEY, 1981). Uma alteração na resistência específica mudaria o tempo de subida aqui apresentado, mas isso teria um impacto negativo na duração do PEPS. Portanto, a parametrização realizada satisfez razoavelmente cada característica.

\subsubsection{Características dos disparos das células de Renshaw}

Usando o $R_{m}$ obtido na seção anterior, $a=1753.8+16756 \mu \mathrm{m}^{2}$ e considerando que $I_{r}=0.5 \mathrm{nA}$, a equação (3.3) resulta em $V_{l}=6.75 \mathrm{mV}$. Além disso, considerando $d=27 \mu \mathrm{m}$, a equação (3.4) fornece o valor de $l=218.2168 \mu \mathrm{m}$. Com os resultados obtidos, a resistência de entrada $R_{i}=\frac{R_{m}}{a}$ resultante foi de $13.50 \mathrm{M} \Omega$. Esse valor é condizente com o fato de que as CRs são menores do que os menores MNs.

Com esses parâmetros, torna-se possível parametrizar a AHP e a curva $F \times I$. As variáveis 
de transição relacionadas com a dinâmica dos canais de potássio rápido foram aumentadas para evitar algum tipo de somação de suas correntes. A partir de então, optou-se por utilizar apenas os canais de potássio lento, com $\alpha_{Q}$ e $\beta_{Q}$, para se obter as taxas de disparos e adaptação apropriados.

Considerando uma sequência de potenciais de ação, uma diminuição no valor de $\alpha_{Q}$ faz com que a exponencial que dita a velocidade de ativação do canal seja mais lenta. Reciprocamente, uma diminuição em $\beta_{Q}$ com o intuito de retardar o fechamento permite que haja uma superposição nos valores da variável de ativação $q$, fazendo com que exista uma corrente iônica abaixando o potencial de membrana para o equilíbrio do canal de potássio lento $(-10 \mathrm{mV})$. Esse comportamento é mostrado na Figura 4.3. Inicialmente, essa corrente é relativamente pequena, mas ela cresce de forma cumulativa. Esse fenômeno, então, gera uma adaptação na frequência de disparo das CRs.

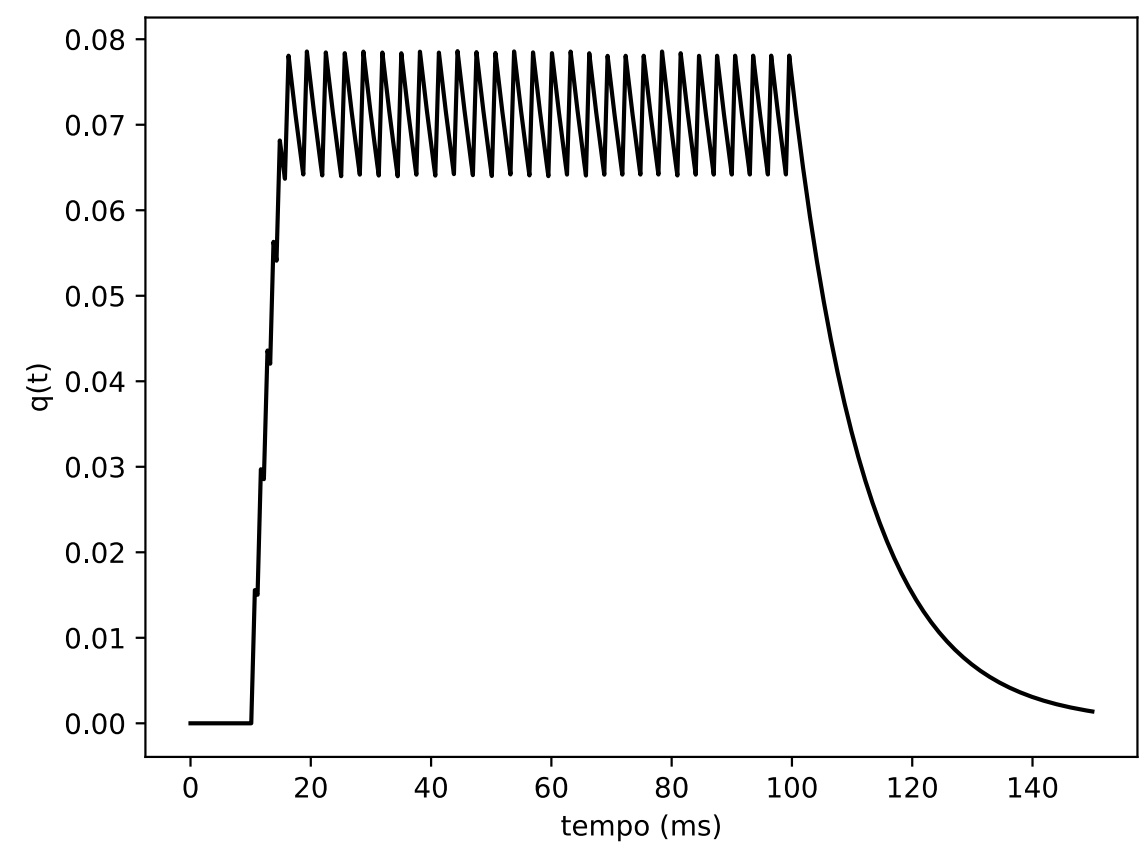

Figura 4.3 - Evolução temporal da variável de ativação $q(t)$.

Em uma bateria de simulações, os valores de $\alpha_{Q}$ e $\beta_{Q}$ foram ajustados com base nas considerações do parágrafo anterior até se obter uma AHP e uma curva $F \times I$ semelhantes à da Figura 3.2. Feito isso, a amplitude do AHP foi obtida alterando as densidades das condutâncias de potássio rápida e lenta. A diferença nos disparos introduzida por isso era verificada e corrigida iterativamente.

Os disparos espontâneos da CR modelada são mostrados na Figura 4.5. A curva $F \times I$ 
obtida, por sua vez, é apresentada na Figura 4.4a, juntamente com detalhes sobre a AHP, na Figura 4.4b. A saturação observada foi causada pela período refratário absoluto do neurônio, que é de $1 \mathrm{~ms}$. O pico da AHP observado foi de $-2.4 \mathrm{mV}$ e sua duração foi de aproximadamente $33 \mathrm{~ms}$.

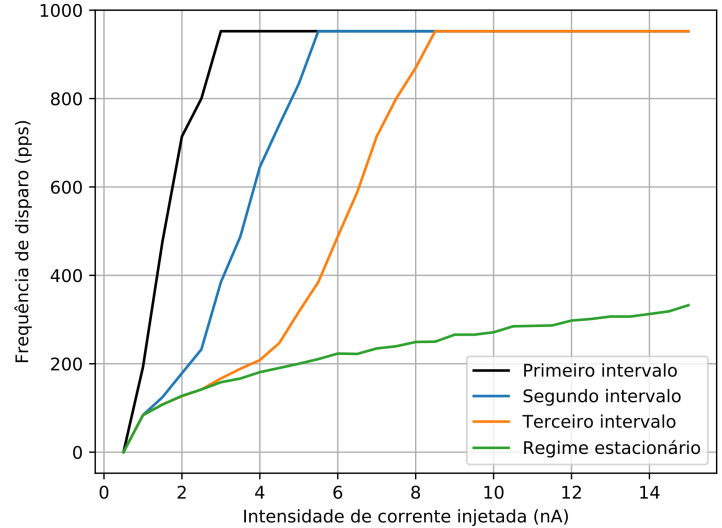

(a)

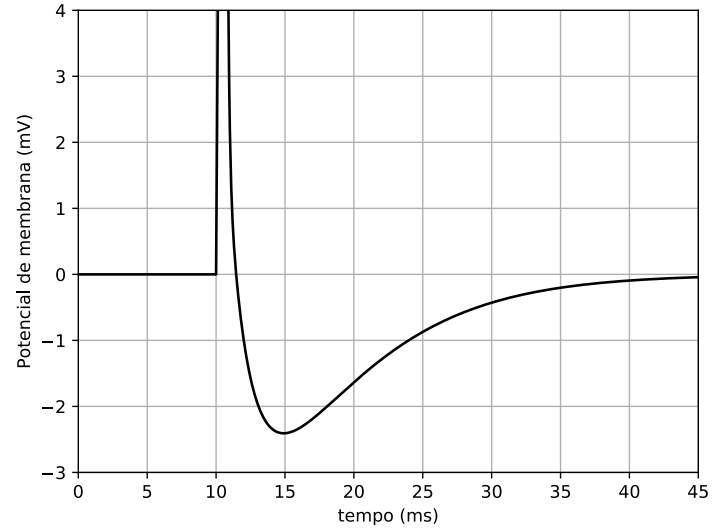

(b)

Figura 4.4 - Característica de disparos da célula de Renshaw. (a) Curva de frequência de disparo versus corrente injetada. (b) Pós-hiperpolarização.

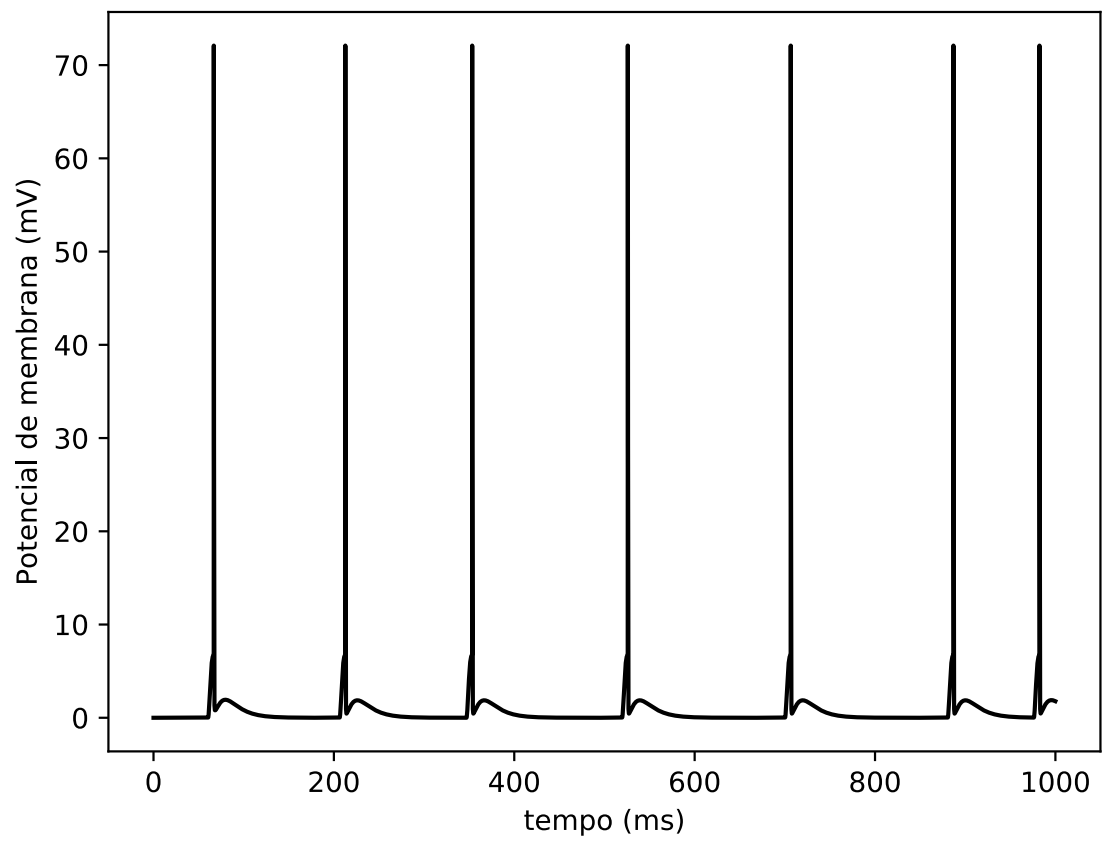

Figura 4.5 - Disparos espontâneos de uma célula de Renshaw.

A AHP e o disparo espontâneo foram semelhantes aos dos estudos eletrofisiológicos. A curva $F \times I$ apresentada se aproximou do que foi descrito na literatura, mas os três primeiros 
intervalos foram mais rápidos do que o esperado, especialmente o segundo e o terceiro. A curva do regime estacionário, por sua vez, foi similar à experimental. De forma geral, outras configurações foram encontradas para corrigir os problemas encontrados, mas isso traria impactos negativos para a AHP ou para os potenciais de ação da CR. Além disso, o tempo de duração da adaptação, que é maior para correntes mais altas, foi sempre menor no modelo aqui descrito. Isso é ilustrado na Figura 4.6.

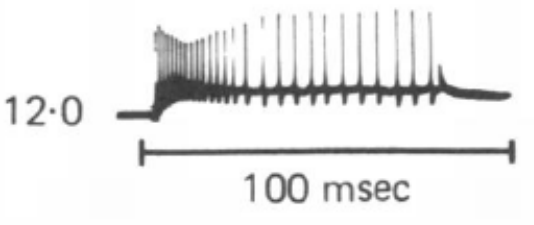

(a)

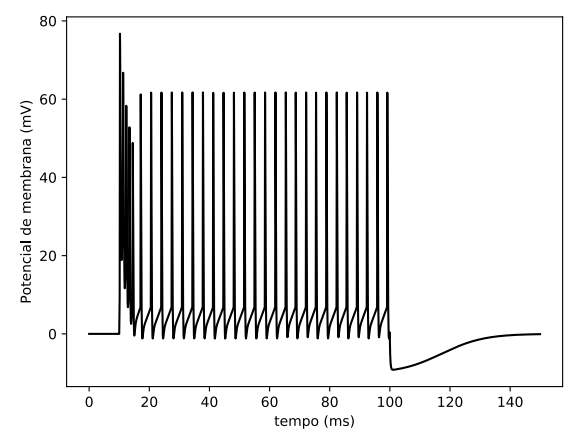

(b)

Figura 4.6 - Comparação dos potenciais de membrana para uma corrente injetada de 12 nA. (a) Tempo da adaptação em uma CR tem uma duração de aproximadamente 30 ms. Fonte: Adaptado de Hultborn e Pierrot-Deseilligny (1979b). (b) Resultado obtido pelo modelo de uma célula de Renshaw nas mesmas condições.

Alguns fatores podem explicar as divergências encontradas. Os principais mecanismos de adaptação, além do utilizado aqui, envolvem canais iônicos relacionados com inativação de correntes de despolarização, concentração intracelular de cálcio e dinâmicas variadas de correntes de potássio (BENDA; HERZ, 2003). Esses canais, contudo, não estão implementados no ReMoto, fazendo com que haja menos opções para se reproduzir essa característica.

De fato, estudos sugerem que as CRs possuem outros tipos de canais iônicos. Sabese que correntes de hiperpolarização e de potássio dependente de cálcio são responsáveis por importantes características de disparos desses neurônios, como, por exemplo, taxas de disparos (PERRY et al., 2015). A utilização de dados disponíveis para implementação desses canais no modelo, entretanto, não é muito apropriada por dois motivos:

a) estes dados foram obtidos de ratos e não há garantias que as CRs desses animais tenham as mesmas características das de gatos, que é a principal fonte de dados utilizada nesse estudo;

b) como as conexões sinápticas relacionadas com as CRs são diferentes em cada estágio de desenvolvimento do rato (ALVAREZ; FYFFE, 2007) e os dados em questão foram 
obtidos em um estágio pós-natal precoce, não se pode garantir que estas propriedades sejam as mesmas das CRs utilizadas aqui.

\subsubsection{Potencial inibitório pós-sináptico em motoneurônios causados pela célula de Renshaw}

Após sucessivas simulações, em que ajustes foram sendo feitos de forma empírica, o resultado final obtido é mostrado na Figura 4.7. Os picos foram de $-26.21 \mu \mathrm{V},-14.76 \mu \mathrm{V}$ e $-7.13 \mu \mathrm{V}$ para MNs do tipo S, FR e FF, respectivamente. Os resultados estiveram, portanto, de acordo com as referências utilizadas.

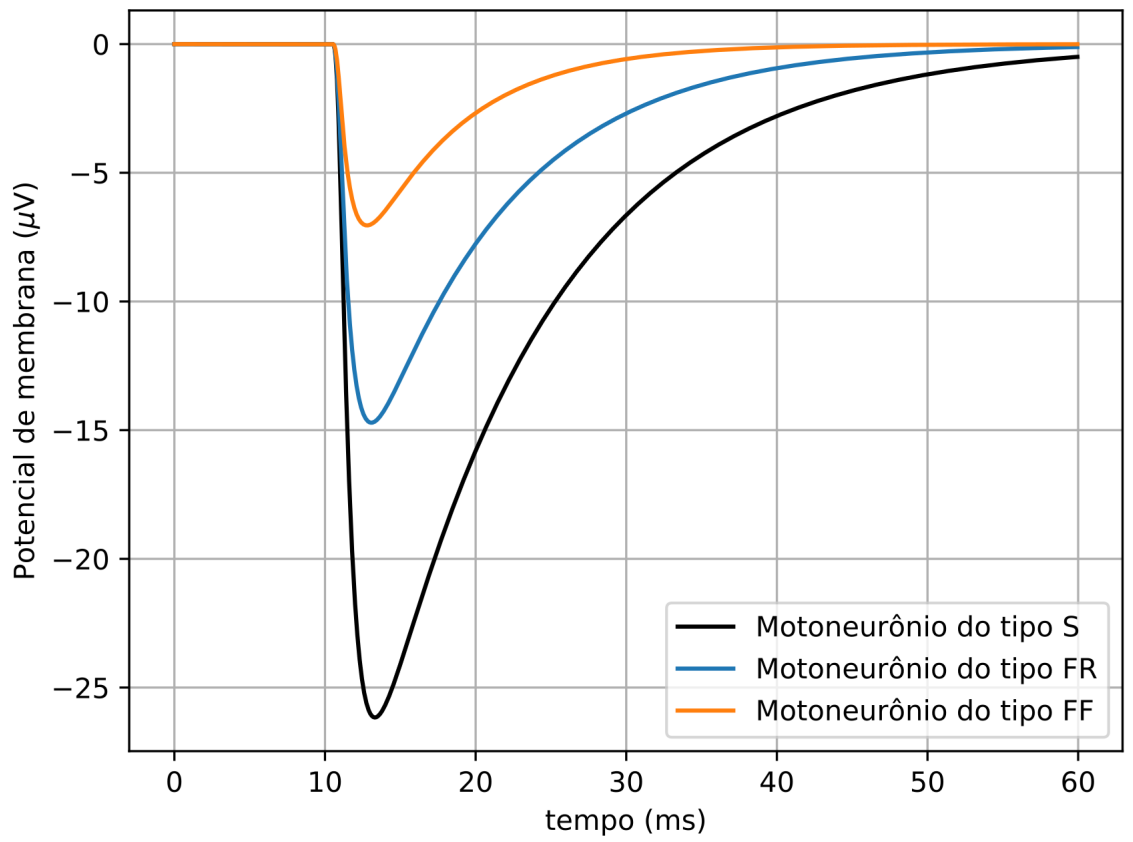

Figura 4.7 - Potencial inibitório pós-sináptico de célula de Renshaw em diferentes tipos de motoneurônios.

\subsubsection{Distribuição e amplitudes da inibição recorrente}

Após uma série de simulações, o valor de $\bar{g}_{\max _{F F}}$ que mostrou os resultados mais apropriados de acordo com a literatura foi $15 \mathrm{nS}$. O efeito da utilização desse parâmetro na distribuição topográfica dos PIPS recorrentes pode ser visto na Figura 4.8.

O padrão de decaimento com a distância foi semelhante ao que foi apresentado na Figura 3.4. A amplitude dos PIPS recorrentes entre pares distantes e próximos foi, em média, -19.88 $\mu \mathrm{V}$ e $-66.56 \mu \mathrm{V}$, respectivamente. 


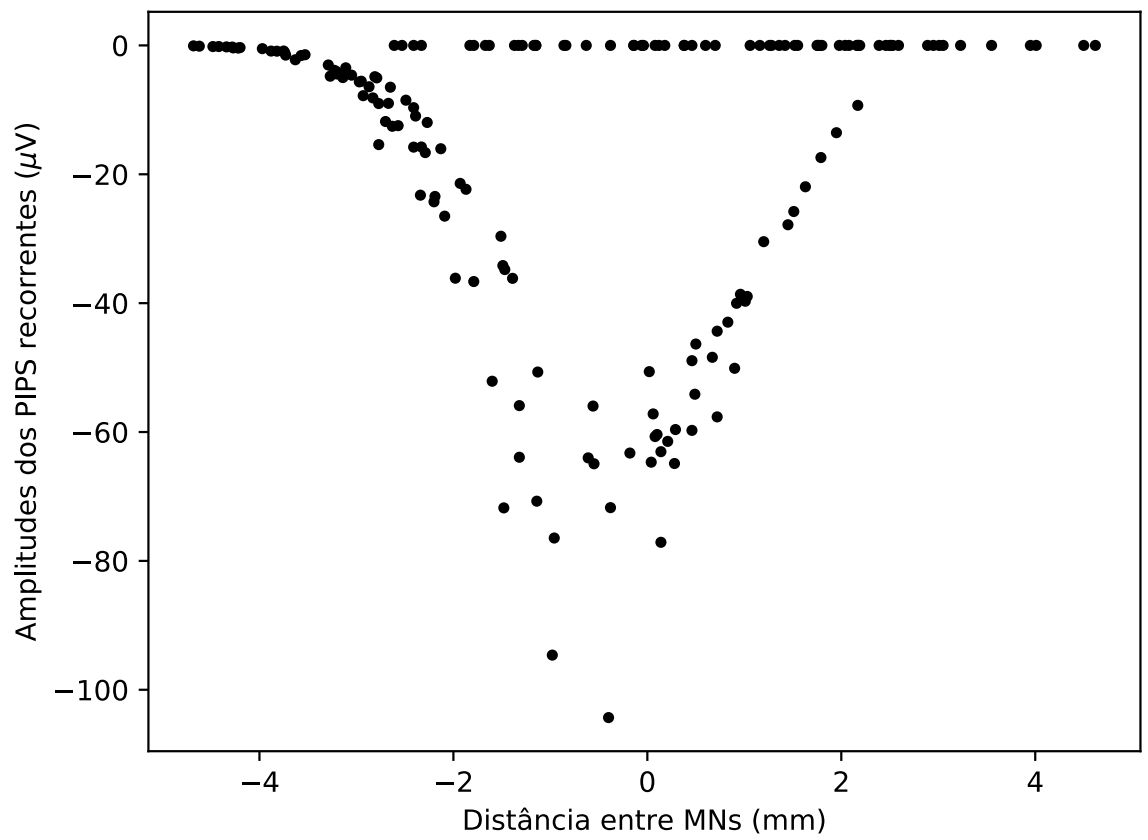

Figura 4.8 - Distribuição topográfica de potenciais inibitórios pós-sinápticos recorrentes. Cada ponto representa a amplitude desses potenciais após o estímulo de outro motoneurônio, localizado em zero na abcissa. Se observado em um motoneurônio rostral (caudal) ao motoneurônio estimulado, é apresentado na parte negativa (positiva) da abcissa.

Sabe-se que a amplitude de PIPS recorrentes entre pares de MNs próximos é relativamente variável, sendo observados valores de $-40 \mu \mathrm{V}$ e $-280 \mu \mathrm{V}$ para uma mesma distância, por exemplo. Os mecanismos responsáveis por essa característica, entretanto, são especulativos (MCCURDY; HAMM, 1994). Nos resultados aqui obtidos, esta variabilidade não foi observada e, por isso, a média de PIPS recorrentes para pares de MNs próximos foi maior do que o esperado.

Vale notar que outros valores maiores de $\bar{g}_{\max _{F F}}$ geraram resultados semelhantes, mas com amplitudes máximas e valores médios elevados. Menores valores de $\bar{g}_{\max _{F F}}$, por sua vez, fariam com que o efeito das CRs fosse muito baixo. Sendo assim, o valor de condutância adotado fornece um equilíbrio razoável dos resultados.

\subsubsection{Característica dinâmica e depressão pós-sináptica da célula de Renshaw}

Para que os resultados de Hultborn e Pierrot-Deseilligny (1979b) possam ser reproduzidos, valores elevados de var e $\tau_{d}$, tais como 0.9 e 400, respectivamente, foram necessários. Isso, entretanto, faz com que as características dinâmicas da CR sejam comprometidas, como visto na Figura 4.9. 


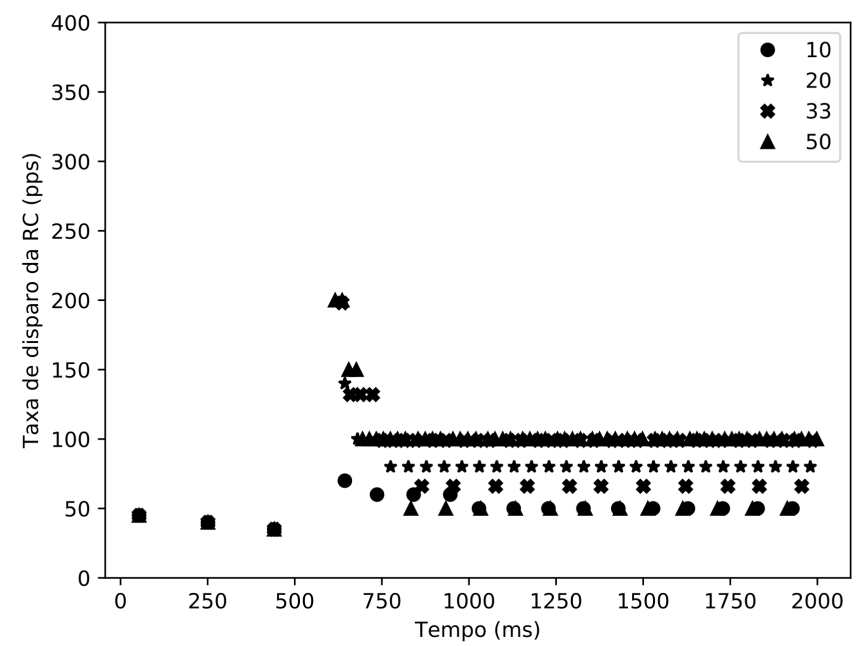

Figura 4.9 - Características dinâmicas de uma célula de Renshaw modelada. A frequência do estímulo, inicialmente de $5 \mathrm{~Hz}$, foi abruptamente aumentada para um dos valores indicados na legenda, em $\mathrm{Hz}$.

Pode-se perceber que as respostas de algumas frequências estão muito próximas e a taxa de disparo foi diminuída a valores muito baixos. Isto está em desacordo com dados fornecidos na literatura (ROSS; CLEVELAND; KUSCHMIERZ, 1982; UCHIYAMA; JOHANSSON; WINDHORST, 2003a). A razão pela qual o modelo também não reproduziu esses resultados experimentais na ausência da dinâmica das sinapses foi, possivelmente, a mesma apresentada por meio da Figura 4.6. Um aumento da condutância sináptica dos MNs sobre as CRs traria resultados positivos, mas também afetaria negativamente as simulações da seção 4.3.2.

Sendo assim, optou-se por não utilizar esse mecanismo de depressão sináptica no modelo. Isso implica que em simulações que envolvam uma parte transiente da resposta da $C R$, como algumas realizadas na seção 4.4.5, é de se esperar que a inibição recorrente seja maior, mesmo que por um breve período. Essa consideração é condizente com investigações experimentais realizadas por Sawicki ${ }^{1}$ (1984, apud WINDHORST, 1982, p. 154).

Vale citar um estudo recente mostrando que, para baixas frequências de estimulação, essa depressão quase não altera as correntes pós-sinápticas geradas (MOORE et al., 2015). Esse resultado vai de encontro com os de Hultborn e Pierrot-Deseilligny (1979b) e deve ser analisado com cautela pois foi realizado em ratos.

Em suma, os resultados das parametrizações realizadas nessa seção foram sumarizados na Tabela 4.2. No ReMoto, os valores desses parâmetros devem ser fornecidos ao programa por meio de um arquivo de configuração.

\footnotetext{
${ }^{1}$ SAWICKI, P. Dynamisches Verhalten der rekurrenten Hemmung monosynaptischer Reflexe. Dissertação. Alemanha: Universidade de Düsseldorf, 1990.
} 
Tabela 4.2 - Valores a serem atribuídos aos parâmetros das células de Renshaw no arquivo de configuração do ReMoto.

\begin{tabular}{ccc}
\hline Parâmetro & Valor & Unidade \\
\hline Resistência específica de membrana & 2500 & $\Omega \mathrm{cm}^{2}$ \\
Capacitância específica de membrana & 1 & $\mu \mathrm{Fm}^{-2}$ \\
Corrente de reobase & 0.5 & $\mathrm{nA}$ \\
Diâmetro & 27 & $\mu \mathrm{m}$ \\
Comprimento & 218.2168 & $\mu \mathrm{m}$ \\
Limiar & 6.7532 & $\mathrm{mV}$ \\
$\alpha_{N}$ & 6 & $\mathrm{~ms}^{-1}$ \\
$\beta_{N}$ & 0.5 & $\mathrm{~ms}^{-1}$ \\
$\alpha_{Q}$ & 0.007 & $\mathrm{~ms}^{-1}$ \\
$\beta_{Q}$ & 0.02 & $\mathrm{~ms}^{-1}$ \\
Condutância máxima do canal de potássio lento & 1100 & $\mathrm{mS}^{2} \mathrm{~cm}^{2}$ \\
Condutância máxima do canal de potássio rápido & 3.8 & $\mathrm{mS} / \mathrm{cm}^{2}$ \\
Condutância máxima CR - MN S & 119 & $\mathrm{nS}$ \\
Condutância máxima CR - MN FR & 119 & $\mathrm{nS}$ \\
Condutância máxima CR - MN FF & 94 & $\mathrm{nS}$ \\
Condutância máxima do ruído & 14 & $\mathrm{nS}$ \\
Condutância máxima MN S - CR & 6.81 & $\mathrm{nS}$ \\
Condutância máxima MN FR - CR & 8.33 & $\mathrm{nS}$ \\
Condutância máxima MN FF - CR & 15 & $\mathrm{nS}$ \\
\hline
\end{tabular}




\subsection{Validações}

\subsubsection{Características de potenciais inibitórios pós-sinápticos recorrentes}

Os resultados de simulação para o tempo de subida e tempo de meia vida são mostrados na Figura 4.10 abaixo. Como pode ser visto, esses tiveram faixas consideravelmente abaixo dos valores esperados. Por outro lado, quando a duração dos PIPS recorrentes foi medida (como na Seção 4.2.1), obteve-se um valor de $20.8 \pm 4.5 \mathrm{~ms}$, que está próximo aos $25.9 \pm 1.2 \mathrm{~ms}$ reportados por McCurdy e Hamm (1994). Nesse caso, a baixa variabilidade nas propriedades de membrana dos MNs modelados ou das sinapses das CRs podem ter sido a causa dessas diferenças, pois durações pequenas de $2.8 \mathrm{~ms}$ e grandes de $85 \mathrm{~ms}$ já foram observadas em experimentos (MCCURDY; HAMM, 1994).

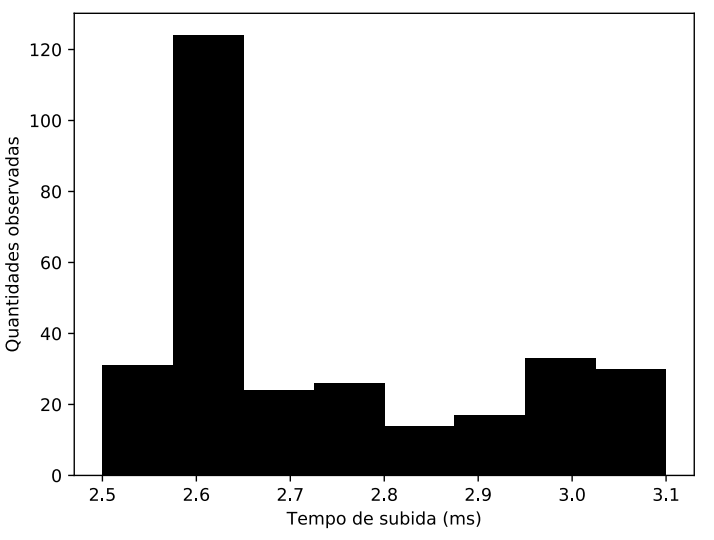

(a)

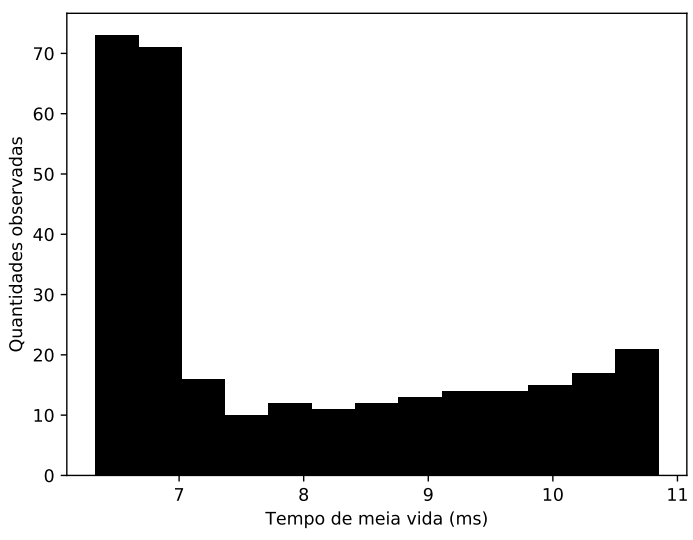

(b)

Figura 4.10 - Validação de resultados com Hamm et al. (1987b). (a) Tempo de subida dos potenciais inibitórios pós-sinápticos gravados. (b) Tempo de meia vidas dos potenciais inibitórios pós-sinápticos gravados.

Os histogramas de amplitude da Figura 4.11 estão dentro das faixas descritas na literatura (HAMM et al., 1987b). Existem registros de PIPS recorrentes maiores (MCCURDY; HAMM, 1994), mas estes se manifestaram esporadicamente e apenas para pares de MNs próximos. Nota-se também que, com a condutância adotada, apenas MNs do tipo FF, ou seja, aqueles com índice maior do que 149, são capazes de causar potenciais de ação nas CRs e, assim, gerar PIPS recorrentes. Esse resultado não é inapropriado pois existem estudos mostrando que a ativação de CRs pode resultar em respostas como ausência, alguns poucos e ate bursts de potenciais de ação (ROSS; CLEVELAND; HAASE, 1972; ROSS; CLEVELAND; KUSCHMIERZ, 1982). Ainda assim, o modelo permite que MNs menores disparando conjuntamente possam produzir inibição recorrente, corroborando Hultborn, Pierrot-Deseilligny e Wigström (1979). 

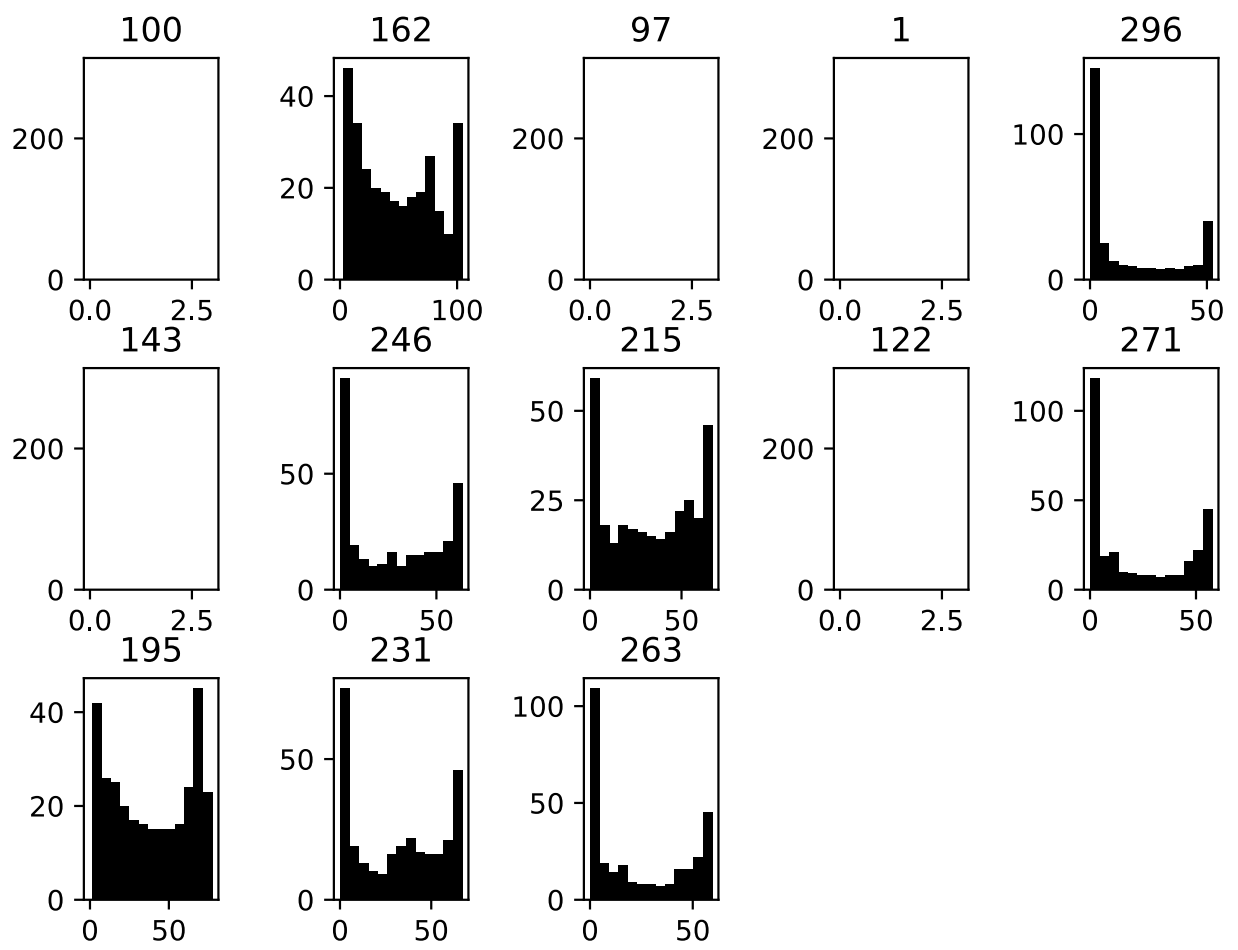

Figura 4.11 - Distribuição de amplitudes de potenciais inibitórios pós-sinápticos recorrentes. Em cada gráfico, o número na parte superior significa o índice do motoneurônio estimulado. Eixo das abcissas indica valores de amplitudes, em $\mu \mathrm{V}$, e eixo das ordenadas indica quantidade. Gráficos vazios indicam a ausência de potenciais inibitórios pós-sinápticos recorrentes gerados pelo estímulo de determinado motoneurônio.

\subsubsection{Relação estática das entradas e saídas das células de Renshaw}

Os resultados são apresentados na Figura 4.12. A Figura 4.12a mostra que as curvas obtidas de 24 CRs diferentes não apresentaram uma saturação tão clara quanto as descritas por Cleveland, Kuschmierz e Ross (1981), de forma que, para taxas menores de estímulos antidrômicos, as taxas de disparos das CRs não aumentaram tão rápido quanto deveriam. Apesar disso, suas taxas de disparos máximas estiveram dentro das faixas de valores esperados, que vão de aproximadamente 50 até 290 pps. A Figura 4.12b corrobora esses resultados e mostra que a média das curvas foi um pouco menor do que o esperado.

Vale notar que o efeito de um estímulo antidrômico em CRs próximas uma das outras é muito parecido e em alguns casos, como visto na Figura 4.12a, estas aparecem sobrepostas. Isso é consistente com o fato de que a taxa de disparo de uma CR está relacionada com dois tipos de entrada: a sua taxa de ativação e o número de sinapses excitatórias agindo sobre ela (CLEVELAND; KUSCHMIERZ; ROSS, 1981), sendo este último, no modelo estudado aqui, entendido como condutâncias sinápticas. Dessa forma, é de se esperar que em regiões com populações localmente homogêneas de MNs as CRs ali presentes recebam uma entrada parecida. 


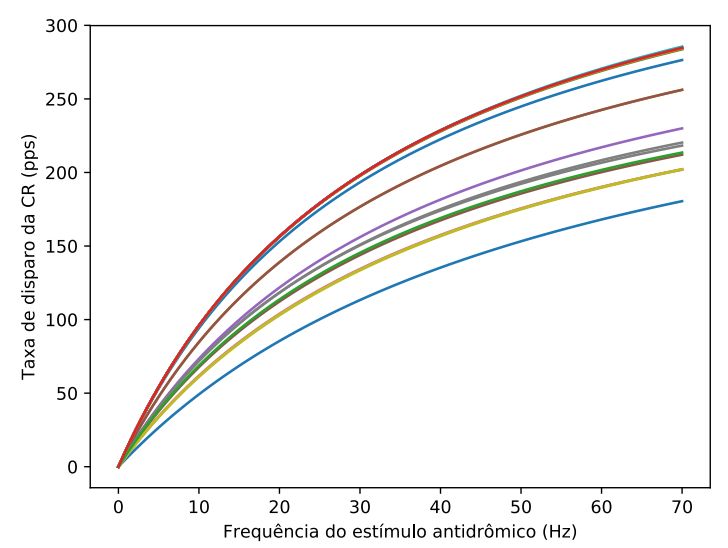

(a)

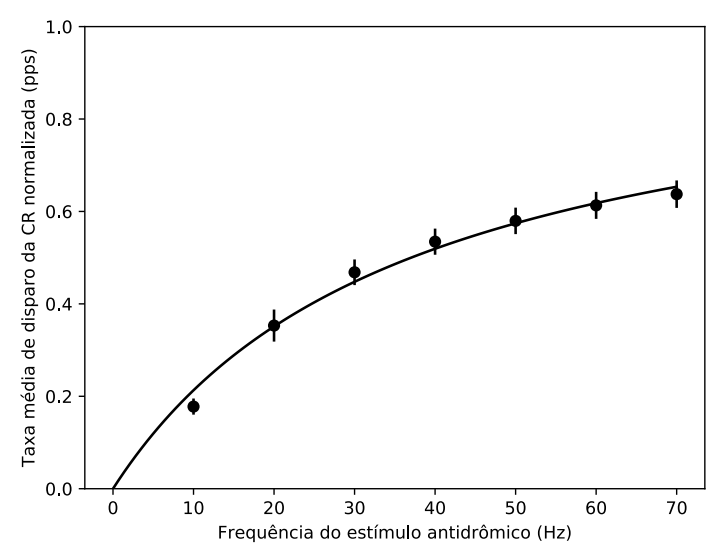

(b)

Figura 4.12 - Relações de entrada e saída da célula de Renshaw modelada. (a) Ajustes de funções de Langmuir às respostas de 24 células de Renshaw escolhidas ao acaso (representadas cada uma por diferentes cores). (b) Média normalizada das curvas obtidas ajustada à uma função de Langmuir. Os pontos são as médias e as barras verticais são os desvios padrões.

\subsubsection{Respostas das células de Renshaw sujeitas a um estímulo antidrômico}

Como mostrado na Figura 4.13, o modelo parametrizado foi capaz de reproduzir essas características. Houve salvas de potenciais de ação com duração de $40 \mathrm{~ms}$ e suas taxas de disparo decaíram de forma semelhante a uma exponencial. Com o estímulo de $67.2 \%$, que é suficiente para ativar apenas os axônios motores dos MNs do tipo FF, o número de disparos e a duração da salva foram menores, pois existe uma força sináptica total menor agindo sobre a CR. Esses resultados são semelhantes aos reproduzidos por (UCHIYAMA; JOHANSSON; WINDHORST, 2003a).

O tipo de estímulo utilizado ativa muitos axônios motores sincronizadamente, criando uma resposta artificial que raramente ocorre naturalmente (UCHIYAMA; JOHANSSON; WINDHORST, 2003a). Apesar disso, esse resultado é útil para testar a parametrização das CRs. 


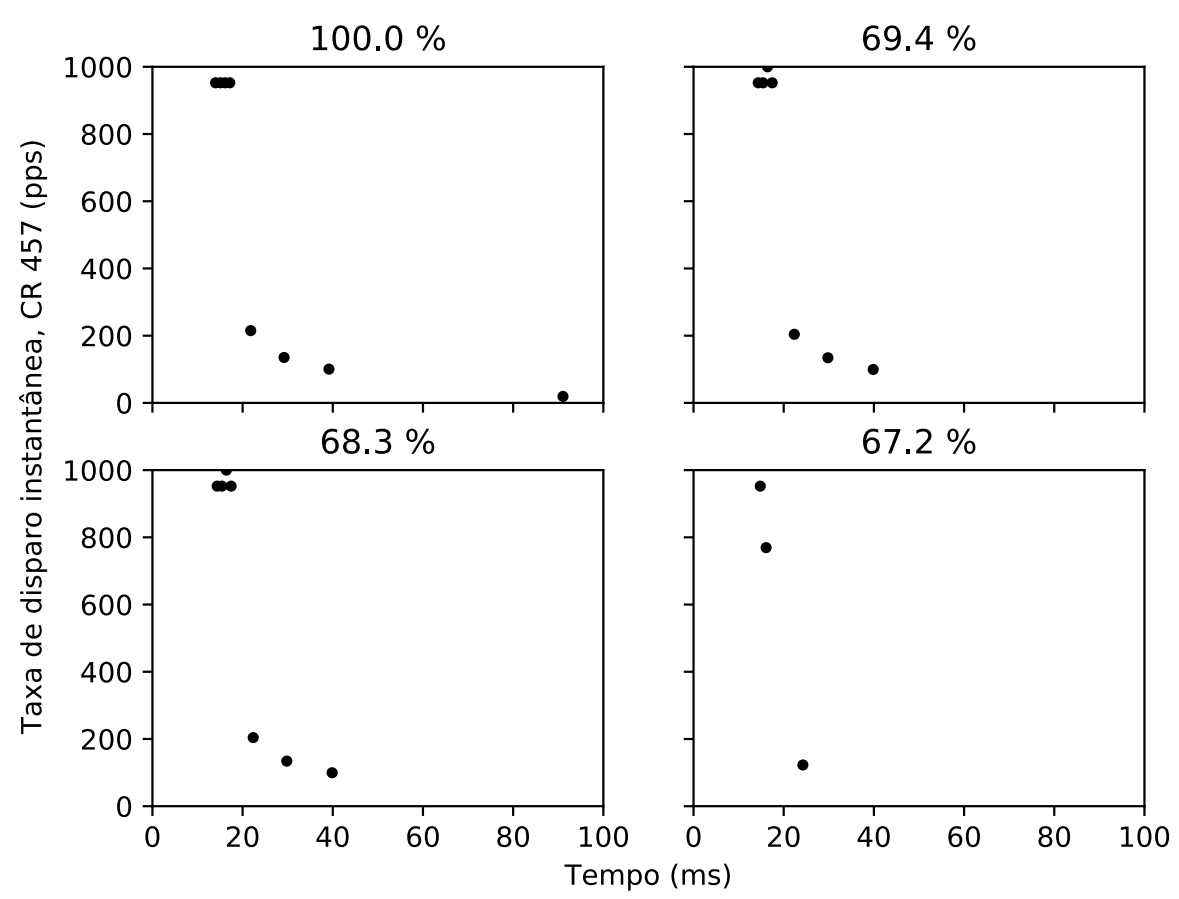

Figura 4.13 - Taxa de disparos instantâneos da célula de Renshaw de índice 457 após um estímulo antidrômico. As porcentagens indicam a intensidade do estímulo, sendo $100 \%$ o caso em que todos os axônios motores são ativados. 


\subsection{Efeitos da inibição recorrente em simulações}

\subsubsection{Características de recrutamento de motoneurônios}

Nas simulações seguintes, o núcleo motor é sujeito a uma corrente em rampa injetada intracelularmente em cada MN, levando a um recrutamento gradativo dos MNs bem como a um aumento gradativo com o tempo da taxa de disparos de cada MN. No intervalo de 1 segundo mostrado na Figura 4.14, pode-se perceber que a presença das CRs resulta em padrões de disparos distintos quando o núcleo motor é estimulado pela corrente descrita pela equação (3.7). Como esperado, as CRs atrasam os disparos dos MNs e também diminuem suas ocorrências. Além disso, é possível notar que, em ambos os casos e de forma geral, os MNs são recrutados de forma ordenada, ou seja, do menor para o maior.

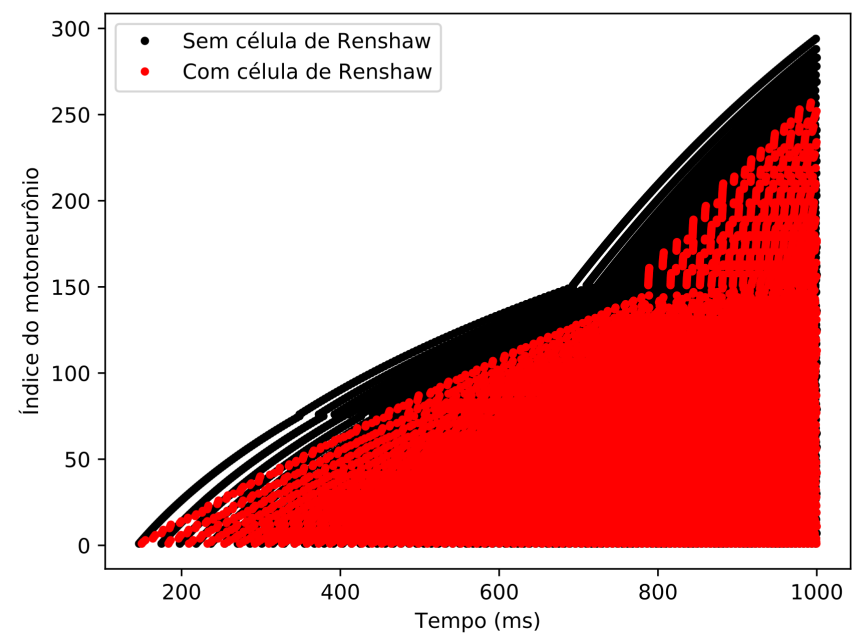

Figura 4.14 - Instantes de disparo dos somas de todos os motoneurônios simulados com uma corrente injetada. O eixo das ordenadas representa os índices dos motoneurônios, que são diretamente proporcionais ao tamanho dos mesmos, e o eixo das abcissas representa os instantes de disparo. Os disparos dos motoneurônios com (pontos vermelhos) e sem (pontos pretos) células de Renshaw estão sobrepostos.

Nesse aspecto, todavia, existem algumas ressalvas. A Figura 4.15 mostra com mais detalhes os instantes de disparos de MNs sob o efeito da inibição recorrente. Como visto na Figura 4.15(a), alguns MNs maiores inicialmente disparam praticamente ao mesmo tempo. Os menores, por sua vez, apresentam um comportamento menos sincronizado, como visto na Figura 4.15(b). Estes efeitos parecem ser razoavelmente complexos, envolvendo sincronismos na interação sináptica de populações de modelos não lineares de neurônios com propriedades não uniformes.

Uma análise mais quantitativa sobre um sincronismo gerado no núcleo motor foi abordada na seção 4.4.5. A seguir, uma simulação um pouco mais realista foi utilizada para analisar a 


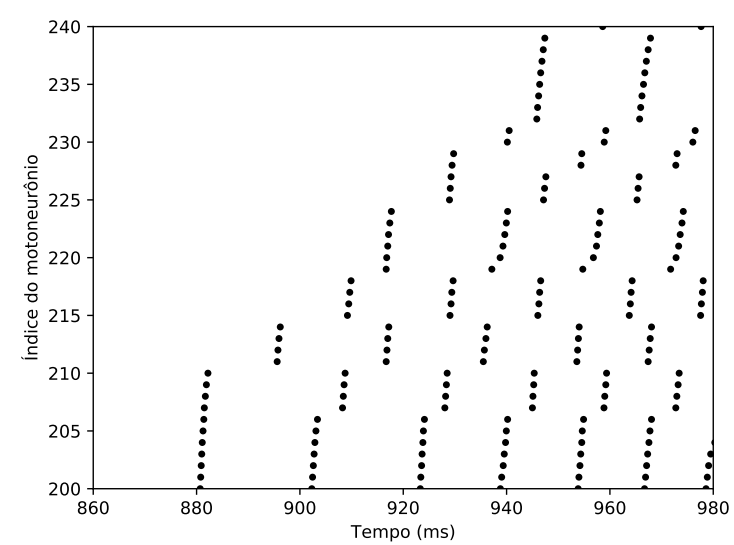

(a)

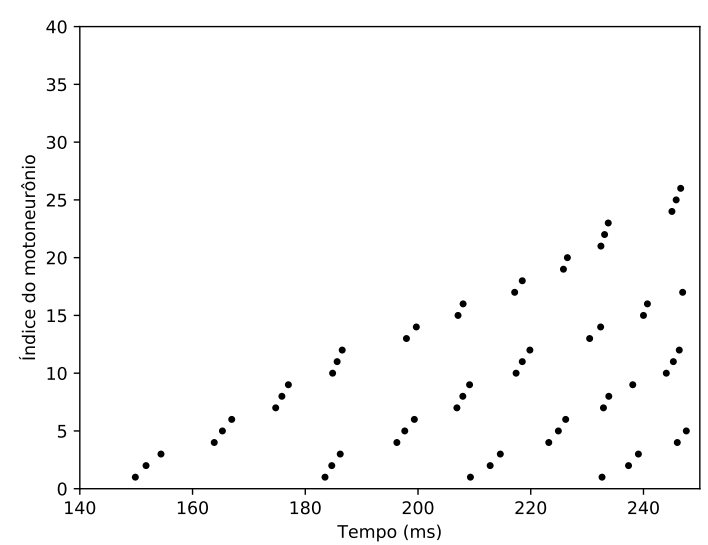

(b)

Figura 4.15 - Visão de um intervalo reduzido dos disparos dos motoneurônios sob efeito da inibição recorrente (é um zoom da Figura 4.14 usando somente os pontos em vermelho). (a) Instantes de disparos de alguns motoneurônios do tipo FF. (b) Instantes de disparos de alguns motoneurônios do tipo S.

ordem de recrutamento dos MNs. Nessa nova simulação, o núcleo motor foi ativado pelo comando descendente composto por processos pontuais estocásticos com frequência de disparos média descrita pela equação (3.8).

Na Figura 4.16, a região de transição entre MNs do tipo S para o tipo FR na presença de inibição recorrente foi mostrada. Tomando o instante do primeiro disparo do índice 83 como referência, foi possível identificar casos em que ocorreram inversões na ordem de recrutamento, ou seja, MNs maiores começam a disparar antes de menores. Também existiram casos de MNs sendo recrutados praticamente ao mesmo instante, como é o caso do 83 com o 67.

Ocorrências semelhantes podem ser encontradas em outras partes do gráfico, mas não foram mostradas para não prejudicar a visualização deste resultado. Deve-se notar, porém, que essa característica também pode ser observada na ausência das CRs. Isso pode ser explicado pelo fato de que as fibras descendentes, além de gerarem potenciais de ação de maneira estocástica, foram parametrizadas com uma conectividade com MNs de 30\%, possibilitando MNs próximos entre si a receber correntes sinápticas que ocasionalmente não favoreçam o princípio do tamanho.

Sendo assim, uma comparação mais direta entre esses casos se faz necessária. Para esse fim, a Figura 4.17 foi apresentada. Com apenas os instantes do primeiro disparo de cada MN mostrado, é possível ver que a presença da CR faz com que haja uma maior dispersão destes, ou seja, o intervalo de tempo entre os disparos foi maior.

Pode-se notar que, em ambos os casos, essa dispersão é mais acentuada para níveis mais altos de excitação, ou seja, quando as maiores unidades motoras do núcleo motor são ativa- 


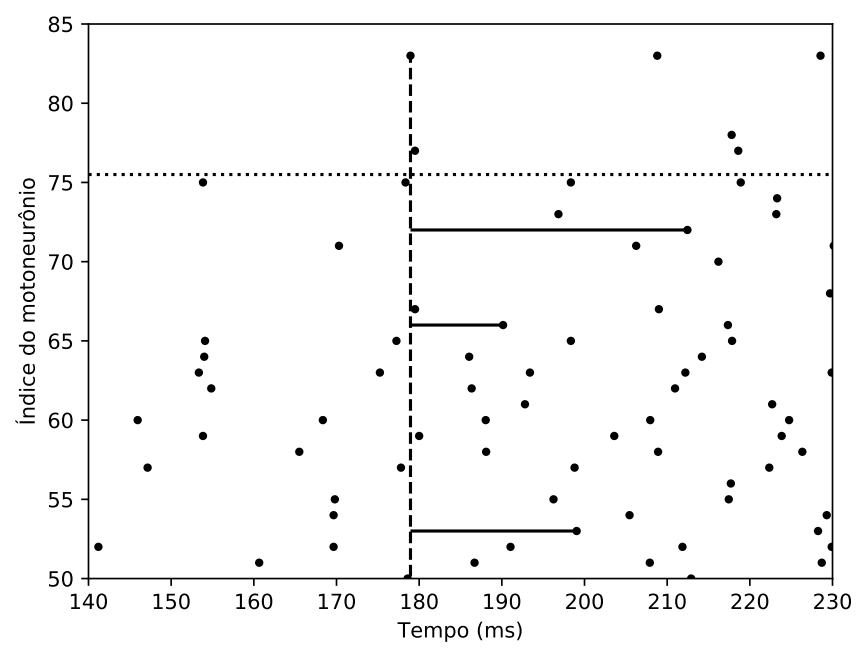

Figura 4.16 - Inversão na ordem de recrutamento de motoneurônios. Motoneurônios do tipo S (abaixo de 75) e do tipo FR (acima de 75) são separados por uma linha horizontal pontilhada. Uma linha vertical tracejada foi traçada sobre o instante do primeiro disparo do motoneurônio 83 e linhas horizontais sólidas representam o quanto algumas unidades menores estiveram atrasadas.

das. Entretanto, experimentos em seres humanos sugeriram que, em contrações voluntárias em rampa, uma crescente inibição de CRs ocorre com o aumento da força (HULTBORN; PIERROT-DESEILLIGNY, 1979a). Isso poderia fazer com que os últimos instantes de disparos da Figura 4.17a se tornassem menos espaçados, semelhantes aos últimos da Figura 4.17b, mas não mudaria os efeitos observados no início da contração. Vale ressaltar que esses resultados experimentais, todavia, se basearam em métodos indiretos e não esclarecem a forma como essa mudança na inibição recorrente ocorre.

Apesar de uma vasta literatura confirmando o princípio do tamanho, existem relatos de que, em algumas situações, esse padrão pode não ser rigorosamente reproduzido (HECKMAN; ENOKA, 2012). Uma contração balística, que se assemelha à simulação em questão, é um desses casos. Nesse contexto, acredita-se que um recrutamento invertido ou misto possa ser responsável pela geração de forças muscular mais intensas (BAWA; JONES; STEIN, 2014; ALLEN; ELBASIOUNY, 2018).

Estudos computacionais mostraram que variabilidade das propriedades de MNs podem reproduzir esse comportamento no músculo gastrocnêmio medial do gato (ALLEN; ELBASIOUNY, 2018). Essas características não estão presentes nas simulações realizadas aqui, indicando que as CRs podem, também, ser um mecanismo para introduzir uma certa inversão na ordem de recrutamento dos MNs. De fato, a forma como o PIPS recorrente é distribuído pelo núcleo motor é um indício disso (WAKELING; UEHLI; ROZITIS, 2006), especialmente em regiões de transição entre tipos de MNs (S para FR e FR para FF). 


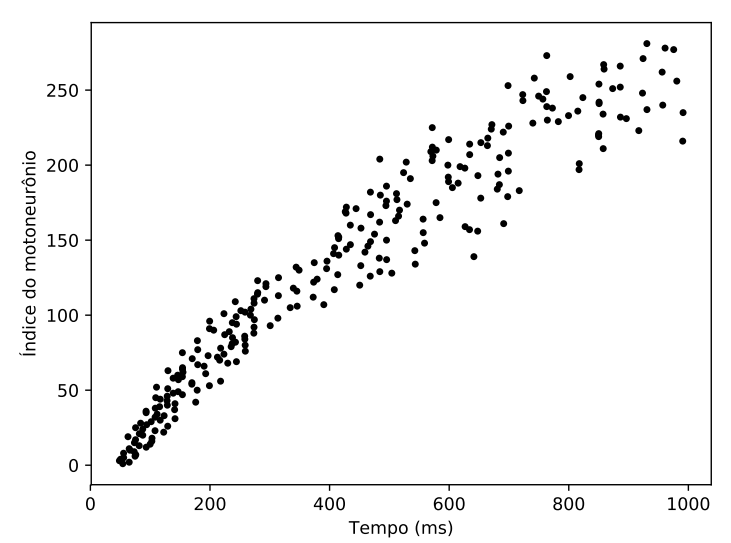

(a)

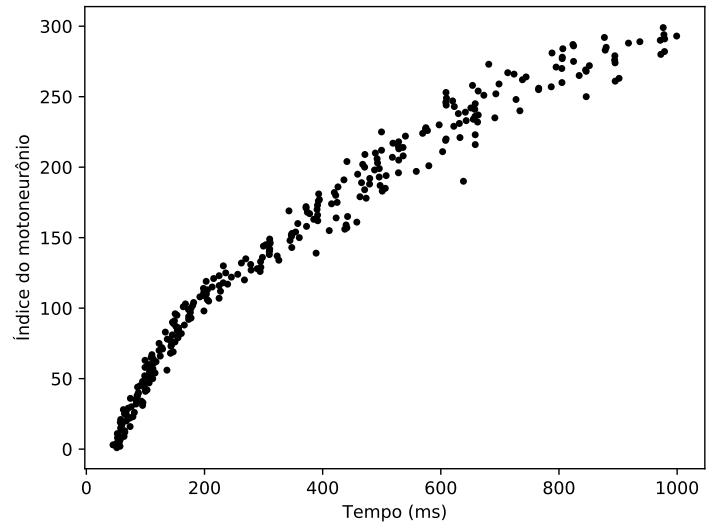

(b)

Figura 4.17 - Primeiros instantes de disparos dos motoneurônios. (a) Com células de Renshaw. (b) Sem células de Renshaw.

Friedman et al. (1981) sugeriram que a presença das CRs poderia ser um mecanismo para gerar uma inversão na ordem de recrutamento de MNs. Os resultados aqui apresentados são parcialmente favoráveis a esta ideia, pois, apesar de uma inversão ter ocorrido entre MNs próximos uns aos outros, um recrutamento seletivo de MNs maiores não foi observado.

Portanto, pelos resultados apresentados, a presença da CR parece ser um elemento capaz de causar uma certa inversão na ordem de recrutamento de MNs próximos uns aos outros. Além disso, ela parece ser capaz de atrasar os disparos desses, possibilitando que mais inversões possam acontecer em outras regiões do núcleo motor e aumentando suas respectivas diferenças entre instantes de disparo. Isso poderia ser uma vantagem em situações de contração muscular rápida, pois twichtes maiores contribuiriam nos instantes inicias de força muscular mais baixa. Os possíveis desdobramentos fisiológicos desses resultados serão explorados na seção 4.4.5.

\subsubsection{Taxa de disparos de motoneurônios}

A Figura 4.18 mostra o resultado de uma simulação com a entrada apresentada na equação (3.9). Tipicamente mostrada em trabalhos que tratam sobre o fenômeno de onion skin (DE LUCA; ERIM, 1994), as curvas mostram a evolução temporal das taxas de disparos de alguns MNs ativados (escolhidos ao acaso), indicados pelo mapa de cores de acordo com seus tamanhos. Nota-se que, na presença da CR (Figura 4.18(b)), houve um pequeno aumento de variabilidade e diminuição de taxas de disparos em comparação com a simulação sem CRs (Figura 4.18(a)). Além disso, foi observado que alguns MNs maiores não tiveram suas taxas diminuídas tanto quanto as dos menores (por exemplo, cinza e bege claro). 


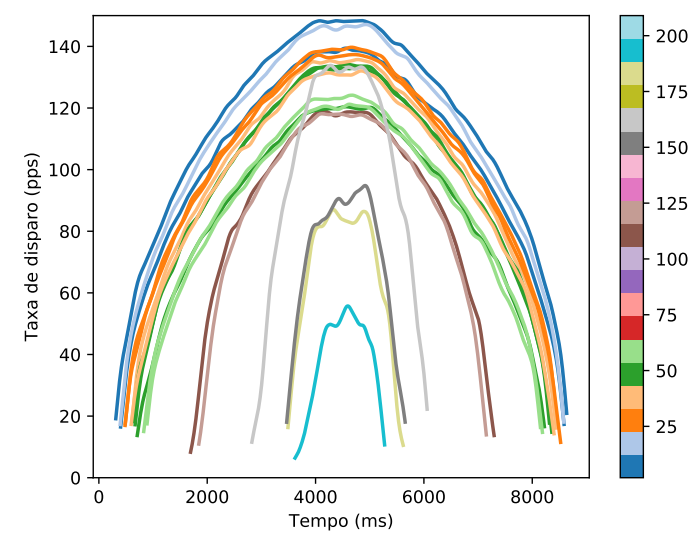

(a)

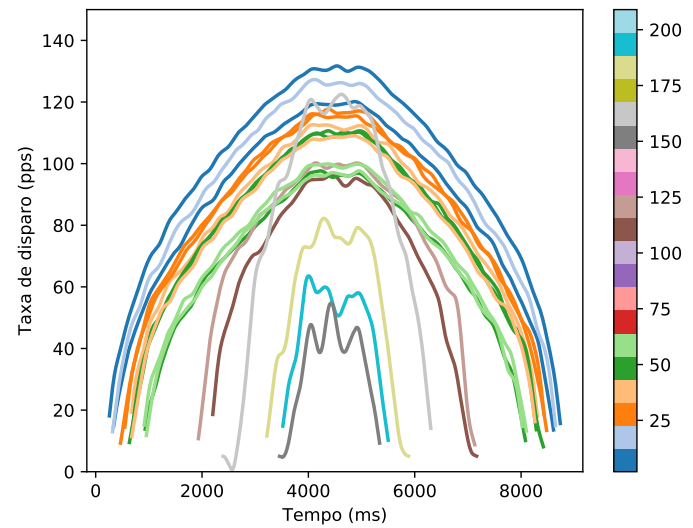

(b)

Figura 4.18 - Taxa de disparo de motoneurônios em função da taxa de disparo de fibras descendentes. O mapa de cores identifica os motoneurônios de acordo com o seus índices. (a) Sem célula de Renshaw. (b) Com célula de Renshaw.

De Luca e Erim (1994) ocasionalmente observaram disparos de uma unidade motora atingindo taxas maiores do que outras ativadas previamente, mas atribuíram isso a características estocásticas dos MNs. Isso pode ser observado na Figura 4.18, em que a natureza do estímulo utilizado ocasionalmente causa respostas que divergem do conceito de onion skin, tanto na ausência quanto na presença de inibição recorrente.

Considerando que as CRs introduzem um ruído descorrelacionado no núcleo motor (ADAM; WINDHORST; INBAR, 1978), pode-se esperar que as CRs tenham alguma influência nessa organização de disparos, afetando, assim, diferentes aspectos da geração de força e eficiência energética (DE LUCA; CONTESSA, 2015; HU; RYMER; SURESH, 2014). Isso, entretanto, foi observado de maneira modesta nos resultados apresentados. Além disso, a crescente inibição de CRs em contrações voluntárias pode ter um efeito direto nesse resultado, sendo necessário determinar a forma como esse efeito modulatório afeta essa população de neurônios.

Existem, ainda, trabalhos experimentais que tentaram relacionar a taxa de disparos de MNs com diferentes tipos de movimentos. Hoffer et al. (1987) mostraram que em um esteira, à velocidade de $0.5 \mathrm{~ms} / \mathrm{s}$, taxas de disparos de MNs dos músculos das patas traseiras de gatos estão contidas no intervalo de 15 até 35 pps, aproximadamente. Paralelamente, Walmsley, Hodgson e Burke (1978) sugeriram que, nessa velocidade, a porcentagem da força tetânica realizada está por volta de $8 \%$. Em movimentos como o pulo vertical, contrações próximas à $100 \%$ da CVM são atingidas (WALMSLEY; HODGSON; BURKE, 1978) e isso poderia envolver maiores taxas de disparos. Um exemplo disso são alguns MNs que durante longos períodos de estimulação podem alcançar até 200 pps (KERNELL, 1965). 
Sendo assim, pode-se perceber que as taxas de disparos encontradas nas simulações estiveram dentro de limites fisiologicamente relevantes. Quando se trata do fenômeno da onion skin, todavia, foi observada uma característica mista. Em ambos os casos (sem ou com CRs), curvas de MNs com tamanhos parecidos se sobrepõe frequentemente, mas, à medida que a diferença entre os tamanhos aumenta, esse comportamento cessa. Apesar da ocorrência de um caso em que um MN do tipo FF tenha disparado a taxas mais altas do que um do tipo $S$, outros estudos devem ser realizados para analisar a relevância fisiológica desses resultados.

\subsubsection{Diminuições dos níveis de força}

A forma como as CRs alteram a geração de força nas simulações é mostrada na Figura 4.19 (a). A inibição recorrente causou um deslocamento da curva de força para a direita e, para baixas taxas de disparos das fibras descendentes, ocasionou uma redução em sua inclinação, ou seja, na sua sensibilidade à mudanças das entradas sinápticas. A diferença entre as respostas com e sem CRs indicam a faixa de valores de entrada em que o efeito da inibição foi considerável.

O decréscimo de força apresentado reflete uma diminuição nas médias de disparos da população de MNs, ilustrada na Figura 4.19(b). Isso aconteceu pois, à medida que a entrada excitatória das fibras descendentes se intensificou, o número de MNs recrutados e suas taxas de disparos aumentou, causando mais atividade nas CRs. Foi notado que, após uma entrada de 225 pps, a diferença entre as duas curvas não aumentou mais de forma linear, se mantendo praticamente constante e indicando uma redução máxima de $33 \%$ nessa simulação de núcleo motor. A razão de tal comportamento se deve, provavelmente, a dois fatores: $O$ recrutamento de todas as unidades motoras, fazendo com que o acréscimo de força dependa do aumento da frequência de disparos dos MNs; A progressiva saturação da resposta da CR, como mostrado na Figura 4.12. Esse resultado, apesar de refletir características populacionais, foi semelhante à função de Langmuir descrita na literatura (CLEVELAND; KUSCHMIERZ; ROSS, 1981).

Existem muitos dados conflitantes na literatura sobre o ganho da inibição recorrente e a consequente diminuição da taxa de disparos. Lindsay e Binder (1991) sugeriram que essa mudança, quando produzida em MNs do músculo gastrocnêmio medial por meio de estimulações em nervos do gastrocnêmio lateral, seria menor do que 2 pps. Esse procedimento, entretanto, não considera que esses núcleos motores se sobrepõem apenas parcialmente na medula espinhal, de forma que a inibição observada poderia ter sido causada por CRs distantes e, por isso, estaria atenuada (MCCURDY; HAMM, 1994). 


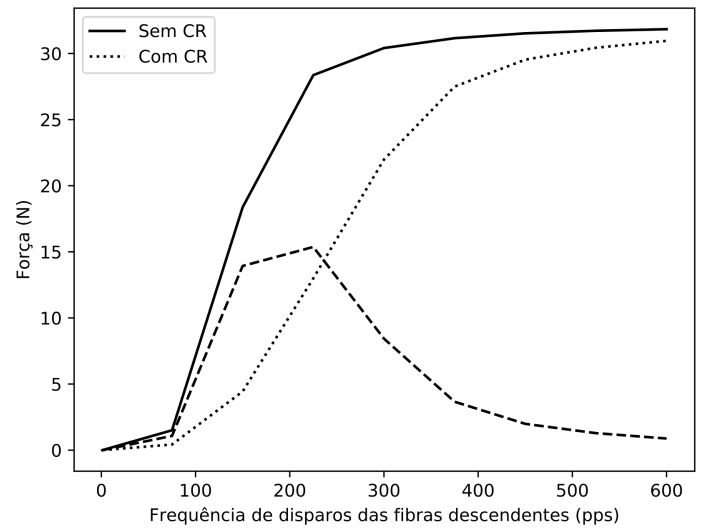

(a)

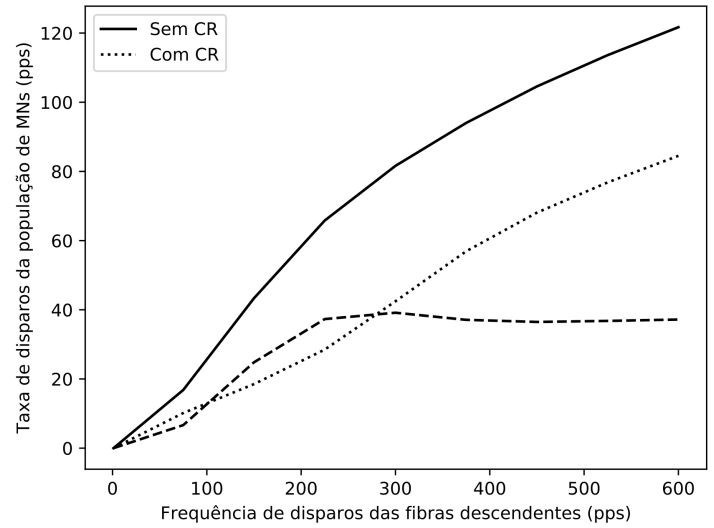

(b)

Figura 4.19 - Efeitos da presença da célula de Renshaw no força gerada pelo modelo e nos disparos de motoneurônios. Curvas pontilhadas e contínuas para respostas com e sem $C R$, respectivamente. Linha tracejada obtida da subtração dessas duas. (a) Força gerada. (b) Média de disparos da população de MNs.

De fato, outros experimentos em gatos mostraram ganhos maiores. Ativando MNs por meio das entradas sinápticas de aferentes la e estimulando uma única fibra de uma raiz ventral, Granit e Renkin (1961) observaram uma redução de 5 pps. Cleveland, Kuschmierz e Ross (1981), por sua vez, combinaram estimulações de raízes ventrais com correntes injetadas no soma dos MNs estudados e encontraram reduções de até 22 pps para altas taxas de estímulos antidrômicos. Os autores atribuíram a discrepância com o trabalho de Granit e Renkin (1961) ao nível de atividade do núcleo motor, mas outros valores maiores foram reportados em outros estudos, como por exemplo uma redução de 44\% (GRANIT; RUTLEDGE, 1960).

Apesar de ser oriundo de experimentos em ratos, vale citar um trabalho recente sugerindo que a inibição proveniente das CRs seja mais forte do que se imagina, de forma que um único potencial de ação seja suficiente para para silenciar um MN (BHUMBRA et al., 2014). Esse resultado poderia indicar ganhos maiores nesse circuito de inibição recorrente.

Mediante o exposto, os resultados das simulações aqui realizadas, de forma geral, foram condizentes com o que foi apresentado por Uchiyama, Johansson e Windhorst (2003b). As reduções na força gerada ocorreram como previsto na literatura, enquanto a diminuição nas taxas de disparos dos MNs foi um pouco maior do que o esperado. Isso, entretanto, não desvalida a parametrização adotada, tendo em visto que o ganho do circuito de inibição recorrente carece de mais análises experimentais para ser determinado com precisão.

De qualquer forma, o ponto de vista de que a CR pode atuar como um regulador de ganho variável pode ser reforçado (HULTBORN et al., 2004). Nesse contexto, é importante dizer que as CRs podem ser inibidas com o aumento da força (HULTBORN; PIERROT-DESEILLIGNY, 
1979a). Sendo assim, é possível que as respostas se tornem mais parecidas, com a curva de força pontilhada se aproximando progressivamente da contínua na Figura 4.19 (UCHIYAMA; JOHANSSON; WINDHORST, 2003b).

\subsubsection{Análise no domínio da frequência}

No contexto de se estudar os efeitos das CRs quando existem oscilações de $10 \mathrm{~Hz}$ no núcleo motor devido ao comando descendente, a Figura 4.20 mostra os resultados de coerências córtico-musculares e espectros da força em variados cenários envolvendo um aumento das taxas de disparos médias das fibras descendentes para manter a média das forças inalterada quando havia realimentação negativa por parte das CRs. Por conveniência, os casos relativos à conexões apresentados na seção 3.3.3 foram denominados da seguinte forma: Ausente (sem CRs), Normal (condutâncias das CRs sob MNs inalteradas), Fraca e Forte (metade e o dobro das condutâncias das CRs sob MNs, respectivamente). Na Figura 4.20(a), é possível ver um pico de $10 \mathrm{~Hz}$ que diminui com o aumento da influência das CRs. Nos casos denominados Normal e Forte, os respectivos picos a $10 \mathrm{~Hz}$ estiveram muito próximos. Curiosamente, para $70 \%$ da força muscular essa ordem se inverte, como mostrado na Figura 4.20(c).

A Figura 4.20(b) mostra que, com 5\% de força muscular, as CRs nos casos Normal e Forte são capazes de diminuir o pico de coerência em $10 \mathrm{~Hz}$ observado nos casos ausente e fraco. Por outro lado, para força de 70\% da CVM (Figura 4.20(d)) pôde-se perceber que apenas o caso Forte causou uma diminuição que se distinguiu das demais, também em outras faixas de frequências.

É importante dizer que os casos Forte e Normal das simulações em 70\% da CVM podem ser interpretados como uma situação possivelmente de menor realismo fisiológico, já que existem mecanismos que inibem as CRs gradualmente com o aumento da força muscular (HULTBORN; PIERROT-DESEILLIGNY, 1979a).

É possível que a diminuição dos picos em $10 \mathrm{~Hz}$ observada tenha sido causada majoritariamente pelo aumento da taxa média de disparos das fibras descendentes em situações de maior inibição recorrente, aumentando o ruído sináptico nos MNs e com isto diminuindo a probabilidade de sincronismo nos disparos dos MNs com a senoide de $10 \mathrm{~Hz}$. Para verificar essa possibilidade, foi realizada uma simulação em que a intensidade média dos comandos descendentes no caso Normal foi mantida igual ao caso sem feedback das CRs. As análises espectrais resultantes apresentadas na Figura 4.21 mostram que nessa situação também houve um decréscimo considerável do pico em $10 \mathrm{~Hz}$. Em comparação com a Figura 4.20(a), em 10 


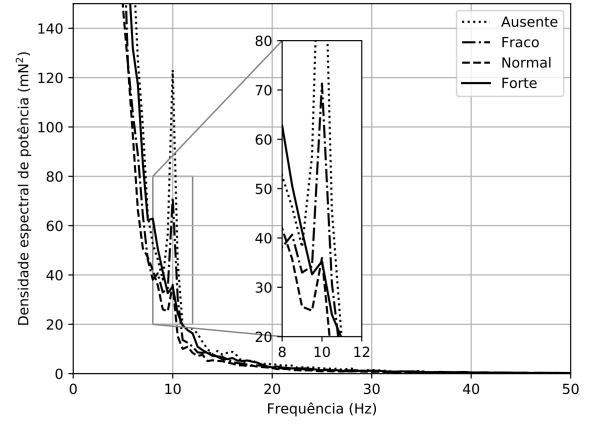

(a)

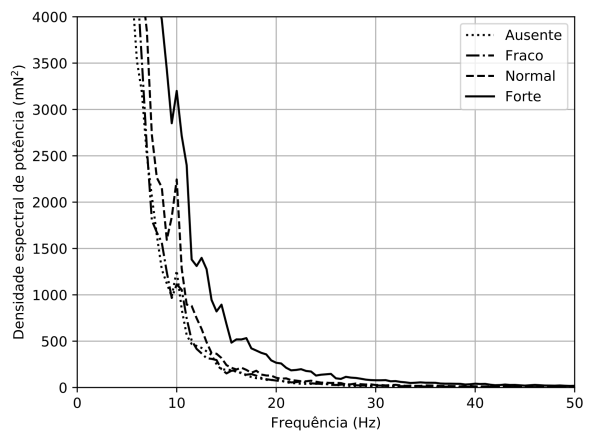

(c)

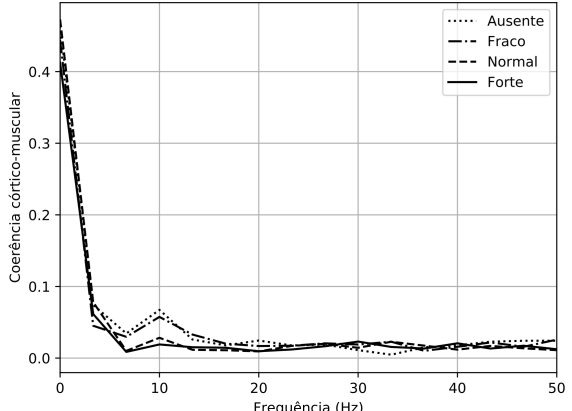

(b)

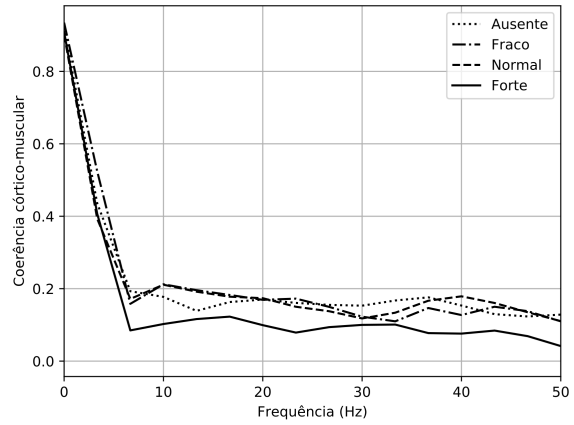

(d)

Figura 4.20 - Efeitos da célula de Renshaw na densidade espectral de potência dos disparos de motoneurônios com compensação obtida por meio de fibras descendentes. Resultados da parte superior são referentes a simulações com $5 \%$ da contração voluntária máxima, enquanto os inferiores, $70 \%$ da contração voluntária máxima. (a) e (c) Espectro de potência da força muscular. (b) e (d) Coerência córtico-muscular.

$\mathrm{Hz}$ o caso normal diminuiu de 35 (com compensação) para 27 (sem compensação), aproximadamente, enquanto os picos da coerência (Figuras 4.21(b) e 4.20(b)) ficaram praticamente inalterados. Portanto, pode-se descartar a hipótese de que a causa primordial para a diminuição do pico espectral foi o aumento da intensidade dos processos pontuais descendentes.

A redução da potência de oscilações em $10 \mathrm{~Hz}$ pode ter implicações importantes na diminuição de tremores. Estudos mostram que a inibição recorrente pode ser capaz de atenuar essas frequências por meio de um cancelamento de fases causado por sinais em antifase realimentados pelas CRs ao circuito neural (KOEHLER; WINDHORST, 1985; WILLIAMS; BAKER, 2009), agindo, assim, como um "filtro neural".

Com o intuito de investigar a possibilidade de ser gerado nos circuitos de inibição recorrente um sinal para cancelar a fase de oscilação de $10 \mathrm{~Hz}$, um nova simulação foi realizada com MNs adicionais que recebiam apenas entradas excitatórias (fibras descendentes e ruído independente) ou somente inibitórias (CRs). Flutuações de condutância e potencial de membrana 


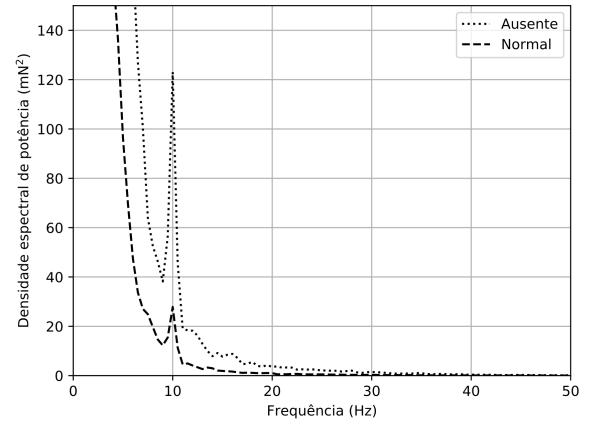

(a)

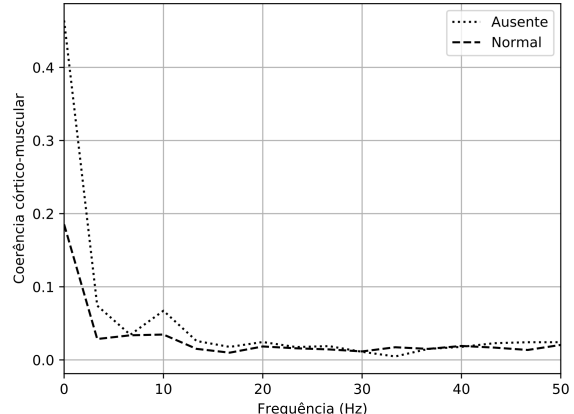

(b)

Figura 4.21 - Análise espectral sem compensação quando o feedback das células de Renshaw é adicionado. (a) Espectro de potência da força muscular. (b) Coerência córtico-muscular.

dendríticos de um desses MNs foram utilizadas nas análises espectrais apresentadas na Figura 4.22. Para essas simulações, a intensidade média das Poissons foi novamente a da situação Normal com 5\% da CVM, conforme mostrado na Tabela 3.2. Além disso, a amplitude pico a pico da senoide foi alterada para 5 vezes o valor da original para aumentar a relação sinal-ruído e facilitar a visualização dos resultados.

As Figuras 4.22(a) e 4.22(b) mostram picos de $10 \mathrm{~Hz}$ nas densidades de potência dos potenciais de membrana e das condutâncias, respectivamente, para MNs que recebem apenas entradas excitatórias (linhas pontilhadas) ou inibitórias (linhas contínuas). Analogamente, o módulo da coerência entre os sinais de condutância sináptica do par de MNs (Figura 4.22(c)) mostra uma coerência alta entre esses sinais em $10 \mathrm{~Hz}$. O gráfico da Figura 4.22(d), por sua vez, apresenta muitas flutuações, mas em $10 \mathrm{~Hz}$ tem fase próxima de zero. Isso significa que, quando o núcleo motor é sincronizado pela entrada utilizada, correntes sinápticas geradas por alterações de condutâncias inibitórias acompanham as excitatórias, mas com sentido oposto. Isso corrobora a ideia de cancelamento de fase abordada por Williams e Baker (2009).

Na Figura 4.23, a fase da coerência em $10 \mathrm{~Hz}$ é mostrada para cada uma das 10 simulações realizadas, tanto para condutância (Figura 4.23(a)) quanto para potencial de membrana (Figura 4.23(b)). Como visto na Figura 4.23(a), é possível notar que existe uma variabilidade, mas os resultados estiveram sempre próximos de zero, sugerindo tendência a cancelamento de fase. A Figura 4.23(b) mostra um deslocamento de fase de $\pm \pi$ entre os potenciais gerados pelas entradas excitatórias e inibitórias indicando, novamente, a possibilidade de um cancelamento de fase.

Antes de se fazer comparações com a Figura 3.10, é importante entender algumas diferenças entre os modelos. Em seus trabalhos, Williams e Baker (2009) incluiram artifícios para 


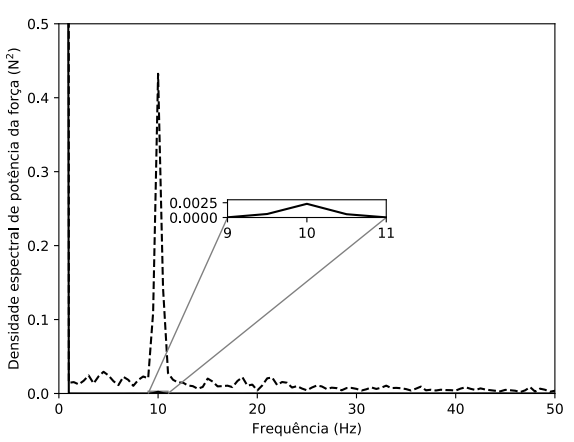

(a)

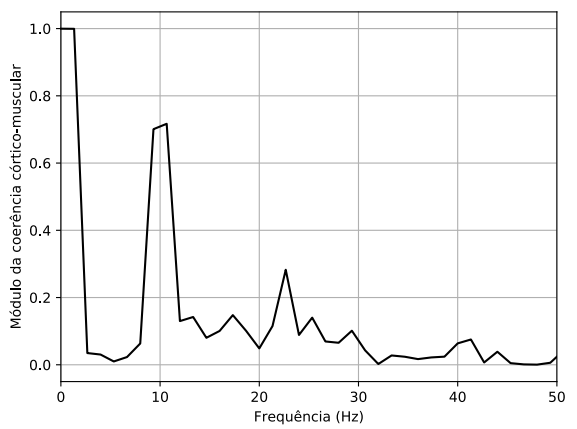

(c)

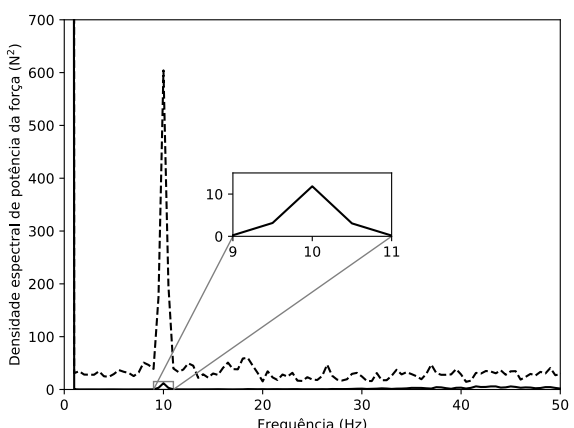

(b)

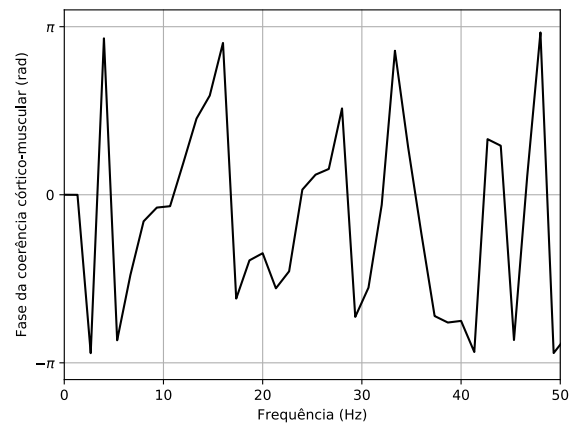

(d)

Figura 4.22 - Exemplo de como um cancelamento de fases causado pelas células de Renshaw pode ser observado. Resultados extraídos de um MN de índice 40, escolhido arbitrariamente. Linhas tracejadas e contínuas em (a) e (b) são relativas às entradas excitatórias e inibitórias, respectivamente. $\mathrm{O}$ pico em $10 \mathrm{~Hz}$ para entradas inibitórias também foi mostrado com amplificação das escalas. (a) Espectros de potência dos potenciais de membrana. (b) Espectros de potência das condutâncias sinápticas. (c) Módulo da coerência entre as condutâncias associadas às entradas excitatórias e inibitórias. (d) Fase da coerência entre as condutâncias associadas às entradas excitatórias e inibitórias.

fazer com que o núcleo motor como um todo estivesse sincronizado em $10 \mathrm{~Hz}$. Apesar de não reproduzir de forma precisa o recrutamento desses MNs, isso possibilitou que os autores pudessem estudar essa situação hipotética. Os MNs do ReMoto, em contrapartida, não são compatíveis com essa abordagem pois se comportam de acordo com o princípio de common drive (DE LUCA; ERIM, 1994). Consequentemente, nas simulações realizadas aqui, optou-se por utilizar uma entrada senoidal oriunda da modulação das vias descendentes (seria um ritmo $\mu$ cerebral) que fosse capaz de impor um certo nível de sincronização na frequência desejada.

Essas diferenças podem ter sido responsáveis pela ausência das harmônicas claramente observadas na Figura 3.10. Além disso, nos resultados apresentados aqui não foi observado um aumento no pico da coerência em $30 \mathrm{~Hz}$.

Sendo assim, os resultados obtidos das simulações dos modelos de conjuntos de MNs e CRs indicam que, conforme sugerido por outros trabalhos, o feedback negativo das CRs tende 


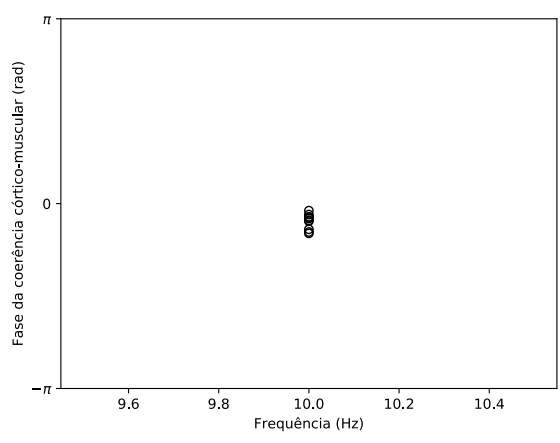

(a)

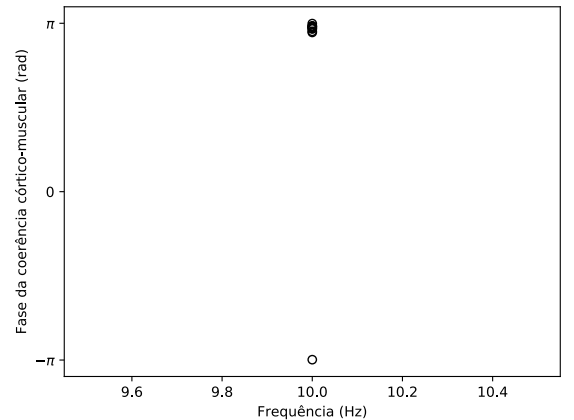

(b)

Figura 4.23 - Fases da coerência entre (a) condutâncias excitatórias e inibitórias em $10 \mathrm{~Hz}$ e (b) potenciais de membrana excitatórias e inibitórias em $10 \mathrm{~Hz}$. Cada círculo vazio representa o resultado de uma das 10 simulações realizadas.

a reduzir oscilações de $10 \mathrm{~Hz}$ na força, pelo menos em parte, devido à dinâmica do feedback que gerou um sinal com fase oposta à da excitação dos comandos descendentes. No presente estudo, a oscilação foi gerada por comandos descendentes. Outra origem seria espinhal, mas essa não foi coberta nas presentes simulações.

\subsubsection{Análises de contrações isométricas}

A Figura 4.24a mostra o efeito de diferentes intensidades de inibição recorrente em contrações isométricas rápidas. Isso pode ser visualizado de forma mais intuitiva por meio da Figura 4.24b, que mostra a derivada da força muscular gerada. Como foi observado que apenas o resultado dos primeiros 20 ms se manteve igual entre simulações e não dependeu do nível do platô obtido, somente esse intervalo de tempo inicial foi considerado nas discussões.

Os resultados apresentados na Figura 4.24 mostram que, dentre os cenários analisados, a contração muscular sob forte inibição recorrente foi a que se iniciou primeiro. Isso possibilitou que, pelo menos nos instantes iniciais, mais força fosse gerada. As pequenas inversões na ordem de recrutamento discutidas na seção 4.4 .1 e, consequentemente, a antecipação de twitches de unidades motoras maiores poderia explicar esse fenômeno.

Nota-se que as linhas pontilhadas e tracejadas da Figura 4.24b não foram iguais, mas as respectivas curvas da Figura 4.24a estiveram muito próximas, indicando pouca diferença entre forças geradas com condutâncias menores nos instantes iniciais.

Apesar das diferenças entre as forças geradas terem sido relativamente pequenas, os resultados apresentados sugerem que a ação da inibição recorrente poderia ser relevante em 


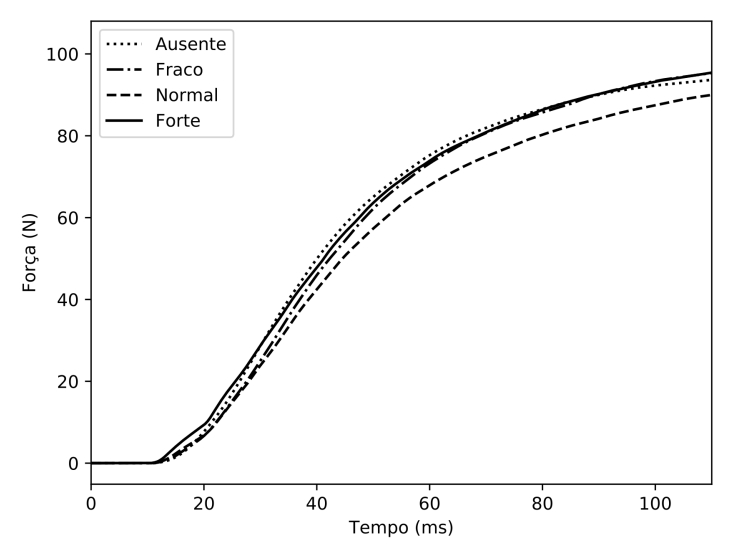

(a)

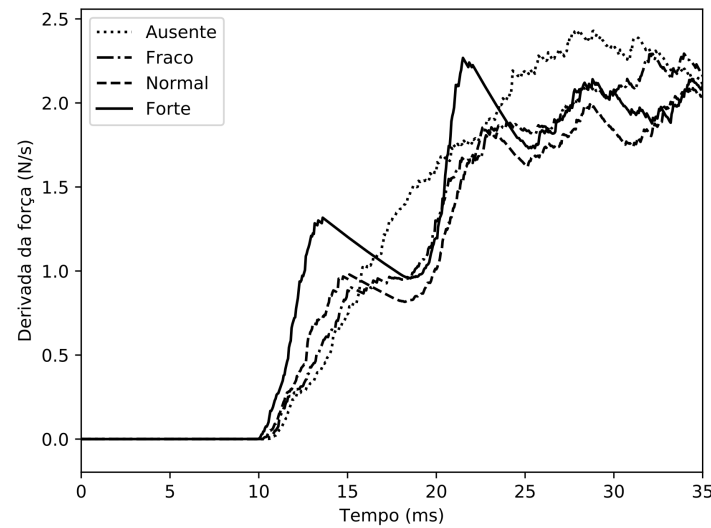

(b)

Figura 4.24 - Efeitos das células de Renshaw em contrações isométricas rápidas. Força da inibição recorrente foi simulada como o dobro (forte) e a metade (fraca) da condutância originalmente parametrizada (normal). (a) Força gerada. (b) Derivada da força.

situações de perigo que demandam contrações rápidas. Experimentos realizados em ratos geraram conclusões semelhantes, apontando a inibição recorrente como um mecanismo capaz de manter uma temporização de disparos coordenada de unidades motoras quando CRs são sincronizadas pela atividade conjunta dos MNs (OBEIDAT et al., 2014). Essa característica poderia afetar a taxa de geração da força muscular.

Vale notar que as limitações mostradas na seção 4.2 .5 podem influenciar os resultados apresentados. A presença da depressão pós-sináptica ou de características dinâmicas no modelo, pelo menos inicialmente, gerariam níveis de inibição recorrente maiores. Em uma situação normal, por exemplo, isso poderia ser observado na Figura 4.24a como uma curva mais próxima à contínua que gradualmente se aproxima da pontilhada. Uma conclusão semelhante poderia ser esboçada quando se considera uma diminuição da inibição recorrente com o aumento da contração muscular (HULTBORN; PIERROT-DESEILLIGNY, 1979a).

Tais considerações, também abordadas no trabalho de Uchiyama, Johansson e Windhorst (2003b), sugerem um efeito de mudança da inclinação da curva apresentada, o que também significa uma alteração da sensibilidade dessa população de MNs a mudanças da entrada excitatória. Essas suposições carecem de mais dados experimentais, pois não se sabe como as CRs se comportam quando os MNs disparam a taxas tão altas e de forma repentina.

Em geral, os coeficientes estudados tiveram características parecidas, tanto em situações de contrações fracas quanto fortes, como mostrado na Figura 4.25. Os coeficientes de variação da força foram maiores para intensidades de inibição recorrente maiores, enquanto, em média, os outros casos estiveram muito próximos entre si. Algo semelhante foi observado nos coefi- 
cientes de sincronia, mas, nesse caso, seus valores foram menores em contrações mais fortes. Nota-se também que os coeficientes de sincronia estiveram muito baixos, sendo necessárias análises complementares para determinar de forma mais confiável um grau de sincronismo de MNs e como este grau dependeria do feedback inibitório das CRs. Esse assunto é controverso, pois existem diversos estudos mostrando as CRs sincronizando ou desincronizando os MNs (UCHIYAMA; WINDHORST, 2007; MATTEI; SCHMIED; VEDEL, 2003; OBEIDAT et al., 2014). Vale notar que os coeficientes de sincronia também foram calculados nas simulações da seção 4.4.4, mas foram iguais aos apresentados aqui.
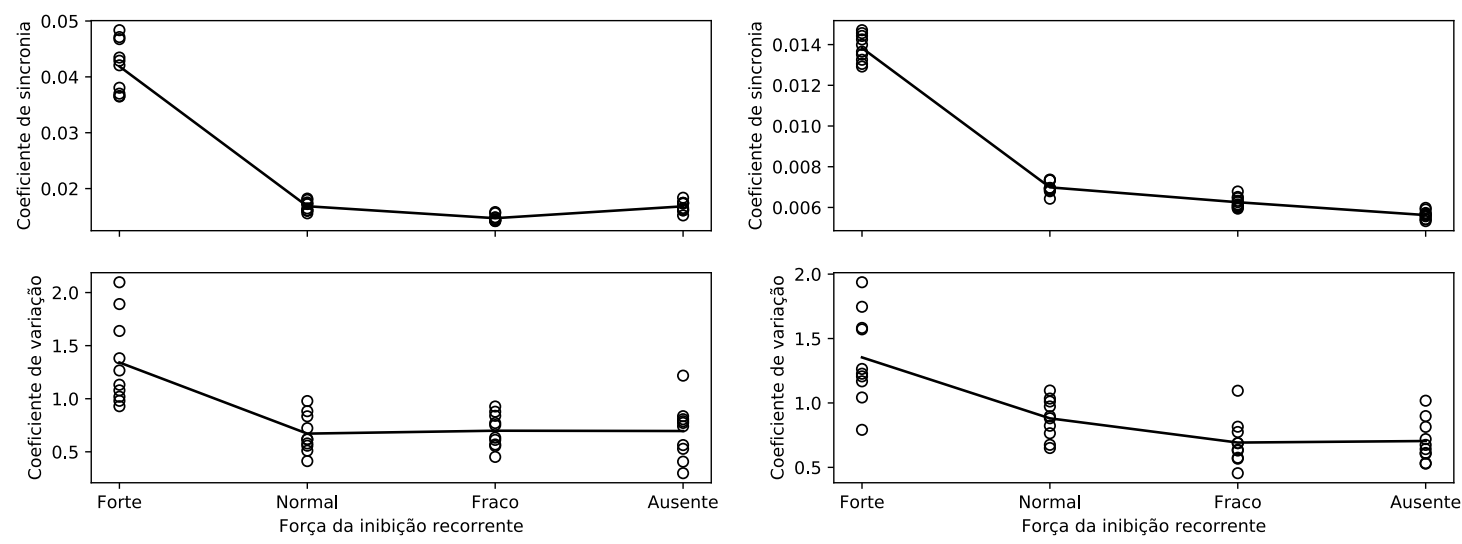

(a)

(b)

Figura 4.25 - Medidas de coeficientes de sincronia e variação em diferentes níveis de força muscular. Círculos vazios representam o resultado de uma simulação para cada intensidade de inibição recorrente e linhas representam suas médias. (a) $5 \%$. (b) $70 \%$.

A Figura 4.26 é apresentada para explorar com mais detalhes o aumento no coeficiente de sincronia, mesmo que de forma qualitativa. Para cada instante em que ocorre um disparo de algum MN, há uma linha vertical. Havendo maior sincronismo de disparos durante um dado intervalo de tempo, haverá uma maior densidade de linhas verticais neste mesmo intervalo de tempo. Sendo assim, pode-se observar que os MNs sob forte inibição recorrente (Figura 4.26(a)) tendem a disparar ao mesmo tempo. Esse fenômeno, em contrapartida, não acontece tanto quando as CRs estão ausentes (Figura 4.26(b)). Tal resultado é condizente com estudos que confirmam o efeito modulatório da inibição recorrente na temporização dos disparos de MNs (DAVEY et al., 1993; OBEIDAT et al., 2014). A lógica por trás disso é que MNs disparando ao mesmo instante (ou próximos) geram uma força de inibição intensa que atrasa o próximo disparo dos MNs nas proximidades.

É importante notar que, por causa da falta de dados experimentais, elementos responsáveis por modular as CRs não foram explicitamente modelados. Estudos realizados em ratos mostram que CRs recebem entradas sinápticas inibitórias com magnitudes correlacionadas 


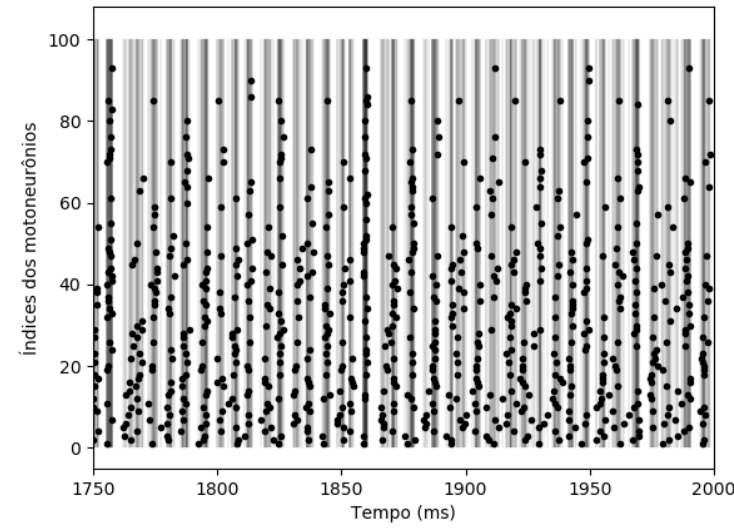

(a)

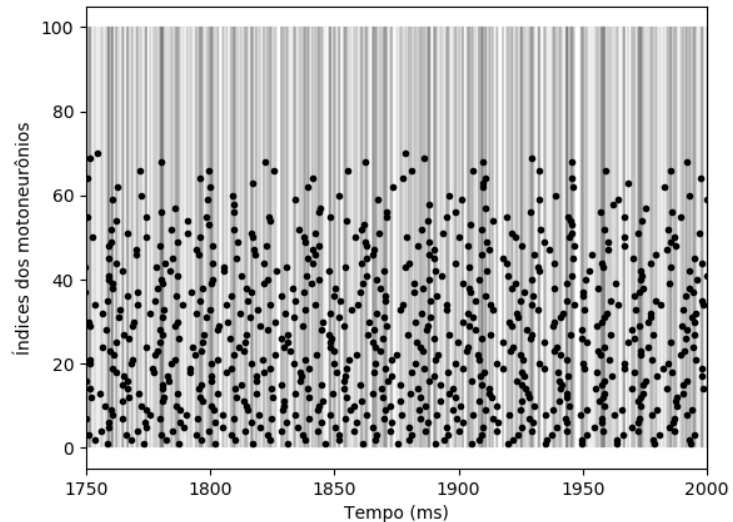

(b)

Figura 4.26 - Linhas verticais para cada instante de disparo são sobrepostas para indicar uma tendência dos motoneurônios a dispararem juntos. Os últimos $250 \mathrm{~ms}$ da simulação com $5 \%$ da contração voluntária máxima foram utilizados para essa demonstração. (a) Inibição recorrente forte. (b) Inibição recorrente ausente.

com as entradas excitatórias de MNs, mas a origem dessa modulação ainda é desconhecida (NISHIMARU et al., 2010). Apesar das diferentes condutâncias em cada simulação servirem ao propósito de elucidar possíveis efeitos modulatórios da inibição recorrente, é importante destacar que experimentos fisiológicos são necessários para determinar se a distribuição homogênea desses efeitos é de fato apropriada.

\subsubsection{Distorções e controle da força}

Eventuais distorções introduzidas pelas CRs podem ser entendidas melhor por meio da análise dos picos da transformada de Fourier da força. As médias dos resultados obtidos das equações (3.15), (3.16) e (3.17) são mostradas na Tabela 4.3.

Tabela 4.3 - Relações entre picos da transformada de Fourier da força sem e com inibição recorrente.

\begin{tabular}{ccc}
\hline Quantificador & sem CRs & com CRs \\
\hline$Q_{1}$ & 2.13 & 2.11 \\
$Q_{2}$ & 6.52 & 6.38 \\
$Q_{3}$ & 0.00180 & 0.00036 \\
\hline
\end{tabular}

Foi possível observar que, em média, os quantificadores $Q_{1}$ e $Q_{2}$ quase não apresentaram diferenças quando a inibição recorrente foi adicionada. Isso indica que as CRs pouco influenciam o espectro da força no intervalo espectral em questão. Entretanto, a pequena diminuição no quantificador $Q_{2}$ pode significar uma tendência das CRs a agirem como um filtro passa-baixas.

Por sua vez, o quantificador $Q_{3}$ foi cerca de 5 vezes menor com as CRs, sugerindo que a 
adição de inibição recorrente ocasionou o surgimento de componentes em frequências espúrias na força muscular. Isso pode ser visualizado na Figura 4.27, que mostra que esse fenômeno é mais relevante nas frequências menores que a primeira harmônica.

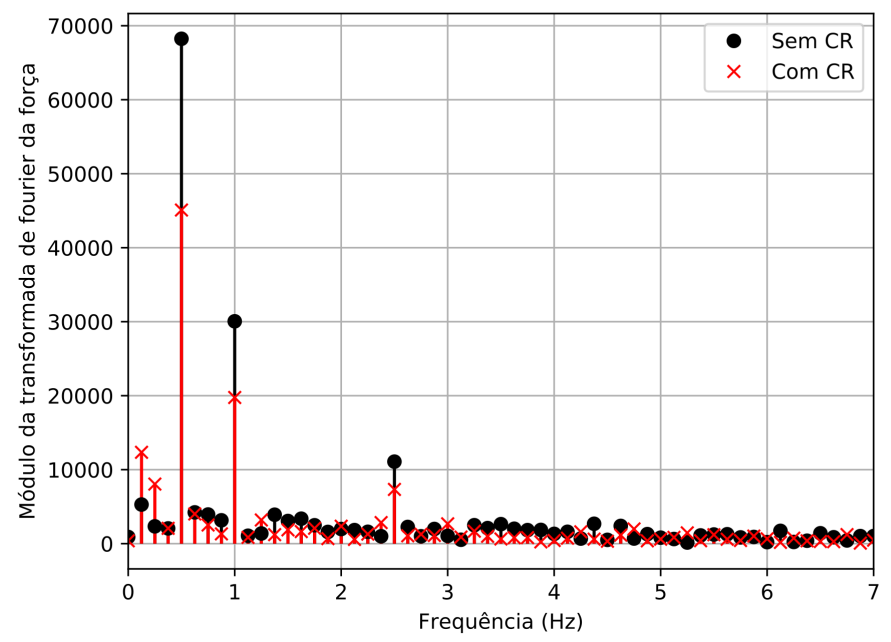

Figura 4.27 - Transformada de Fourier da força muscular.

Nesse ponto, faz-se necessária uma pequena observação sobre a simulação sem inibição recorrente apresentada. O sinal de ativação em questão, ou seja, $10 \operatorname{sen}(2 \pi 0.5 t)+5 \operatorname{sen}(2 \pi 1.0 t)+$ $2.5 \operatorname{sen}(2 \pi 2.5 t)$, é composto por autofunções do sistema linear de segunda ordem criticamente amortecido utilizado para gerar twitches. Se o módulo da função resposta em frequência desse sistema de segunda ordem fosse relativamente plano para as baixas frequências estudadas, os valores de $Q_{1}$ e $Q_{2}$ estariam perto de 2 e 4 , respectivamente. Como visto na primeira coluna da Tabela 4.3, isso foi verdade apenas no caso de $Q_{1}$.

Na verdade, cada unidade motora está associada a um sistema de segunda ordem diferente, de forma que a frequência de corte de uma função resposta em frequência é proporcional ao tamanho de um MN. Sendo assim, o MN de índice 1, por exemplo, com frequência de corte em $0.9 \mathrm{~Hz}$, causaria um aumento considerável em $Q_{1}$ e $Q_{2}$.

O valor de $Q_{2}$ encontrado, entretanto, pode ser explicado pelo fato de que, no nível de contração muscular simulado, as unidades motoras maiores teriam mais influencia sobre a força muscular gerada. Dessa forma, uma análise da função resposta em frequência associada ao MN de índice 90 mostrou que o cálculo de $Q_{2}$, nesse caso, resultaria em 6.33, que é um valor próximo ao encontrado na primeira coluna da Tabela 4.3. De qualquer forma, outros estudos são necessários para determinar a relevância dessa diminuição.

Dando prosseguimento ao que foi proposto na seção 3.3.5, os CSTs de alguns MNs foram 
computados para que se pudesse entender melhor a influência das CRs na transmissão do sinal de entrada para os músculos. Os resultados da Figura 4.28 mostram CSTs de 5 MNs. Para facilitar a comparação com a entrada fornecida pelas fibras descendentes (em cinza claro), ambos sinais tiveram suas respectivas médias subtraídas e, em seguida, foram divididos por seus respectivos valores máximos.

Foi possível notar que a adição da inibição recorrente, como mostrado na Figura 4.28(b), resultou em algo mais ruidoso quando comparado com a situação sem CRs da Figura 4.28(a). Uma conclusão semelhante pode ser tirada quando MNs maiores são simulados, como visto na Figura 4.28(c) e (d). Contudo, nesse caso observou-se que o CST desses MNs (Figura 4.28(d)) não representa tão bem a entrada comum quanto o dos MNs menores (Figura 4.28(b)). Para investigar a causa disso, o CST das CRs também foi computado.

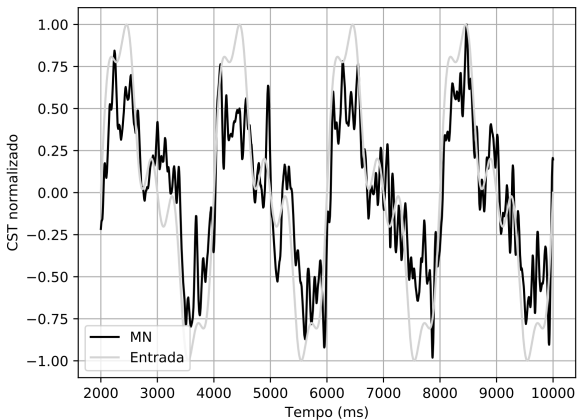

(a)

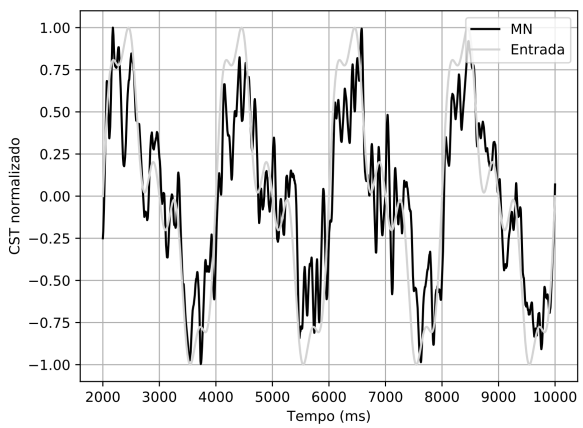

(c)

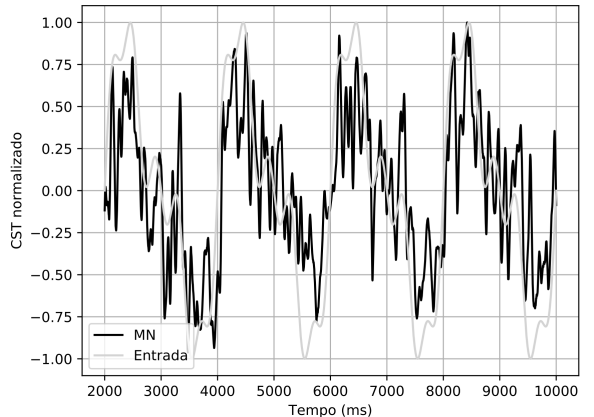

(b)

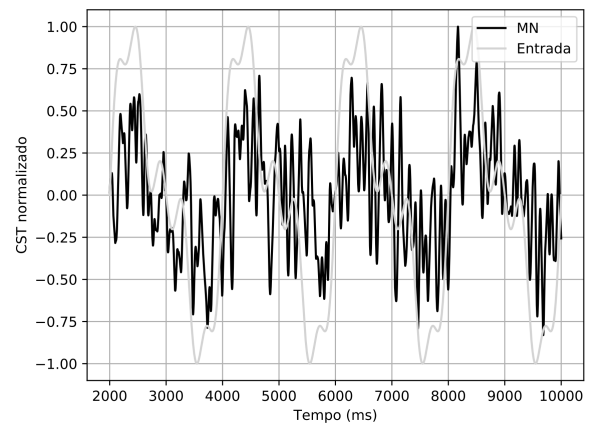

(d)

Figura 4.28 - Trens de disparos cumulativos filtrados e normalizados de motoneurônios. A primeira coluna mostra resultados sem células de Renshaw, enquanto a segunda coluna mostra resultados com células de Renshaw. Em (a) e (b), o trem de disparos cumulativo foi computado com os disparos de motoneurônios de índices 5 até 9 . Em (c) e (d), foram utilizados motoneurônios 95 até 99 . Curva em cinza claro mostra o formato da entrada fornecida pelas fibras descendentes, também normalizadas.

A média dos CSTs das 5 CRs mais próximas dos MNs de índices 7 e 97 foram próximas (0.046 e 0.045 , respectivamente), sugerindo que o comportamento observado na Figura 
4.28(d) não foi ocasionado por isso. Por outro lado, tais CSTs são diferentes, como visto na Figura 4.29. CRs próximas a MNs menores não tiveram CSTs (Figura 4.29(a)) tão parecidos com a entrada comum quanto CSTs de CRs próximas a MNs maiores (Figura 4.29(b)).

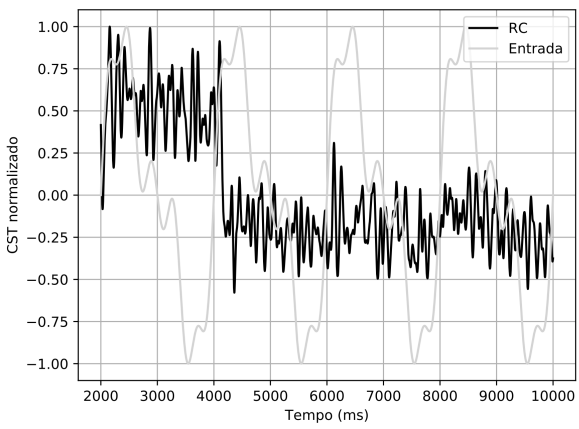

(a)

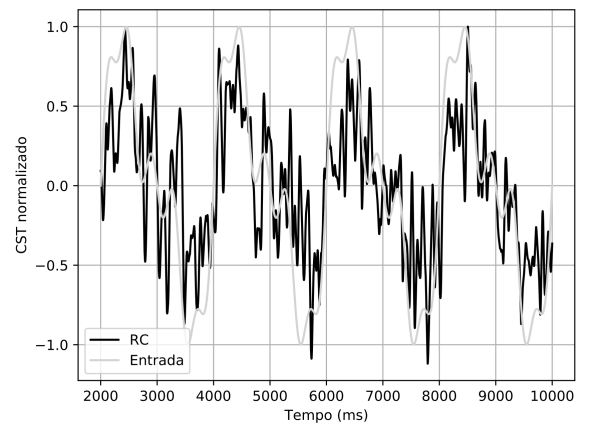

(b)

Figura 4.29 - Trens de disparos cumulativos filtrado e normalizado das células de Renshaw. (a) Trem de disparos cumulativo das 5 células de Renshaw mais próximas ao motoneurônio de índice 7. (b) Trem de disparos cumulativo das 5 células de Renshaw mais próximas ao motoneurônio de índice 97.

Uma possível explicação para as diferenças observadas na Figura 4.29 pode ser a saturação das respostas dos MNs menores, já que, nesse caso, esses dispararam a uma taxa relativamente alta de 110 pps. Outra possibilidade seria a força sináptica excitatória de MNs maiores sobre as CRs ser maior do que a de MNs menores (HULTBORN et al., 1988; CULLHEIM; KELLERTH, 1978). Como os MNs do tipo $S$ do modelo não são eficientes em ativar CRs (vide Figura 4.11), é de se esperar que essas não apresentem saídas parecidas com suas entradas se alguns desses MNs não dispararem simultaneamente. Por outro lado, essa condição não seria tão importante no caso dos MNs do tipo FR pois a força sináptica de suas conexões com as CRs são mais elevadas.

De qualquer forma, os resultados da Figura 4.29 sugerem que, em alguns casos, a atividade das CRs pode não ser apropriada para representar uma predição (BROWNSTONE; BUI; STIFANI, 2015) ou mudanças da ativação muscular (LOEB; HE; LEVINE, 1990).

Por fim, vale notar um resultado apresentado na Figura 4.30. Nessa, observou-se que houve um aumento no número de MNs recrutados quando as CRs foram adicionadas (com um simultâneo aumento na taxa média dos comandos descendentes). Uma explicação para esse resultado é que com as CRs há uma diminuição na taxa de disparos dos MNs recrutados (vide Figura 4.18) e para que a força gerada seja a mesma em média, novos MNs tiveram que ser recrutados. 


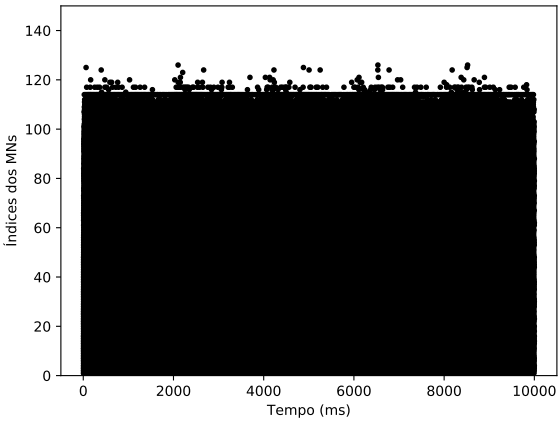

(a)

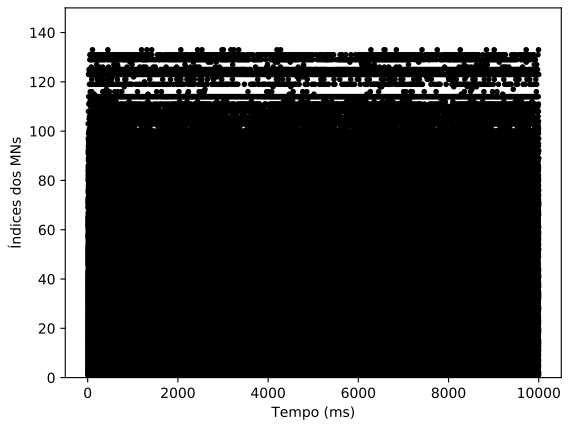

(b)

Figura 4.30 - Instantes de disparo dos somas do motoneurônios simulados com a entrada utilizada nessa seção. (a) Sem células de Renshaw. (b) Com células de Renshaw. 


\section{CONCLUSÕES}

Os resultados relativos ao desempenho computacional sugeriram possíveis melhorias para o ReMoto. A implementação de matrizes de condutâncias adequada para operações vetorizadas foi, inclusive, incorporada na versão do ReMoto em Fortran. A utilização de clusters, por sua vez, seria mais complexa, envolvendo o desenvolvimento de uma arquitetura de processamento que incluísse INs.

Baseando-se em dados experimentais, parâmetros de MNs e CRs foram ajustados para simular características importantes do circuito de inibição recorrente. A parametrização foi satisfatória e foi possível observar uma série de respostas apropriadas. Características dinâmicas e de depressão pós-sináptica não puderam ser reproduzidas como na literatura, mas essa limitação, quando relevante, foi considerada nas análises dos resultados de simulações.

Para testar a parametrização adotada, simulações de procedimentos experimentais envolvendo CRs também foram realizadas. Relações estáticas, PIPS recorrentes, resposta a estímulos antidrômicos e diminuições da força muscular causadas pelas CRs foram comparados com a literatura e utilizados para delimitar propriedades gerais do modelo do circuito de inibição recorrente gerado.

De acordo com o que foi apresentado nos dois parágrafos anteriores, pode-se dizer que o modelo parametrizado foi suficiente para os estudos aqui realizados sobre o circuito de inibição recorrente no gato. Diferentemente de outros trabalhos computacionais sobre as CRs, esse modelo foi implementado em uma sistema de simulação open source, reforçando aspectos importantes como extensibilidade e reproduzibilidade.

Considerando as parametrizações realizadas, resultados de simulações sem e com inibição recorrente foram avaliados sob diversas perspectivas. Os MNs sob efeito das CRs apresentaram maior tendência a inverter a ordem de seus recrutamentos, algo que parece ter um afetado a velocidade do desenvolvimento da força. Isso sugere uma função importante da CR em contrações musculares rápidas.

Nas comparações em regime estacionário e com aproximadamente o mesmo nível de força, a presença das CRs em geral causou diminuições das taxas de disparos, que foram acompanhadas por um aumento no número de unidades motoras recrutadas. Por outro lado, as médias 
dos coeficientes de variação da força, que foram avaliadas com diferentes intensidades de inibição recorrente, foram praticamente iguais entre si, com exceção do caso de inibição forte, que foi maior. Isso mostra que a inibição recorrente, apesar de ter causado uma mudança na forma como os MNs no núcleo motor disparam, não necessariamente afeta a variabilidade da força. O mesmo comportamento das médias dos coeficientes de variação da força foi observado nas médias dos coeficientes de sincronia. De qualquer forma, estudos experimentais e computacionais adicionais são necessários para se chegar a um consenso sobre a capacidade da CR em sincronizar MNs. Vale notar que os resultados observados para forças de inibição recorrente altas reforçam a ideia de que as CRs podem ser moduladas para gerarem efeitos distintos.

Por meio de análises no domínio da frequência, foi possível confirmar que as CRs podem atenuar tremores indesejados oriundos de vias descendentes (mais especificamente, oscilações de $10 \mathrm{~Hz}$ ) por meio de cancelamento de fases. Isso foi estudado por outro grupo, mas considerando uma ativação oscilatória de MNs de origem local ao invés de se originar de vias descendentes. As análises também mostraram que as CRs poderiam atuar como um filtro passa baixas e introduzir componentes espúrias na força muscular gerada pelo modelo. Esta distorção, juntamente com o fato de que foram observados CSTs de MNs mais ruidosos quando as CRs estavam presentes, mostra que não necessariamente todos os efeitos da CRs no núcleo motor serão vantajosos. Dessa forma, a inibição recorrente poderia estar relacionada com melhoras no desenvolvimento da força e redução de tremores em detrimento de uma maior qualidade na transmissão de comandos descendentes para o músculo.

Por fim, os CSTs de grupos de CRs foram diferentes dependendo de quais MNs fossem escolhidos para realizar as computações. Tais resultados não foram conclusivos, mas sugerem que a inibição da CR não necessariamente reflete a força (ou sua derivada). 


\section{REFERÊNCIAS BIBLIOGRÁFICAS}

ADAM, D.; WINDHORST, U.; INBAR, G. F. The effects of recurrent inhibition on the cross-correlated firing patterns of motoneurones (and their relation to signal transmission in the spinal cord-muscle channel). Biological Cybernetics, v. 29, n. 4, p. 229-235, dez. 1978. ISSN 1432-0770.

ALLEN, J. M.; ELBASIOUNY, S. M. The effects of model composition design choices on high-fidelity simulations of motoneuron recruitment and firing behaviors. Journal of Neural Engineering, v. 15, n. 3, p. 036024, 2018. ISSN 1741-2552.

ALVAREZ, F. J. et al. Distribution of cholinergic contacts on Renshaw cells in the rat spinal cord: a light microscopic study. The Journal of Physiology, v. 515, n. Pt 3, p. 787-797, mar. 1999. ISSN 0022-3751.

ALVAREZ, F. J.; FYFFE, R. E. W. The continuing case for the Renshaw cell: The continuing case for the Renshaw cell. The Journal of Physiology, v. 584, n. 1, p. 31-45, out. 2007. ISSN 00223751.

APPELBERG, B. et al. Recurrent actions on gamma-motoneurones mediated via large and small ventral root fibres in the cat. The Journal of Physiology, v. 335, n. 1, p. 293-305, fev. 1983. ISSN 1469-7793.

BALDISSERA, F.; HULTBORN, H.; ILLERT, M. Integration in Spinal Neuronal Systems. Comprehensive Physiology, jan. 2011. ISSN 2040-4603. DOI: 10.1002/cphy.cp010212.

BAWA, P. N. S.; JONES, K. E.; STEIN, R. B. Assessment of size ordered recruitment. Frontiers in Human Neuroscience, v. 8, 2014. ISSN 1662-5161.

BEAR, M. F.; CONNORS, B. W.; PARADISO, M. A. Neuroscience: exploring the brain. 4th. ed. Philadelphia: Wolters Kluwer, 2016. ISBN 978-0-7817-7817-6.

BENDA, J.; HERZ, A. V. M. A universal model for spike-frequency adaptation. Neural Computation, v. 15 , n. 11, p. 2523-2564, nov. 2003. ISSN 0899-7667. 
BENDAT, J.; PIERSOL, A. Random Data: analysis and measurement procedures. 4th. ed. New Jersey: Wiley, 2011. (Wiley Series in Probability and Statistics). ISBN 978-1-118-21082-6.

BHUMBRA, G. S. et al. The Recurrent Case for the Renshaw Cell. Journal of Neuroscience, v. 34, n. 38, p. 12919-12932, set. 2014. ISSN 0270-6474, 1529-2401.

BROWNSTONE, R. M.; BUI, T. V.; STIFANI, N. Spinal circuits for motor learning. Current Opinion in Neurobiology, v. 33, p. 166-173, ago. 2015. ISSN 0959-4388.

BUI, T. V. Comparison of the Morphological and Electrotonic Properties of Renshaw Cells, la Inhibitory Interneurons, and Motoneurons in the Cat. Journal of Neurophysiology, v. 90, n. 5, p. 2900-2918, jul. 2003. ISSN 0022-3077, 1522-1598.

BURKE, R. E. Motor Units: anatomy, physiology, and functional organization. Comprehensive Physiology, American Cancer Society, p. 345-422, 2011. ISSN 2040-4603.

BURKE, R. E. et al. Mammalian Motor Units: Physiological-Histochemical Correlation in Three Types in Cat Gastrocnemius. Science, v. 174, n. 4010, p. 709-712, nov. 1971. ISSN 0036-8075, 1095-9203.

BURKE, R. E. et al. Anatomy of medial gastrocnemius and soleus motor nuclei in cat spinal cord. Journal of Neurophysiology, v. 40, n. 3, p. 667-680, maio 1977. ISSN 0022-3077, 1522-1598.

CARR, P. A. et al. Calbindin D28k expression in immunohistochemically identified Renshaw cells. Neuroreport, v. 9, n. 11, p. 2657-2661, ago. 1998. ISSN 0959-4965.

CISI, R. R. L. Sistema de Simulação de Circuitos Neuronais da Medula Espinhal Desenvolvido em Arquitetura Web. Tese (Doutorado) — Universidade de São Paulo, São Paulo, 2007.

CISI, R. R. L.; KOHN, A. F. Simulation system of spinal cord motor nuclei and associated nerves and muscles, in a Web-based architecture. Journal of Computational Neuroscience, v. 25 , n. 3, p. 520-542, dez. 2008. ISSN 0929-5313, 1573-6873.

CLEVELAND, S.; KUSCHMIERZ, A.; ROSS, H.-G. Static input-output relations in the spinal recurrent inhibitory pathway. Biological Cybernetics, v. 40, n. 3, p. 223-231, maio 1981. ISSN 0340-1200, 1432-0770.

CULLHEIM, S.; KELLERTH, J. O. A morphological study of the axons and recurrent axon collaterals of cat alpha-motoneurones supplying different hind-limb muscles. The Journal of Physiology, v. 281, p. 285-299, 1978. ISSN 0022-3751. 
DAVEY, N. J. et al. Rhythmicity associated with a high degree of short-term synchrony of motor unit discharge in man. Experimental Physiology, v. 78, n. 5, p. 649-661, 1993. ISSN $1469-445 X$.

DESTEXHE, A.; MAINEN, Z. F.; SEJNOWSKI, T. J. An Efficient Method for Computing Synaptic Conductances Based on a Kinetic Model of Receptor Binding. Neural Computation, v. 6 , n. 1, p. 14-18, jan. 1994. ISSN 0899-7667.

DESTEXHE, A.; MAINEN, Z. F.; SEJNOWSKI, T. J. Synthesis of models for excitable membranes, synaptic transmission and neuromodulation using a common kinetic formalism. Journal of Computational Neuroscience, v. 1, n. 3, p. 195-230, ago. 1994. ISSN 0929-5313.

ECCLES, J. C. et al. Distribution of recurrent inhibition among motoneurones. The Journal of Physiology, v. 159, n. 3, p. 479-499, dez. 1961. ISSN 0022-3751.

ECCLES, J. C. et al. Electrophysiological investigations on Renshaw cells. The Journal of Physiology, v. 159, n. 3, p. 461-478, dez. 1961. ISSN 0022-3751.

ECCLES, J. C.; FATT, P.; KOKETSU, K. Cholinergic and inhibitory synapses in a pathway from motor-axon collaterals to motoneurones. The Journal of Physiology, v. 126, n. 3, p. 524-562, 1954. ISSN 0022-3751.

ELIAS, L. A.; WATANABE, R. N.; KOHN, A. F. Spinal Mechanisms May Provide a Combination of Intermittent and Continuous Control of Human Posture: predictions from a biologically based neuromusculoskeletal model. PLoS Computational Biology, v. 10, n. 11, nov. 2014. ISSN 1553-734X.

ELLAWAY, P. H.; MURPHY, P. R. A comparison of the recurrent inhibition of alpha- and gamma-motoneurones in the cat. The Journal of Physiology, v. 315, p. 43-58, jun. 1981. ISSN 0022-3751.

ENOKA, R. Neuromechanics of Human Movement. 4th. ed. Champaign, III.: Human Kinetics, 2008. ISBN 978-0-7360-6679-2.

FARINA, D.; NEGRO, F. Common Synaptic Input to Motor Neurons, Motor Unit Synchronization, and Force Control. Exercise and Sport Sciences Reviews, v. 43, n. 1, p. 23, jan. 2015. ISSN 0091-6331.

FRIEDMAN, W. A. et al. Recurrent inhibition in type-identified motoneurons. Journal of Neurophysiology, v. 46, n. 6, p. 1349-1359, dez. 1981. ISSN 0022-3077. 
FYFFE, R. E. Spatial distribution of recurrent inhibitory synapses on spinal motoneurons in the cat. Journal of Neurophysiology, v. 65, n. 5, p. 1134-1149, maio 1991. ISSN 0022-3077. FYFFE, R. E. W. Evidence for separate morphological classes of Renshaw cells in the cat's spinal cord. Brain Research, v. 536, n. 1, dez. 1990. ISSN 0006-8993.

GOLOMB, D.; HANSEL, D.; MATO, G. Chapter 21 Mechanisms of synchrony of neural activity in large networks. In: MOSS, F.; GIELEN, S. (Ed.). Handbook of Biological Physics. [S.I.]: North-Holland, 2001, (Neuro-Informatics and Neural Modelling, v. 4). p. 887-968.

GORELICK, M.; OZSVALD, I. High performance Python. 1st. ed. Sebastopol, CA: O'Reilly, 2014. OCLC: ocn868080968. ISBN 978-1-4493-6159-4.

GRAMA, A. et al. Introduction to Parallel Computing. 2nd. ed. Harlow, England ; New York: Pearson, 2003. ISBN 978-0-201-64865-2.

GRANIT, R.; PASCOE, J. E.; STEG, G. The behaviour of tonic alpha and beta motoneurones during stimulation of recurrent collaterals. The Journal of Physiology, v. 138, n. 3, p. 381-400, out. 1957. ISSN 1469-7793.

GRANIT, R.; RENKIN, B. Net depolarization and discharge rate of motoneurones, as measured by recurrent inhibition. The Journal of Physiology, v. 158, p. 461-475, out. 1961. ISSN 0022-3751.

GRANIT, R.; RUTLEDGE, L. Surplus excitation in reflex action of motoneurones as measured by recurrent inhibition. The Journal of Physiology, v. 154, n. 2, p. 288-307, dez. 1960.

HAMM, T. M. et al. Distribution of single-axon recurrent inhibitory post-synaptic potentials in a single spinal motor nucleus in the cat. The Journal of Physiology, v. 388, p. 653-664, jul. 1987. ISSN 0022-3751.

HAMM, T. M. et al. The measurement of single motor-axon recurrent inhibitory post-synaptic potentials in the cat. The Journal of Physiology, v. 388, p. 631-651, jul. 1987. ISSN 0022-3751.

HECKMAN, C.; ENOKA, R. M. Motor Unit. Comprehensive Physiology, out. 2012. ISSN 9780470650714.

HENNEMAN, E.; SOMJEN, G.; CARPENTER, D. O. Functional Significance of Cell Size in Spinal Motoneurons. Journal of Neurophysiology, v. 28, p. 560-580, maio 1965. ISSN 0022-3077. 
HOFFER, J. A. et al. Cat hindlimb motoneurons during locomotion. II. Normal activity patterns. Journal of Neurophysiology, v. 57, n. 2, p. 530-553, fev. 1987. ISSN 0022-3077. HU, X.; RYMER, W. Z.; SURESH, N. L. Motor unit firing rate patterns during voluntary muscle force generation: a simulation study. Journal of Neural Engineering, v. 11, n. 2, p. 026015, 2014. ISSN 1741-2552.

HULTBORN, $\mathrm{H}$. et al. Key mechanisms for setting the input-output gain across the motoneuron pool. In: Brain Mechanisms for the Integration of Posture and Movement. [S.I.]: Elsevier, 2004, (Progress in Brain Research, v. 143). p. 75 - 95.

HULTBORN, H.; JANKOWSKA, E.; LINDSTRÖM, S. Recurrent inhibition from motor axon collaterals of transmission in the la inhibitory pathway to motoneurones. The Journal of Physiology, v. 215, n. 3, p. 591-612, jul. 1971. ISSN 0022-3751.

HULTBORN, H.; JANKOWSKA, E.; LINDSTRÖM, S. Relative contribution from different nerves to recurrent depression of la IPSPs in motoneurones. The Journal of Physiology, v. 215 , n. 3, p. 637-664, jul. 1971. ISSN 0022-3751.

HULTBORN, H.; KATZ, R.; MACKEL, R. Distribution of recurrent inhibition within a motor nucleus. II. Amount of recurrent inhibition in motoneurones to fast and slow units. Acta Physiologica Scandinavica, v. 134, n. 3, p. 363-374, nov. 1988. ISSN 0001-6772.

HULTBORN, $\mathrm{H}$. et al. Distribution of recurrent inhibition within a motor nucleus. I. Contribution from slow and fast motor units to the excitation of Renshaw cells. Acta Physiologica Scandinavica, v. 134, n. 3, p. 347-361, nov. 1988. ISSN 0001-6772.

HULTBORN, H.; PIERROT-DESEILLIGNY, E. Changes in recurrent inhibition during voluntary soleus contractions in man studied by an $\mathrm{H}$-reflex technique. The Journal of Physiology, v. 297, n. 1, p. 229-251, 1979. ISSN 1469-7793.

HULTBORN, H.; PIERROT-DESEILLIGNY, E. Input-output relations in the pathway of recurrent inhibition to motoneurones in the cat. The Journal of Physiology, v. 297, p. 267-287, dez. 1979. ISSN 0022-3751.

HULTBORN, H.; PIERROT-DESEILLIGNY, E.; WIGSTRÖM, H. Recurrent inhibition and afterhyperpolarization following motoneuronal discharge in the cat. The Journal of Physiology, v. 297, n. 1, p. 253-266, dez. 1979. ISSN 1469-7793.

JANKOWSKA, E.; LINDSTRÖM, S. Morphological identification of Renshaw cells. Acta Physiologica Scandinavica, v. 81, n. 3, p. 428-430, mar. 1971. ISSN 0001-6772. 
JANKOWSKA, E.; SMITH, D. O. Antidromic Activation of Renshaw Cells and their Axonal Projections. Acta Physiologica Scandinavica, v. 88, n. 2, p. 198-214, jun. 1973. ISSN 1365-201X.

KANDEL, E. R. et al. Principles of neural science. [S.I.]: McGraw-Hill Medical, 2013. OCLC: 852737181. ISBN 978-0-07-139011-8 978-0-07-181001-2 978-1-283-65624-5.

KATO, M.; FUKUSHIMA, K. Effect of differential blocking of motor axons on antidromic activation of Renshaw cells in the cat. Experimental Brain Research, v. 20, n. 2, p. 135-143, maio 1974. ISSN 0014-4819, 1432-1106.

KERNELL, D. The Limits of Firing Frequency in Cat Lumbosacral Motoneurones Possessing Different Time Course of Afterhyperpolarization. Acta Physiologica Scandinavica, v. 65, n. $1-2$, p. $87-100$, set. 1965 . ISSN 1365-201X.

KERNELL, D. Motoneurone and its Muscle Fibres - Oxford Scholarship. [S.I.: s.n.], 2006. VAN KEULEN, L. Autogenetic recurrent inhibition of individual spinal motoneurones of the cat. Neuroscience Letters, v. 21, n. 3, p. 297-300, fev. 1981. ISSN 0304-3940.

VAN KEULEN, L. C. M. Axon trajectories of Renshaw cells in the lumbar spinal cord of the cat, as reconstructed after intracellular staining with horseradish peroxidase. Brain Research, v. 167, n. 1 , p. 157-162, maio 1979. ISSN 0006-8993.

KOEHLER, W.; WINDHORST, U. Responses of the spinal alpha-motoneurone-Renshaw cell system to various differentially distributed segmental afferent and descending inputs. Biological Cybernetics, v. 51, n. 6, p. 417-426, abr. 1985. ISSN 1432-0770.

LAGERBÄCK, P.-A.; KELLERTH, J.-O. Light microscopic observations on cat Renshaw cells after intracellular staining with horseradish peroxidase. I. The axonal systems. Journal of Comparative Neurology, v. 240, n. 4, p. 359-367, out. 1985. ISSN 1096-9861.

LIDDELL, E. G. T. et al. Recruitment and some other features of reflex inhibition. Proceedings of the Royal Society of London, v. 97, n. 686, p. 488-518, abr. 1925. ISSN 0950-1193, 2053-9185.

LINDSAY, A. D.; BINDER, M. D. Distribution of effective synaptic currents underlying recurrent inhibition in cat triceps surae motoneurons. Journal of Neurophysiology, v. 65, n. 2, p. 168-177, fev. 1991. ISSN 0022-3077. 
LINDSTRÖM, S.; SCHOMBURG, E. D. Recurrent inhibition from motor axon collaterals of ventral spinocerebellar tract neurones. Acta Physiologica Scandinavica, v. 88, n. 4, p. 505-515, ago. 1973. ISSN 0001-6772.

LOEB, G.; HE, J.; LEVINE, W. S. Spinal cord circuits: are they mirrors of musculoskeletal mechanics? Journal of motor behavior, v. 21, p. 473-91, jan. 1990.

DE LUCA, C. J.; CONTESSA, P. Biomechanical benefits of the Onion-Skin motor unit control scheme. Journal of biomechanics, v. 48, n. 2, p. 195-203, jan. 2015. ISSN 0021-9290.

DE LUCA, C. J.; ERIM, Z. Common drive of motor units in regulation of muscle force. Trends in Neurosciences, v. 17, n. 7, p. 299-305, jan. 1994. ISSN 0166-2236.

LYTTON, W. W. Optimizing synaptic conductance calculation for network simulations. Neural Computation, v. 8, n. 3, p. 501-509, abr. 1996. ISSN 0899-7667.

MACLEAN, J. B.; LEFFMAN, H. Supraspinal control of Renshaw cells. Experimental Neurology, v. 18, n. 1, p. 94-104, maio 1967. ISSN 0014-4886.

MALTENFORT, M. G.; HECKMAN, C. J.; RYMER, W. Z. Decorrelating actions of Renshaw interneurons on the firing of spinal motoneurons within a motor nucleus: a simulation study. Journal of neurophysiology, v. 80, n. 1, p. 309-323, 1998.

MALTENFORT, M. G. et al. Location and Magnitude of Conductance Changes Produced by Renshaw Recurrent Inhibition in Spinal Motoneurons. Journal of Neurophysiology, v. 92, n. 3, p. 1417-1432, set. 2004. ISSN 0022-3077.

MATTEI, B.; SCHMIED, A.; VEDEL, J.-P. Recurrent inhibition of wrist extensor motoneurones: a single unit study on a deafferented patient. The Journal of Physiology, v. 549, n. Pt 3, p. 975-984, jun. 2003. ISSN 0022-3751.

MCCURDY, M. L.; HAMM, T. M. Topography of recurrent inhibitory postsynaptic potentials between individual motoneurons in the cat. Journal of Neurophysiology, v. 72, n. 1, p. 214-226, jul. 1994. ISSN 0022-3077.

MOORE, N. J. et al. Synaptic Connectivity between Renshaw Cells and Motoneurons in the Recurrent Inhibitory Circuit of the Spinal Cord. The Journal of Neuroscience, v. 35, n. 40, p. 13673-13686, out. 2015. ISSN 0270-6474, 1529-2401.

MORRISON, A. et al. Advancing the boundaries of high-connectivity network simulation with distributed computing. Neural computation, v. 17, n. 8, p. 1776-1801, 2005. 
MRÓWCZYŃSKI, W.; CELICHOWSKI, J.; KRUTKI, P. Interspecies differences in the force-frequency relationship of the medial gastrocnemius motor units. Journal of Physiology and Pharmacology: an official journal of the polish physiological society, v. $57, \mathrm{n} .3, \mathrm{p}$. 491-501, set. 2006. ISSN 0867-5910.

MULLER, E. et al. Python in neuroscience. Frontiers in Neuroinformatics, v. 9, abr. 2015. ISSN 1662-5196.

NISHIMARU, H. et al. Inhibitory Synaptic Modulation of Renshaw Cell Activity in the Lumbar Spinal Cord of Neonatal Mice. Journal of Neurophysiology, v. 103, n. 6, p. 3437-3447, jun. 2010. ISSN 0022-3077, 1522-1598.

OBEIDAT, A. Z. et al. Modulation of motoneuron firing by recurrent inhibition in the adult rat in vivo. Journal of Neurophysiology, v. 112, n. 9, p. 2302-2315, nov. 2014. ISSN 0022-3077, 1522-1598.

OYA, T.; RIEK, S.; CRESSWELL, A. G. Recruitment and rate coding organisation for soleus motor units across entire range of voluntary isometric plantar flexions. The Journal of Physiology, v. 587, n. Pt 19, p. 4737-4748, out. 2009. ISSN 0022-3751.

PERRY, S. et al. Firing properties of Renshaw cells defined by Chrna2 are modulated by hyperpolarizing and small conductance ion currents $I_{\mathrm{h}}$ and $I_{\text {sk }}$. European Journal of Neuroscience, v. 41, n. 7, p. 889-900, abr. 2015. ISSN 0953816X.

PIERROT-DESEILLIGNY, E.; BURKE, D. J. The circuitry of the human spinal cord: spinal and corticospinal mechanisms of movement. Cambridge, England ; New York: Cambridge University Press, 2012. ISBN 978-0-521-19258-3.

PIOTRKIEWICZ, M.; TÜRKER, K. S. Onion Skin or Common Drive? Frontiers in Cellular Neuroscience, v. 11, jan. 2017. ISSN 1662-5102.

POMPEIANO, O.; WAND, P.; SRIVASTAVA, U. C. Influence of Renshaw cells on the response gain of hindlimb extensor muscles to sinusoidal labyrinth stimulation. Pflügers Archiv, v. 404, n. 2, p. 107-118, maio 1985. ISSN 0031-6768, 1432-2013.

RENSHAW, B. Influence of discharge of motoneurons upon excitation of neighboring motoneurons. Journal of Neurophysiology, v. 4, n. 2, p. 167-183, 1941. ISSN 0022-3077, 1522-1598.

ROMANES, G. J. The motor cell columns of the lumbo-sacral spinal cord of the cat. The Journal of Comparative Neurology, v. 94, n. 2, p. 313-363, abr. 1951. ISSN 1096-9861. 
ROSS, H.-G.; CLEVELAND, S.; HAASE, J. Quantitative relation of Renshaw cell discharges to monosynaptic reflex height. Pflügers Archiv, v. 332, n. 1, p. 73-79, mar. 1972. ISSN 0031-6768, 1432-2013.

ROSS, H.-G.; CLEVELAND, S.; KUSCHMIERZ, A. Dynamic properties of renshaw cells: Equivalence of responses to step changes in recruitment and discharge frequency of motor axons. Pflügers Archiv, v. 394, n. 3, p. 239-242, set. 1982. ISSN 0031-6768, 1432-2013.

RYALL, R. W. Excitatory convergence on Renshaw cells. The Journal of Physiology, v. 226, n. 2, p. 69P-70P, out. 1972. ISSN 0022-3751.

RYALL, R. W. Patterns of recurrent excitation and mutual inhibition of cat Renshaw cells. The Journal of Physiology, v. 316, p. 439-452, jul. 1981. ISSN 0022-3751.

SHERRINGTON, S. C. S.; M, O.; S, P. R. Remarks on some aspects of reflex inhibition. Proceedings of the Royal Society of London, v. 97, n. 686, p. 519-545, abr. 1925. ISSN 0950-1193, 2053-9185.

SIMPSON, J.; WEINER, E.; PRESS, O. U. The Oxford English dictionary. [S.I.]: Clarendon Press, 1989. (The Oxford English Dictionary, v. 17). ISBN 9780198612292.

STERRATT, D. et al. Principles of Computational Modelling in Neuroscience. 1st. ed. Cambridge ; New York: Cambridge University Press, 2011. ISBN 978-0-521-87795-4.

UCHIYAMA, T.; JOHANSSON, H.; WINDHORST, U. A model of the feline medial gastrocnemius motoneuron-muscle system subjected to recurrent inhibition. Biological Cybernetics, v. 89, n. 2, p. 139-151, ago. 2003. ISSN 0340-1200, 1432-0770.

UCHIYAMA, T.; JOHANSSON, H.; WINDHORST, U. Static and dynamic input-output relations of the feline medial gastrocnemius motoneuron-muscle system subjected to recurrent inhibition: a model study. Biological Cybernetics, v. 89, n. 4, p. 264-273, out. 2003. ISSN 0340-1200, 1432-0770.

UCHIYAMA, T.; WINDHORST, U. Effects of spinal recurrent inhibition on motoneuron short-term synchronization. Biological Cybernetics, v. 96, n. 6, p. 561, jun. 2007. ISSN 0340-1200, 1432-0770.

WAKELING, J. M.; UEHLI, K.; ROZITIS, A. I. Muscle fibre recruitment can respond to the mechanics of the muscle contraction. Journal of the Royal Society Interface, v. 3, n. 9, p. 533-544, ago. 2006. ISSN 1742-5689. 
WALMSLEY, B.; HODGSON, J. A.; BURKE, R. E. Forces produced by medial gastrocnemius and soleus muscles during locomotion in freely moving cats. Journal of Neurophysiology, v. 41, n. 5 , p. 1203-1216, set. 1978. ISSN 0022-3077.

WALMSLEY, B.; TRACEY, D. J. An intracellular study of Renshaw cells. Brain Research, v. 223 , n. 1 , p. $170-175$, out. 1981 . ISSN 0006-8993.

WATANABE, R. N.; KOHN, A. F. Fast Oscillatory Commands from the Motor Cortex Can Be Decoded by the Spinal Cord for Force Control. The Journal of Neuroscience, v. 35, n. 40, p. 13687-13697, out. 2015. ISSN 0270-6474, 1529-2401.

WATANABE, R. N.; KOHN, A. F. Nonlinear Frequency-Domain Analysis of the Transformation of Cortical Inputs by a Motoneuron Pool-Muscle Complex. IEEE Transactions on Neural Systems and Rehabilitation Engineering, v. 25, n. 11, p. 1930-1939, nov. 2017. ISSN 1534-4320.

WATANABE, R. N. et al. Influences of premotoneuronal command statistics on the scaling of motor output variability during isometric plantar flexion. Journal of Neurophysiology, v. 110, n. 11 , p. 2592-2606, set. 2013. ISSN 0022-3077.

WESTBURY, D. R. A comparison of the structures of alpha- and gamma-spinal motoneurones of the cat. The Journal of Physiology, v. 325, n. 1, p. 79-91, abr. 1982. ISSN 1469-7793.

WILLIAMS, E. R.; BAKER, S. N. Renshaw Cell Recurrent Inhibition Improves Physiological Tremor by Reducing Corticomuscular Coupling at $10 \mathrm{~Hz}$. Journal of Neuroscience, v. 29, n. 20, p. 6616-6624, maio 2009. ISSN 0270-6474, 1529-2401.

WINDHORST, U. Activation of Renshaw cells. Progress in Neurobiology, v. 35, n. 2, p. 135-179, 1990. ISSN 0301-0082.

WINDHORST, U. On The Role Of Recurrent Inhibitory Feedback In Motor Control. 1996.

ZENGEL, J. E. et al. Membrane electrical properties and prediction of motor-unit type of medial gastrocnemius motoneurons in the cat. Journal of Neurophysiology, v. 53, n. 5, p. 1323-1344, maio 1985. ISSN 0022-3077. 